\title{
A REE-in-Garnet-Clinopyroxene Thermobarometer for Eclogites, Granulites and Garnet Peridotites
}

\author{
Chenguang Sun* and Yan Liang \\ Department of Earth, Environmental and Planetary Sciences, Brown University \\ Box 1846, Providence, RI 02912, USA \\ * Corresponding author: Chenguang Sun \\ E-mail: csun@whoi.edu \\ Tel.: +1 5082892706 \\ Department of Geology and Geophysics, Woods Hole Oceanographic Institution \\ Woods Hole, MA 02543, USA
}

Chemical Geology

Volumes 393-394, 30 January 2015, Pages 79-92

doi:10.1016/j.chemgeo.2014.11.014 
Abstract

2 A REE-in-garnet-clinopyroxene thermobarometer for eclogites, granulites, and garnet

3 peridotites has been developed on the basis of the temperature, pressure and mineral composition

4 dependent partitioning of rare earth elements (REEs) between garnet and clinopyroxene. This

5 new thermobarometer is derived from the garnet-clinopyroxene REE partitioning model of Sun

6 and Liang (2014) that was calibrated against experimentally determined garnet-melt and

7 clinopyroxene-melt partitioning data. It makes use of a group of trace elements that have similar

8 geochemical behaviors at magmatic and subsolidus conditions, and allows one to invert

9 temperature and pressure simultaneously using a least squares method. Application of the REE-

10 in-garnet-clinopyroxene thermobarometer to REE partitioning data from laboratory experiments

11 and field samples (quartz-bearing, graphite-bearing, and diamond-bearing granulites and eclogites;

12 and well-equilibrated mantle eclogite xenoliths) published in the literature validates its reliability

13 at both magmatic and subsolidus conditions. Application of the new thermobarometer to eclogites,

14 garnet granulites and peridotites from various tectonic settings reveals an intriguing observation:

15 temperatures derived from the REE-based thermobarometer are consistently higher than those

16 derived from the widely used Fe-Mg thermometer of Krogh (1988) for samples that experienced

17 cooling, but systematically lower than temperatures derived from the Fe-Mg thermometer for

18 samples from thermally perturbed tectonic settings. The temperature discrepancies are likely due

19 to the relative differences in diffusion rates between trivalent REEs and divalent Fe-Mg in garnet

20 and clinopyroxene. Temperatures derived from the REE-based thermometer are closely related to

21 closure temperatures for samples that experienced cooling, but are likely equilibrium or apparent

22 re-equilibration temperatures at an early stage of heating for samples from thermally perturbed

23 tectonic environments. The REE-in-garnet-clinopyroxene thermobarometer can shed new light on

24 thermal histories of mafic and ultramafic rocks.

25 Keywords: thermobarometer; garnet; clinopyroxene; eclogite; granulite; garnet peridotite 


\section{Introduction}

3 The exchange of Fe-Mg between garnet and clinopyroxene has been successfully calibrated

4 as thermometers that can be used to determine equilibrium temperatures of eclogites, garnet

5 peridotites, and garnet pyroxenites (e.g., Råheim and Green, 1974; Ellis and Green, 1979;

6 Ganguly, 1979; Saxena, 1979; Powell, 1985; Krogh, 1988; Ai, 1994; Ravna, 2000; Nakamura,

7 2009). However, all these thermometers require independent estimates of pressures, which

8 usually need additional phases to constrain (e.g., the garnet-orthopyroxene barometer; Brey et al.,

9 2008). Since a significant fraction of mantle eclogites is bi-mineralic, a reliable garnet-

10 clinopyroxene barometer is a prerequisite for a better constraint of their equilibrium pressures and

11 temperatures. Attempts have been made to calibrate garnet-clinopyroxene barometers through

12 thermodynamic analysis of experimental data (e.g., Brey et al., 1986; Mukhopadhyay, 1991;

13 Simakov and Taylor, 2000; Simakov, 2008), yet these barometers are still not as reliable as the

14 garnet-orthopyroxene barometers (see Fig. 2 in Nimis and Grütter, 2010). Hence, the equilibrium

15 temperatures of bi-mineralic eclogites are often calculated using the garnet-clinopyroxene

16 thermometers at an assumed pressure. Because the garnet-clinopyroxene thermometers are all

17 pressure dependent, temperature estimations can differ by up to $150^{\circ} \mathrm{C}$ if the assumed pressure is

18 off by $2 \mathrm{GPa}$. This is illustrated in Fig. 1. Assuming that the eclogites approach chemical

19 equilibrium at a temperature and pressure along the local geotherm, one can estimate the

20 equilibrium pressure and temperature by coupling the local geotherm with the garnet-

21 clinopyroxene thermometers (e.g., Griffin and O'Reilly, 2007). However, the pressure along the

22 local geotherm derived from garnet peridotite xenoliths can vary by \pm 1 GPa at a given

23 temperature (Griffin et al., 2003). Thus, uncertainties in the temperature estimations are still

24 significant.

25 Another important source of uncertainties in the garnet-clinopyroxene thermometers is the

26 presence of $\mathrm{Fe}^{3+}$ in garnet and clinopyroxene. Given the reducing conditions imposed by graphite 
1 capsules in phase equilibrium experiments, $\mathrm{Fe}^{3+}$ abundances in the minerals are likely very small

2 and thus total $\mathrm{Fe}$ is used to represent $\mathrm{Fe}^{2+}$ in the calibration of the garnet-clinopyroxene

3 thermometers. However, a significant amount of $\mathrm{Fe}^{3+}$ may be present in natural minerals. This

4 may result in large errors $\left(>200^{\circ} \mathrm{C}\right)$ in temperature estimations using the garnet-clinopyroxene

5 Fe-Mg thermometers (e.g., Ravna and Paquin, 2003). Recently, Matjuschkin et al. (2014)

6 experimentally examined the $\mathrm{Fe}^{3+}$ effect on the $\mathrm{Fe}-\mathrm{Mg}$ exchange thermometers at $1100-1400{ }^{\circ} \mathrm{C}$

7 and $5 \mathrm{GPa}$. Although they observed substantial amounts of $\mathrm{Fe}^{3+}$ in their experiments $\left(\mathrm{Fe}^{3+} / \Sigma \mathrm{Fe}=\right.$

$80.116-0.206$ in garnet), the temperatures calculated using the garnet-clinopyroxene thermometer

9 of Krogh (1988) are within $25^{\circ} \mathrm{C}$ of the experimental temperatures, except that for one

10 experiment conducted at $1400^{\circ} \mathrm{C}\left(\mathrm{Fe}^{3+} / \Sigma \mathrm{Fe}=0.199\right.$ in garnet). Consequently, these authors

11 suggested that the garnet-clinopyroxene $\mathrm{Fe}-\mathrm{Mg}$ thermometers are insensitive to the presence of

$12 \mathrm{Fe}^{3+}$, which contradicts the study of Ravna and Paquin (2003) on natural eclogite samples.

13 Clearly, detailed experimental and field studies are needed to further address the $\mathrm{Fe}^{3+}$ problem.

14 In this study, we present a new garnet-clinopyroxene thermobarometer that is based on the 15 exchange of rare earth elements (REEs) between garnet and clinopyroxene. The distribution of 16 trace elements between minerals depends on temperature, pressure, and mineral major element 17 compositions and can be calibrated as thermometers (e.g., Stosch, 1982; Seitz et al., 1999; Witt18 Eickschen and O’Neill, 2005; Lee et al., 2007; Liang et al., 2013; Sun and Liang, 2014). Based on 19 the temperature-dependent REE partitioning between orthopyroxene and clinopyroxene, Liang et 20 al. (2013) developed a REE-in-two-pyroxene thermometer by combining the clinopyroxene-melt 21 and orthopyroxene-melt REE partitioning models (Sun and Liang, 2012; Yao et al., 2012). This 22 thermometer treats REEs as a group in temperature calculation, which helps to reduce analytical 23 uncertainties. Through numerical simulations, Yao and Liang (2014) showed that the

24 temperatures calculated by the REE-in-two-pyroxene thermometer are the closure temperature of 25 REEs in cooling two-pyroxene systems. Because diffusion coefficients of REEs in pyroxenes are 
1 about two to three orders of magnitude smaller than those of divalent cations (e.g., $\mathrm{Ca}^{2+}, \mathrm{Mg}^{2+}$,

$2 \mathrm{Fe}^{2+}$ ) in pyroxenes (Cherniak and Dimanov, 2010 and references therein), the REE-based

3 thermometers can record higher closure temperatures of mafic and ultramafic rocks that

4 experienced cooling.

5 We have recently developed a parameterized lattice strain model for REE partitioning

6 between garnet and clinopyroxene (Sun and Liang, 2014). The lattice strain parameters in the

7 models were calibrated by experimentally determined mineral-melt partitioning data. We showed

8 that REE partitioning between garnet and clinopyroxene is very sensitive to temperature and

9 pressure as well as mineral major element composition. Specifically, garnet-clinopyroxene REE

10 partition coefficients decrease by up to two orders of magnitude as temperature decreases from

$111300{ }^{\circ} \mathrm{C}$ to $700{ }^{\circ} \mathrm{C}$, whereas they increase by about one order of magnitude as pressure decreases

12 from $14 \mathrm{GPa}$ to $2 \mathrm{GPa}$ [see Figs. 4c-d in Sun and Liang (2014)]. Here we expand the idea of the

13 REE-in-two-pyroxene thermometer to garnet-clinopyroxene systems and develop a REE-in-

14 garnet-clinopyroxene thermobarometer using the garnet-clinopyroxene REE partitioning model in

15 Sun and Liang (2014). This new thermobarometer enables us to obtain the equilibrium or closure

16 temperature and pressure simultaneously by analyzing REEs and major elements in coexisting

17 garnet and clinopyroxene, and shed new light on thermal histories of mafic and ultramafic rocks.

\section{Developing a REE-in-Garnet-Clinopyroxene Thermobarometer}

\section{$20 \quad$ 2.1. Theoretical basis}

21 In general, thermometers or barometers are based on the temperature- or pressure-sensitive 22 exchange of elements (or components) of interest between two coexisting minerals. The exchange 23 coefficient (or partition coefficient), $D$, can be described by the thermodynamic expression

$$
\ln D=\frac{\Delta S}{R}-\frac{\Delta H+P \Delta V}{R T}-\ln \gamma_{R}
$$


1 where $\Delta S, \Delta H$ and $\Delta V$ are the changes of entropy, enthalpy and volume of the exchange reaction,

2 respectively; $R$ is the gas constant; $T$ is the temperature; $P$ is the pressure; and $\gamma_{R}$ represents the

3 ratio of the activity coefficients of the element (or component) in the two minerals. Eq. (1) can

4 also be written in a general form as

$5 \quad \ln D=A+\frac{B-f(P)}{T}$,

6 where $A$ and $B$ are coefficients that depend on mineral major element compositions; $f(P)$ is a

7 function of pressure. When the volume change of the exchange reaction is independent of

8 pressure, $f(P)$ takes on the simple expression $C \times P$ in which $C$ is a coefficient independent of

9 pressure. From Eq. (2), we can obtain generalized equations for thermometers and/or barometers:

$10 \quad T=\frac{B-C \times P}{\ln D-A}$,

$11 \quad P=-\frac{1}{C}[T(\ln D-A)-B]$.

12 The temperature-, pressure-, and composition-dependent partitioning of trace elements

13 between a pair of minerals also takes the simple form of Eq. (2) (e.g., Stosch, 1982; Seitz et al.,

14 1999; Witt-Eickschen and O’Neill, 2005; Lee et al., 2007; Liang et al., 2013). Similar to Eq. (3a)

15 in Liang et al. (2013), we rearrange Eq. (2) in a linear form for a group of geochemically similar

16 elements, such as REEs,

$17 \quad B_{i}=T\left(\ln D_{i}-A_{i}\right)+f(P)$,

18 where $i$ is an element in the group. If the partitioning of a group of trace elements is sensitive to

19 both temperature and pressure, we can use Eq. (5) to determine the temperature and pressure

20 simultaneously. In a plot of $\left(\ln D_{i}-A_{i}\right)$ vs. $B_{i}$ for REEs, Eq. (5) defines a line passing through all

21 REEs in a well-equilibrated sample. The slope of this line is the equilibrium or closure

22 temperature, and the intercept can be used to calculate the pressure. 


\section{2.2. Garnet-clinopyroxene REE partitioning model}

2 The exchange of a REE between garnet and clinopyroxene can be quantify by a 3 parameterized lattice strain model (Sun and Liang, 2014)

$$
\begin{aligned}
D_{\mathrm{REE}}^{\mathrm{grt}-\mathrm{cpx}}=\frac{D_{0}^{\mathrm{grt}}}{D_{0}^{\mathrm{cpx}}} \exp [ & -\frac{4 \pi N_{A} E^{\mathrm{grt}}}{R T}\left(\frac{r_{0}^{\mathrm{grt}}}{2}\left(r_{0}^{\mathrm{grt}}-r_{\mathrm{REE}}\right)^{2}-\frac{1}{3}\left(r_{0}^{\mathrm{grt}}-r_{\mathrm{REE}}\right)^{3}\right) \\
& \left.+\frac{4 \pi N_{A} E^{\mathrm{cpx}}}{R T}\left(\frac{r_{0}^{\mathrm{cpx}}}{2}\left(r_{0}^{\mathrm{cpx}}-r_{\mathrm{REE}}\right)^{2}-\frac{1}{3}\left(r_{0}^{\mathrm{cpx}}-r_{\mathrm{REE}}\right)^{3}\right)\right]
\end{aligned}
$$

5 where $D_{\mathrm{REE}}^{\mathrm{grt}-\mathrm{cpx}}$ is the partition coefficient of a given REE between garnet and clinopyroxene; $D_{0}$ is

6 the partition coefficient for strain-free substitution; $E$ is the apparent Young's modulus for the

7 lattice site; $r_{0}$ is the size of the strain-free lattice site; $r_{\mathrm{REE}}$ is the ionic radius of the REE; $N_{A}$ is

8 Avogadro's number; superscripts grt and cpx denote garnet and clinopyroxene, respectively. The

9 lattice strain parameters $\left(D_{0}, r_{0}\right.$ and $\left.E\right)$ are the same as those in the mineral-melt lattice strain

10 model of Blundy and Wood (1994). In a mineral-melt system, the lattice strain parameters

11 generally depend upon temperature, pressure and compositions of the mineral and melt (e.g.,

12 Blundy and Wood, 1994; Wood and Blundy, 1997, 2002, 2003; van Westrenen and Draper,

13 2007; Draper and van Westrenen, 2007; Sun and Liang, 2012, 2013a, 2013b; Yao et al.,

14 2012). To quantify the distribution of REEs between garnet and clinopyroxene, one can

15 parameterize the lattice strain parameters as functions of temperature, pressure and composition

16 using experimentally determined mineral-melt REE partition coefficients.

17 Because clinopyroxene-melt and garnet-melt REE partition coefficients are important to the

18 interpretation of magmatic processes in the Earth's mantle, considerable efforts have been

19 devoted to developing parameterized lattice strain models for REE partitioning between

20 clinopyroxene and basaltic melt (Wood and Blundy, 1997, 2002; Sun and Liang, 2012) and

21 between garnet and basaltic melt (van Westrenen et al., 2001; Wood and Blundy, 2002; van

22 Westrenen and Draper, 2007; Draper and van Westrenen, 2007; Corgne et al., 2012; Sun and 
1 Liang, 2013a). In two recent studies, we systematically examined clinopyroxene-melt and garnet-

2 melt REE and Y partition coefficients as functions of temperature, pressure, mineral and melt

3 compositions using the lattice strain model (Sun and Liang, 2012, 2013a). Our new models were

4 calibrated against a carefully selected high quality experimental partitioning dataset through

5 parameter swiping and simultaneous or global nonlinear least squares inversion of all the filtered

6 partitioning data for each mineral-melt system. Fig. 2 displays the major element compositions of

7 clinopyroxene and garnet from the compiled experiments. These include 344 clinopyroxene-melt

8 partitioning data (REEs and Y) from 43 experiments (conducted at $1042-1470{ }^{\circ} \mathrm{C}$ and 1 atm-4

$9 \mathrm{GPa}$ ) and 538 garnet-melt partitioning data (REEs and Y) from 64 experiments (conducted at

$10 \quad 1325-2300{ }^{\circ} \mathrm{C}$ and $2.4-25 \mathrm{GPa}$ ). The clinopyroxenes are rich in magnesium but also include some

11 with jadeite and Tschermak components $\left[\mathrm{Mg} \#=54-100, \mathrm{Na}_{2} \mathrm{O}=0-3.6 \%, X_{\mathrm{Al}}^{\mathrm{T}}=0.05-0.44\right.$;

$12 \mathrm{Mg} \#=100 \times \mathrm{Mg} /(\mathrm{Mg}+\mathrm{Fe})$ in mole, and $X_{\mathrm{Al}}^{\mathrm{T}}$ is the amount of the tetrahedral $\mathrm{Al}$ in pyroxene per

13 six-oxygen], while the garnets are rich in pyrope or majorite components $(\mathrm{Mg} \#=54-100)$. The

14 interested reader is referred to Sun and Liang (2012, 2013a, 2014) for additional information.

15 The compiled clinopyroxene-melt REE and Y partitioning data can be best fit by a lattice 16 strain model using the following lattice strain parameters (Sun and Liang, 2012):

$$
\begin{aligned}
\ln D_{0}^{\mathrm{cpx}} & =-7.14( \pm 0.53)+\frac{7.19( \pm 0.73) \times 10^{4}}{R T}+4.37( \pm 0.47) X_{\mathrm{Al}}^{T} \\
& +1.98( \pm 0.36) X_{\mathrm{Mg}}^{\mathrm{M} 2}-0.91( \pm 0.19) X_{\mathrm{H}_{2} \mathrm{O}}^{\mathrm{melt}}
\end{aligned}
$$

$$
r_{0}^{\mathrm{cpx}}(\AA)=1.066( \pm 0.007)-0.104( \pm 0.035) X_{\mathrm{Al}}^{\mathrm{M} 1}-0.212( \pm 0.033) X_{\mathrm{Mg}}^{\mathrm{M} 2}
$$

$$
E^{\mathrm{cpx}}(\mathrm{GPa})=\left[2.27( \pm 0.44) r_{0}-2.00( \pm 0.44)\right] \times 10^{3}
$$

20 where numbers in parentheses are $2 \sigma$ uncertainties estimated directly from the simultaneous

21 inversion; $X_{\mathrm{Al}}^{\mathrm{M} 1}$ is the amount of $\mathrm{Al}$ in the $\mathrm{M} 1$ site in pyroxene per six-oxygen; $X_{\mathrm{Mg}}^{\mathrm{M} 2}$ is the cation

22 content of $\mathrm{Mg}$ in the M2 site in pyroxene; and $X_{\mathrm{H}_{2} \mathrm{O}}^{\text {melt }}$ is the molar fraction of $\mathrm{H}_{2} \mathrm{O}$ in the melt per 
1 six-oxygen calculated following the procedure of Wood and Blundy (2002). Pyroxene structure

2 formulae are calculated by assuming a random distribution of $\mathrm{Fe}^{2+}$ and $\mathrm{Mg}^{2+}$ over the M1 and M2

3 sites (Wood and Banno, 1973) and that all iron is present as ferrous iron.

4 The compiled garnet-melt REE and Y partitioning data can be best fit by a lattice strain 5 model using the following lattice strain parameters (Sun and Liang, 2013a, 2014):

$$
\begin{aligned}
\ln D_{0}^{\mathrm{grt}} & =-2.01( \pm 0.70)+\frac{9.03( \pm 0.98) \times 10^{4}-93.02( \pm 17.06) P(37.78-P)}{R T} \\
& -1.04( \pm 0.44) X_{\mathrm{Ca}}^{\mathrm{grt}}
\end{aligned},
$$

$$
r_{0}^{\mathrm{grt}}(\AA)=0.785( \pm 0.031)+0.153( \pm 0.029) X_{\mathrm{Ca}}^{\mathrm{grt}},
$$

$$
E^{\mathrm{grt}}(\mathrm{GPa})=\left[-1.67( \pm 0.45)+2.35( \pm 0.51) r_{0}\right] \times 10^{3}
$$

9 where $P$ is the pressure in $\mathrm{GPa} ; X_{\mathrm{Ca}}^{\mathrm{grt}}$ is the cation content of $\mathrm{Ca}$ in garnet per 12-oxygen. In both

10 clinopyroxene and garnet partitioning models, we used 8-fold coordinated ionic radii of REE and 11 Y from Shannon (1976). Eqs. (7a-c) and Eqs. (8a-c) indicate that temperature, pressure and 12 mineral major element compositions dominate REE and $\mathrm{Y}$ partitioning in clinopyroxene and 13 garnet. The effect of water in the melt on clinopyroxene-melt REE partitioning is only significant 14 under very hydrous magmatic conditions.

15 Combining Eqs. (6, 7a-c, and 8a-c), Sun and Liang (2014) obtained a generalized lattice 16 strain model for REE and Y partitioning between garnet and clinopyroxene under anhydrous 17 conditions (i.e., by setting $X_{\mathrm{H}_{2} \mathrm{O}}^{\text {melt }}=0$ in Eq. 7a). They demonstrated that REE partition 18 coefficients calculated using this model agree very well with directly measured values in well19 equilibrated mantle eclogite xenoliths (Type II) from the Roberts Victor kimberlite, South Africa 20 reported in Harte and Kirkley (1997) and Huang et al. (2012). In the supplementary material, we 21 further test the validity of this model using published mineral-melt partitioning experiments with 22 coexisting clinopyroxene and garnet and additional well-equilibrated mantle eclogite xenoliths 23 from various locations (see also Supplementary Fig. S1). These experiments and additional 
1 mantle xenoliths confirm that the independently calibrated lattice strain parameters for REE

2 partitioning in clinopyroxene and garnet are internally consistent and can be extrapolated to 3 subsolidus conditions.

\section{2.3. A REE-in-garnet-clinopyroxene thermobarometer}

6 Given the garnet-clinopyroxene REE partitioning model (Eqs. 6, 7a-c, and 8a-c), we can

7 obtain a REE-in-garnet-clinopyroxene thermobarometer by rewriting Eq. (6) in the form of Eq.

8 (5). The corresponding terms of Eq. (5) now take on the following expressions:

9

11

12

$$
A=5.13-1.04 X_{\mathrm{Ca}}^{\mathrm{grt}}-4.37 X_{\mathrm{Al}}^{T, \mathrm{cpx}}-1.98 X_{\mathrm{Mg}}^{\mathrm{M} 2 \mathrm{cpx}}
$$

13 where $E$ and $r_{0}$ are given by Eqs. (7b-c and 8b-c); $A$ and $B$ are coefficients in Eq. (5); and $f(P)$

14 replaces the pressure term in Eq. (5). The coefficient $A$ depends strongly on major element

15 compositions of garnet and clinopyroxene, while the coefficient $B$ is a function of mineral major

16 element composition and the ionic radii of REEs. Note that the $X_{\mathrm{H}_{2} \mathrm{O}}^{\text {melt }}$ term is excluded in Eq. (9a)

17 because it is irrelevant to REE partitioning between garnet and clinopyroxene under subsolidus

18 conditions. This term also has negligible effect on REE partitioning between garnet and

19 clinopyroxene under anhydrous magmatic conditions.

20 To calculate the equilibrium temperature and pressure simultaneously for a given sample, we

21 follow the steps similar to those for the REE-in-two-pyroxene thermometer in Liang et al. (2013). 
1 First, we calculate the coefficients $A$ and $B$ from Eqs. (9a-b) using major element compositions of

2 garnet and clinopyroxene. Second, we examine the quality of measured REE abundances in 3 garnet and clinopyroxene in a spider diagram and check if REEs define a line in the plot of $(\ln D-$

4 A) vs. $B$. Finally, we carry out a linear least squares analysis for garnet-clinopyroxene REE

5 partition coefficients in the plot of $(\ln D-A)$ vs. $B$. We obtain the temperature $\left(T_{\mathrm{REE}}\right)$ from the

6 slope, and calculate the pressure $\left(P_{\mathrm{REE}}\right)$ from the intercept $f(P)$ through Eq. (9c). From the linear

7 least squares analysis of garnet-clinopyroxene REE and Y partition coefficients in the plot of ( $\ln D$

$8-A$ ) vs. $B$, we can also make estimates on the uncertainties of the calculated temperature and

9 pressure. In the online supplementary data, we present a simple Excel worksheet that can assist

10 interested readers to calculate temperatures and pressures using the REE-in-garnet-clinopyroxene 11 thermobarometer.

12 Figures 3a-b show an example of the temperature and pressure inversion for a well13 equilibrated diamond-bearing eclogite reported in Smart et al. (2009). In this sample, light REEs

14 are enriched in the clinopyroxene but highly depleted in the garnet, while heavy REEs are 15 depleted in the clinopyroxene but enriched in garnet (Fig. 3a). The distribution of REEs between 16 garnet and clinopyroxene generally agree with their partitioning behaviors. Fig. $3 b$ shows that all 17 REEs and $\mathrm{Y}$ define a straight line in the plot of $(\ln D-A)$ vs. $B$. The slope and intercept of this 18 line provide a temperature of $846 \pm 21^{\circ} \mathrm{C}$ and a pressure of $4.21 \pm 0.38 \mathrm{GPa}$, respectively. The 19 temperature and pressure places this diamond-bearing eclogite in the diamond stability field and 20 hence can be interpreted as the equilibrium temperature and pressure of this sample. Assuming an 21 equilibrium pressure of $4.21 \mathrm{GPa}$, we calculated the equilibrium temperature for this eclogite 22 sample using several garnet-clinopyroxene Fe-Mg thermometers ( $T_{\mathrm{EG}}$ : Ellis and Green, 1979; $23 \mathrm{~T}_{\mathrm{K} 88}:$ Krogh, 1988; $\mathrm{T}_{\mathrm{KR}}$ : Ravna, 2000; $\mathrm{T}_{\mathrm{N} 09}$ : Nakamura, 2009). The temperature derived from the

24 REE-in-garnet-clinopyroxene thermobarometer is in excellent agreement with that derived from 25 the widely used thermometer of Krogh (1988) but is lower than those derived from other three 26 garnet-clinopyroxene Fe-Mg thermometers (listed in Fig. 3b). 
Because some REEs are highly depleted in garnet or clinopyroxene (e.g., light REEs in garnet

2 and heavy REEs in clinopyroxene), they may be easily affected by secondary alterations or have

3 significant analytical errors. One of the advantages of the REE-based thermobarometer is that one

4 can eliminate the outliers using a robust linear least squares regression method (Figs. 3c-d).

5 Alternatively, one can manually exclude the outliers and obtain the temperature and pressure

6 using a linear least squares regression. However, when all REEs and $\mathrm{Y}$ in the plot of $(\ln D-A)$ vs.

$7 \quad B$ become continuously curved, the garnet and clinopyroxene may be strongly perturbed by

8 secondary processes. It is then impossible to obtain a meaningful temperature and pressure

9 (Supplementary Fig. S2).

\section{Validation of the REE-in-Garnet-Clinopyroxene Thermobarometer}

\section{3.1. Experimental test}

13 To assess the validity of the REE-in-garnet-clinopyroxene thermobarometer, we apply the 14 new thermobarometer to partitioning experiments that have coexisting garnet, clinopyroxene and 15 melts. We compiled 14 experiments reported in the literature (Green et al., 2000; Adam and 16 Green, 2006; Tuff and Gibson, 2007; Suzuki et al., 2012). Four experiments from Green et al. 17 (2000) and Adam and Green (2006) were conducted at $1100-1200{ }^{\circ} \mathrm{C}$ and $3-4 \mathrm{GPa}$ for $22.5-$ $1848 \mathrm{hrs}$ under hydrous conditions (10.91 - $17.35 \mathrm{wt} \%$ water in the melt). Four experiments from

19 Tuff and Gibson (2007) were conducted at $1425-1750{ }^{\circ} \mathrm{C}$ and $3-7 \mathrm{GPa}$ for $4-25 \mathrm{hrs}$ under

20 anhydrous conditions. Six experiments from Suzuki et al. (2012) were conducted at $1550-1900$

$21{ }^{\circ} \mathrm{C}$ and $3-12 \mathrm{GPa}$ for $1-2 \mathrm{hrs}$ under anhydrous conditions. All these experiments used basaltic

22 starting compositions and produced garnets and clinopyroxenes with relatively large ranges in

23 compositions (e.g., $\mathrm{Mg} \#=66-77$ for garnet, and $\mathrm{Mg} \#=76-86$ for clinopyroxene). The

24 clinopyroxenes from the experiments in Tuff and Gibson (2007) are on the boundary of augite

25 and sub-calcium augite. Application of the REE-in-garnet-clinopyroxene thermobarometer to 
1 these clinopyroxenes may involve a significant extrapolation. Following the procedure described

2 in Section 2.3, we calculated the temperatures and pressures for the 14 experiments using the

3 REE-in-garnet-clinopyroxene thermobarometer (Fig. 4; and see Supplementary Fig. S3 for

4 temperature and pressure inversions for individual experiments).

5 The temperatures and pressures calculated using the REE-in-garnet-clinopyroxene

6 thermobarometer agree very well with the experimental temperatures $\left(T_{\exp }\right)$ and pressures $\left(P_{\exp }\right)$

7 (Fig. 4). Except for one experiment from Suzuki et al. $\left(2012,1900^{\circ} \mathrm{C}\right.$ and $\left.12 \mathrm{GPa}\right)$, the absolute

8 differences between the calculated temperatures and experimental temperatures are generally

9 within $100^{\circ} \mathrm{C}\left(6-129^{\circ} \mathrm{C}\right.$; Fig. $\left.4 \mathrm{a}\right)$. Interestingly, the larger temperature difference $\left(174^{\circ} \mathrm{C}\right)$ in the

$101900^{\circ} \mathrm{C}$ run of Suzuki et al. (2012) is comparable to the thermal gradient $\left(\sim 150{ }^{\circ} \mathrm{C}\right)$ near hot spots

11 in the very high temperature multi-anvil experiments (van Westrenen et al., 2003). The

12 differences between the calculated pressures and the experimental pressures are within $1 \mathrm{GPa}$

$13(0.08-0.76 \mathrm{GPa})$ for 8 of the 14 experiments (Fig. 4b). The calculated pressures for three

14 experiments from Suzuki et al. (2012) and one experiment from Tuff and Gibson (2007) are 2.2 -

$152.9 \mathrm{GPa}$ greater than the experimental pressures, while that for the $8 \mathrm{GPa}$ experiment from Suzuki

16 et al. (2012) is $1.5 \mathrm{GPa}$ smaller than the experimental pressure. The significant differences in

17 temperatures and pressures could be attributed to potential disequilibrium in these partitioning

18 experiments, analytical uncertainties (due in part to very small crystal sizes), and/or limitations of

19 the REE-in-garnet-clinopyroxene thermobarometer. For instance, curvatures in the plot of $(\ln D-$

$20 A$ ) vs. $B$ for the garnet-clinopyroxene REE partition coefficients from one experiment at $1900{ }^{\circ} \mathrm{C}$

21 in Suzuki et al. (2012) (Supplementary Fig. S3) may result from disequilibrium between garnet

22 and clinopyroxene and/or melt contamination during trace element analysis.

23 The aforementioned partitioning experiments with coexisting garnet and clinopyroxene also

24 enable us to compare the accuracy between the REE-in-garnet-clinopyroxene thermobarometer

25 and the major element-based garnet-clinopyroxene thermobarometers. The conventional garnet-

26 clinopyroxene thermometers were all calibrated based on the Fe-Mg exchange between garnet 
1 and clinopyroxene. Garnet-clinopyroxene barometers were based on $\mathrm{Ca}-\mathrm{Mg}$ exchange between

2 garnet and clinopyroxene (Brey et al., 1986) or Ca-Tschermak (CaTs) solubility in clinopyroxene

3 coexisting with garnet (e.g., Mukhopadhyay, 1991; Simakov and Taylor, 2000; Simakov, 2008).

4 To assess the accuracy of different thermobarometers, we calculated the relative Chi-squares

5 using the expression

$6 \quad \chi_{r}^{2}=\sum_{j=1}^{N} \frac{\left(M_{j}-E_{j}\right)^{2}}{E_{j}}$,

7 where $N$ is the total number of samples used in the comparison; $M_{j}$ is the temperature (or pressure)

8 measured for sample $j ; E_{j}$ is the temperature (or pressure) estimated using different

9 thermobarometers for sample $j$. A smaller $\chi_{r}^{2}$ indicates that the thermobarometer is more

10 accurate to reproduce the experimental temperatures (or pressures).

11 We calculated equilibrium temperatures for the 14 experiments using four garnet12 clinopyroxene Fe-Mg thermometers (Ellis and Green, 1979; Krogh, 1988; Ravna, 2000;

13 Nakamura, 2009) and equilibrium pressures using the recent garnet-clinopyroxene barometer of

14 Simakov (2008). The thermometers of Ellis and Green (1979), Krogh (1988) and Ravna (2000)

15 have been widely applied to garnet- and clinopyroxene-bearing rocks. The thermometer of

16 Nakamura (2009) was recently calibrated by adopting a subregular solution model for garnet. The

17 experimental pressures were used in these thermometers to estimate temperatures, while the

18 experimental temperatures and the garnet-clinopyroxene thermometer of Krogh (1988) were used

19 in the barometer of Simakov (2008).

20 Figure 5 displays the comparisons between the calculated temperatures and the

21 experimental run temperatures. The four thermometers consistently provide temperatures about

$22265-568{ }^{\circ} \mathrm{C}$ greater than the run temperatures of two experiments from Green et al. (2000). The

23 overestimates for the two experimental temperatures may be due to significant amounts of $\mathrm{Fe}^{3+}$ in

24 garnet and clinopyroxene, potential effects of water on garnet-clinopyroxene Fe-Mg exchange, 
1 and/or disequilibrium of Fe-Mg between garnet and clinopyroxene. Although the thermometer of

2 Ellis and Green (1979) seems to best reproduce the 14 experimental temperatures among the four

3 thermometers, its $\chi_{r}^{2}(=244)$ remains significantly greater than that of the REE-in-garnet-

4 clinopyroxene thermobarometer $\left(\chi_{r}^{2}=55\right)$. Excluding the two experiments (Runs 1798 and

5 1807) from Green et al. (2000), the thermometer of Krogh (1988) best reproduces the 12

6 experimental temperatures with the smallest $\chi_{r}^{2}(=43)$, which is similar to that of the REE-in-

7 garnet-clinopyroxene thermobarometer $\left(\chi_{r}^{2}=41\right)$.

8 Figure 6 shows the comparisons between the calculated pressures using the barometer of 9 Simakov (2008, designated as $\left.P_{\mathrm{S} 08}\right)$ and the experimental pressures. For the low-pressure 10 experiments $(<5 \mathrm{GPa})$, the barometer of Simakov (2008) reproduces the experimental pressures

11 to within $0.01-1.14 \mathrm{GPa}$ using the experimental temperatures; however, for the high-pressure 12 experiments $(>5 \mathrm{GPa})$, the barometer of Simakov (2008) reproduces the experimental pressures 13 to within $1.53-2.37 \mathrm{GPa}$ (Fig. 6a). Combining with the thermometer of Krogh (1988), the 14 barometer of Simakov (2008) produces larger errors particularly for the two experiments from

15 Green et al. (2000), and has greater $\chi_{r}^{2}\left(=8\right.$; Fig. 6b) than that $\left(\chi_{r}^{2}=3\right.$; Fig. 6a) using the 16 experimental temperatures. Excluding the two experiments from Green et al. (2000) in Fig. 6b 17 reduces $\chi_{r}^{2}$ for Simakov's barometer to 5, comparable to that in Fig. 6a. The barometer of 18 Simakov (2008) generally gives rise to $\chi_{r}^{2}$ values similar to that $\left(\chi_{r}^{2}=4\right.$; Fig. $\left.4 \mathrm{~b}\right)$ derived from 19 the REE-in-garnet-clinopyroxene thermobarometer.

20 It is important to bear in mind that the experimental test of the REE-in-garnet-clinopyroxene 21 thermobarometer is based on a rather limited laboratory partitioning dataset. To further test and 22 validate the REE-in-garnet-clinopyroxene thermobarometer, we turn to field data. 


\section{$1 \quad$ 3.2. Field test}

2 Because the diamond-graphite phase boundary and the quartz-coesite transformation have

3 been well-constrained (e.g., Kennedy and Kennedy, 1976; Bohlen and Boettcher, 1982; Day,

4 2012), diamond-, graphite-, coesite- and quartz-bearing eclogites, granulites, and peridotites are

5 excellent candidates to test the reliability of a garnet-clinopyroxene thermobarometer. Here we

6 use the REE-in-garnet-clinopyroxene thermobarometer to calculate equilibrium temperatures and

7 pressures for three types of samples (9 diamond-bearing eclogites, 2 graphite-bearing eclogites,

8 and 12 quartz-bearing eclogites or granulites) with major and trace element compositions of

9 garnet and clinopyroxene reported in the literature. The 9 diamond-bearing eclogites include 1

10 sample from Udachnaya kimberlite pipe in Siberia (Shatsky et al., 2008) and 8 samples from the

11 Jericho Kimberlite in the northern Slave Craton (Smart et al., 2009; up to 20\% diamond); the 2

12 graphite-bearing eclogites are from the West Africa Craton (Barth et al., 2001); the 12 quartz-

13 bearing samples contain 7 eclogites from Dabie-Sulu terrane (Tang et al., 2007), 1 granulite from

14 Central Finland (Nehring et al., 2010), and 4 granulites from Udachnaya and Komsomolskaya

15 Kimberlite Pipes in Siberia (Koreshkova et al., 2011). The individual temperature and pressure

16 inversions for these samples can be found in Supplementary Fig. S4. For comparison, we also

17 calculate the equilibrium temperatures and pressures for these samples using the barometer of

18 Simakov (2008) and the thermometer of Krogh (1988).

19 The REE-in-garnet-clinopyroxene thermobarometer generates reasonable temperatures and

20 pressures for the three types of samples except pressures for two diamond-bearing eclogites $(0.2-$

$210.5 \mathrm{GPa}$ shallower than the diamond-graphite boundary; Fig. 7a). Because the barometer of

22 Simakov (2008) does not work for clinopyroxene without CaTs or enstatite components, the

23 combination of the barometer of Simakov (2008) and the thermometer of Krogh (1988) only

24 produces temperatures and pressures for 12 samples (5 diamond-bearing, 1 graphite-bearing, and

256 quartz-bearing). However, the pressures of the 12 samples are highly problematic (Fig. 7b).

26 Combining with other garnet-clinopyroxene thermometers (e.g., Ellis and Green, 1979; Ravna, 
1 2000; Nakamura, 2009) or using temperatures derived from the REE-in-garnet-clinopyroxene

2 thermobarometer would not significantly improve the pressures derived from the barometer of

3 Simakov (2008) for these field samples. This is probably because Simakov's barometer is very

4 sensitive to the ordering of Fe-Mg over the M1 and M2 sites in clinopyroxene at low

5 temperatures. The sensitivity of the REE-in-garnet-clinopyroxene thermobarometer to $\mathrm{Fe}-\mathrm{Mg}$

6 ordering in clinopyroxene is discussed in Section 5.

7 To further examine the accuracy and reliability of our REE-in-garnet-clinopyroxene

8 thermobarometer, we compare the equilibrium temperatures of well-equilibrated mantle eclogites

9 calculated using our REE-based thermobarometer with those calculated using the Fe-Mg

10 thermometers of Ellis and Green (1979), Krogh (1988), Ravna (2000), and Nakamura (2009) at

11 equilibrium pressures derived from the REE-in-garnet-clinopyroxene thermobarometer (Fig. 8).

12 We compiled 35 mantle eclogite xenoliths with mineral major and trace element compositions

13 reported in the literature that most likely approach equilibrium in the mantle. They include 14

14 Type II eclogites from the Kaapvaal Craton (Harte and Kirkley, 1997; Huang et al., 2012), 2

15 Group 2 eclogites from the Siberian Craton (Jacob and Foley, 1999), 11 low-MgO eclogites from

16 the West African Craton (Barth et al., 2001), and 8 diamond eclogites from the Slave Craton

17 (Smart et al., 2009). To facilitate comparisons between thermometers, we calculate the relative

18 Chi-squares $\left(\chi_{r}^{2}\right)$ using Eq. (10) and replace the measured temperatures $\left(M_{j}\right.$ in Eq. 10) by those

19 derived from the REE-in-garnet-clinopyroxene thermobarometer. The smaller $\chi_{r}^{2}$ value, the

20 better agreement between the REE and Fe-Mg thermometer is. For the 35 well-equilibrated

21 mantle eclogites, the widely used garnet-clinopyroxene Fe-Mg thermometers of Ellis and Green

22 (1979), Krogh (1988) and Ravna (2000) provide temperatures generally within $100^{\circ} \mathrm{C}$ (dashed

23 lines) of those calculated using the REE-in-garnet-clinopyroxene thermobarometer (Figs. 8a-c).

24 Note that the $100^{\circ} \mathrm{C}$ temperature differences are comparable to the uncertainties of the garnet-

25 clinopyroxene Fe-Mg thermometers. However, the recent Fe-Mg thermometer of Nakamura 
1 (2009) generates temperatures for many samples significantly (up to $341^{\circ} \mathrm{C}$ ) higher than those

2 derived from our REE-based thermobarometer (Fig. 8d). Overall, for these well-equilibrated

3 samples, temperature estimations by Krogh's thermometer (1988) are in excellent agreement with

4 those of the REE-in-garnet-clinopyroxene thermobarometer $\left(\chi_{r}^{2}=297\right)$.

5 In summary, the 14 partitioning experiments demonstrate that the REE-in-garnet-

6 clinopyroxene thermobarometer generally better reproduces the experimental temperatures than

7 the garnet-clinopyroxene Fe-Mg thermometers, and has a good reproducibility for the

8 experimental pressures comparable to that of the barometer of Simakov (2008). Applications to

9 diamond-, graphite-, and quartz-bearing field samples further validate the reliability of the REE-

10 in-garnet-clinopyroxene thermobarometer. Finally, the excellent agreement in temperatures

11 derived from the REE-in-garnet-clinopyroxene thermobarometer and the widely used

12 thermometer of Krogh (1988) for the 35 well-equilibrated mantle eclogites demonstrates the

13 accuracy of the REE-in-garnet-clinopyroxene thermobarometer for field samples at subsolidus

14 conditions.

\section{Geological Applications}

17 There is a large body of work on major and trace element abundances in garnet- and 18 clinopyroxene-bearing rocks from active tectonic environments in the Earth's mantle and lower

19 crust (e.g., high pressure and ultra-high pressure terranes, subducted oceanic lithosphere, and

20 thermally eroded lithospheric mantle). Because garnet- and clinopyroxene-bearing rocks from

21 active tectonic settings have complex thermal histories, major and trace elements in the garnet

22 and clinopyroxene may depart from chemical equilibrium at the local geotherm during

23 exhumation, subduction or thermal erosion processes. Applying the REE-in-two-pyroxene

24 thermometer to abyssal peridotites and mafic cumulates, Liang et al. (2013) demonstrated that the

25 REE-in-two-pyroxene thermometer records higher closure temperatures than the major element- 
1 based two-pyroxene thermometers for mafic and ultramafic rocks that experienced cooling. This

2 raises two important questions for the REE-in-garnet-clinopyroxene thermobarometer. (1) Are

3 there any differences in temperatures derived from the REE-in-garnet-clinopyroxene

4 thermobarometer and the garnet-clinopyroxene Fe-Mg thermometers for garnet- and

5 clinopyroxene-bearing rocks from different tectonic environments? (2) Can the REE-in-garnet-

6 clinopyroxene thermobarometer be used to study thermal histories of these rocks? In this section,

7 we first discuss the physical meaning of temperatures and pressures derived from the REE-in-

8 garnet-clinopyroxene thermobarometer. We then apply the REE-in-garnet-clinopyroxene

9 thermobarometer to garnet- and clinopyroxene-bearing rocks from tectonic settings that

10 experienced cooling or heating processes. For comparison, we also calculate temperatures using

11 the garnet-clinopyroxene Fe-Mg thermometer of Krogh (1988) at pressures derived from the

12 REE-in-garnet-clinopyroxene thermobarometer.

\section{4.1. Physical meaning of calculated temperatures and pressures}

15 Diffusive re-distribution of REEs between a pair of minerals during subsolidus re16 equilibration depends on the diffusion coefficients of REEs in the two minerals, partition

17 coefficients of REEs between the pair of minerals, grain sizes and relative volume proportions of

18 the two minerals (Liang, 2014). The diffusion coefficients of REEs in clinopyroxene decrease

19 systematically with their ionic radii (Van Orman et al., 2001), whereas those in garnet are not

20 very sensitive to their ionic radii (Van Orman et al., 2002; Carlson, 2012; Fig. 9a). As

21 demonstrated in Section 2.2, the partition coefficients of REEs between garnet and clinopyroxene

22 also depend on their ionic radii. In general, light REEs are highly compatible in clinopyroxene

23 relative to garnet, while heavy REEs are very compatible in garnet relative to clinopyroxene (Fig.

$249 \mathrm{~b})$. To assess the dominant factors determining the diffusive re-distribution of REEs, we use the

25 following equation to calculate the time scales of diffusive re-equilibration $\left(t_{D}\right)$ for REEs in

26 garnet-clinopyroxene bi-mineralic systems (Liang, 2014) 
$1 \quad t_{D}=\left(\frac{\phi_{\mathrm{cpx}}}{\phi_{\mathrm{grt}} D_{\mathrm{REE}}^{\mathrm{grt}-\mathrm{cpx}}+\phi_{\mathrm{cpx}}}\right) \frac{L_{\mathrm{grt}}^{2}}{\beta \mathfrak{D}_{\mathrm{REE}}^{\mathrm{grt}}}+\left(\frac{\phi_{\mathrm{grt}} D_{\mathrm{REE}}^{\mathrm{grt}-\mathrm{cpx}}}{\phi_{\mathrm{grt}} D_{\mathrm{REE}}^{\mathrm{grt}-\mathrm{cpx}}+\phi_{\mathrm{cpx}}}\right) \frac{L_{\mathrm{cpx}}^{2}}{\beta \mathfrak{D}_{\mathrm{REE}}^{\mathrm{cpx}}}$,

2 where $\phi_{\mathrm{cpx}}$ and $\phi_{\mathrm{grt}}$ are the volume proportions of clinopyroxene and garnet, respectively; $\mathfrak{D}_{\mathrm{REE}}^{\mathrm{grt}}$

3 and $\mathfrak{D}_{\mathrm{REE}}^{\mathrm{cpx}}$ are the diffusivities of a REE in garnet and clinopyroxene, respectively; $\beta$ is a

4 geometric factor, and is 1,4 , or 5 for a plane sheet of half length $L$, cylinder or sphere of radius $L$,

5 respectively. For the purpose of demonstration, here we consider garnet-clinopyroxene aggregates

6 with a uniform spherical grain size $\left(L_{\mathrm{grt}}=L_{\mathrm{cpx}}=0.5 \mathrm{~mm} ; \beta=5\right)$.

7 Figure 9c compares the diffusive re-equilibration times for REEs in garnet-clinopyroxene 8 aggregates for three choices of mineral proportions $\left(\phi_{\mathrm{cpx}}=20 \%, 50 \%\right.$, and $\left.80 \%\right)$ at $1200^{\circ} \mathrm{C}$ and

$9 \quad 1000^{\circ} \mathrm{C}$. Because of their smaller diffusion coefficients in clinopyroxene and large garnet-

10 clinopyroxene partition coefficients [cf. Figs. 9a-b and Eq. (11)], heavy REEs in clinopyroxene

11 determine their diffusive re-equilibration times in garnet-clinopyroxene aggregates. However, the

12 diffusive re-equilibration times for light REEs are sensitive to partition coefficients, diffusion

13 coefficients, and mineral proportions. For garnet-clinopyroxene aggregates with less than $20 \%$

14 clinopyroxene, light REEs in clinopyroxene dominate their diffusive re-equilibration times. As

15 the clinopyroxene proportion increases, light REEs in garnet become more important to affecting

16 their diffusive re-equilibration times in garnet-clinopyroxene aggregates, which leads to

17 comparable diffusive re-equilibration times for light and heavy REEs. Because the REE-in-

18 garnet-clinopyroxene thermobarometer are based on the temperature- and pressure-dependent

19 garnet-clinopyroxene REE exchange, for a garnet- and clinopyroxene-bearing rock that

20 experienced cooling, temperatures (and pressures) derived from this thermobarometer is thus

21 closely related to the average closure temperature (and pressure) of REEs in garnet-clinopyroxene

22 bi-mineralic systems, and may be affected by the relative mineral proportions when the

23 clinopyroxene abundance in the sample is small. 
To further examine the physical meaning of temperatures (and pressures) derived from the

2 REE-in-garnet-clinopyroxene thermobarometer for thermally perturbed samples, we compare the

3 "diffusive opening" temperatures of Fe-Mg with those of REEs in garnet and clinopyroxene.

4 Using the garnet Fe-Mg diffusion data from Freer and Edwards (1999) and the garnet REE

5 diffusion data from Van Orman et al. (2002), we calculated the "diffusive opening" temperatures

6 of Fe-Mg and REEs in a garnet $(0.5 \mathrm{~mm}$ radius $)$ with a linear heating rate $\left(200^{\circ} \mathrm{C} / \mathrm{Myr}\right)$ using the

7 simple equation developed by Watson and Cherniak (2013). We found that the 50\% retention

8 level for $\mathrm{Fe}-\mathrm{Mg}$ in garnet is reached at $677^{\circ} \mathrm{C}$ while that for REEs in garnet is reached at $1049-$

$91083^{\circ} \mathrm{C}$. Similarly, we also calculated the "diffusive opening" temperatures of Fe-Mg and REEs

10 in a clinopyroxene ( $0.5 \mathrm{~mm}$ radius) using the clinopyroxene $\mathrm{Fe}-\mathrm{Mg}$ diffusion data from Ganguly

11 and Tazzoli (1994) and the clinopyroxene REE diffusion data from Van Orman et al. (2001). The

$1250 \%$ retention level for Fe-Mg in clinopyroxene is reached at $801{ }^{\circ} \mathrm{C}$ while that for REEs in

13 clinopyroxene is reached at $1037-1187^{\circ} \mathrm{C}$. The "diffusive opening" temperatures of Fe-Mg in

14 garnet and clinopyroxene $\left(677-801^{\circ} \mathrm{C}\right)$ are significantly lower than those of REEs $(1037-1187$

$15{ }^{\circ} \mathrm{C}$ ). Therefore, for a garnet- and clinopyroxene-bearing rock that underwent heating,

16 temperatures (and pressures) estimated by the REE-in-garnet-clinopyroxene thermobarometer are

17 likely the equilibrium temperature (and pressure) before heating or an average re-equilibration

18 temperature (and pressure) of REEs in garnet-clinopyroxene bi-mineralic systems at an early

19 stage of heating. In the succeeding discussion, we will further demonstrate this using field data.

\section{4.2. Granulites, eclogites and peridotites from cooling tectonic settings}

22 We compiled 27 samples with major and trace element compositions of garnet and 23 clinopyroxene reported in the literatures from cooling tectonic environments. These samples 24 include 8 granulite xenoliths from Siberia (Koreshkova et al., 2011), 6 granulites from granulite 25 blocks in Central Finland (Nehring et al., 2010), 8 eclogites from Dabie-Sulu ultra-high pressure 26 terrane (Tang et al., 2007), 3 garnet peridotites from the orogenic peridotite massif in the Western 
1 Gneiss Region in Norway (Spengler et al., 2006), and 2 garnet peridotite xenoliths from the arc

2 lithosphere in Sierra Nevada (Chin et al., 2012). Based on the decrease of Mg\# in the rims of

3 garnet grains, Koreshkova et al. (2011) suggest that the granulites from Siberia experienced

4 subsequent cooling and decompression following the last granulite metamorphic event. A similar

5 cooling and decompression process was also inferred from the thermobarometry and

6 metamorphic reactions for the granulites from Finland (Hölttä and Paavola, 2000; Nehring et al.,

7 2010). The 8 eclogites from Dabie-Sulu and the 3 garnet peridotites from Norway were exhumed

8 to the surface presumably associated with cooling. Based on the low equilibrium temperatures $(<$

$9800{ }^{\circ} \mathrm{C}$ at $\sim 3 \mathrm{GPa}$ ) derived from the pyroxene thermobarometer, Chin et al. (2012) suggested that

10 the garnet peridotite xenoliths from Sierra Nevada underwent compression and cooling after melt

11 depletion at shallow depth.

12 For the aforementioned samples, the temperatures derived from the REE-in-garnet-

13 clinopyroxene thermobarometer are systematically higher than those calculated using the garnet-

14 clinopyroxene Fe-Mg thermometer of Krogh (1988) (Fig. 10a; see Supplementary Fig. S4 for

15 temperature and pressure inversions for individual samples). One exception is an eclogite from

16 Dabie-Sulu with a higher Fe-Mg temperature. The higher REE temperature is a common feature

17 for samples experienced cooling processes. Because REEs diffuse significantly slower than Fe

18 and $\mathrm{Mg}$ in garnet and clinopyroxene (e.g., Van Orman et al., 2002; Carlson, 2012; see also

19 Cherniak and Dimanov, 2010 and references therein), the REE-in-garnet-clinopyroxene

20 thermobarometer records temperatures at the early stage of cooling (i.e., higher closure

21 temperatures). For retrograde granulites or eclogites, it would be particularly useful to reveal peak

22 metamorphic conditions. Therefore, the pressures and temperatures derived from the REE-in-

23 garnet-clinopyroxene thermobarometer may be used to define exhumation trajectories for the

24 garnet and clinopyroxene-bearing rocks (Fig. 10b). It may be possible to estimate cooling or

25 exhumation histories of these rocks by coupling the Sm-Nd isotope ages with the REE-in-garnet-

26 clinopyroxene thermobarometer. 


\section{4.3. Eclogites, garnet pyroxenites and peridotites from thermally perturbed settings}

3 We compiled 37 garnet- and clinopyroxene-bearing rocks with mineral major and trace 4 element compositions reported in the literature from thermally perturbed tectonic settings. The 37 5 samples include 4 eclogite xenoliths from the Siberia Craton (3 Group-1 eclogites: Jacob and

6 Foley, 1999; 1 diamond-bearing eclogite: Shatsky et al., 2008), 17 eclogite xenoliths from

7 Kimberley, South Africa (Jacob et al., 2009), 2 eclogite xenoliths from Jericho in the Slave

8 Craton (Group B and Group C eclogites; Smart et al., 2009), 4 M3 garnets from the Western

9 Gneiss Region in Norway (Scambelluri et al., 2008), 4 Type-IV garnet pyroxenites from the Beni

10 Bousera massif in Morocco (Gysi et al., 2011), and 6 garnet peridotite xenoliths from 11 Prahuaniyeu, South America (Bjerg et al., 2009).

12 The diamond-bearing eclogite from Siberia displays light carbon isotope composition in 13 diamond, indicating that it derived from subducted oceanic or continental lithosphere (Shatsky et 14 al., 2008). The Group-1 eclogite xenoliths from Siberia show elevated oxygen isotope ratios than 15 the mantle values, suggesting a low-temperature altered upper crust origin (Jacob and Foley, 16 1999). Although the eclogite xenoliths from Kimberley were metasomatized as evidenced by the 17 presence of a significant amount of phlogotites, they retained the lighter oxygen isotope 18 compositions derived from their protoliths, seawater altered oceanic cumulates (Jacob et al., 19 2009). The Group B and Group C eclogites from the Slave Craton have been interpreted as 20 remnants of subducted oceanic crust mainly based on the U-Pb ages of zircon and rutile in the 21 eclogites (Heaman et al., 2002). The formation of the M3 majoritic garnets from Norway also

22 involved deep subduction during the orogenic process according to the phase assemblages in the

23 M3 minerals (e.g., Scambelluri et al., 2008). The preserved magmatic plagioclase and prograde

24 metamorphic phase assemblages indicate that the Type-IV pyroxenites from Morocco originated

25 from delaminated crustal cumulates (Gysi et al., 2011). During subduction and delamination

26 processes, the aforementioned samples presumably have undergone heating. Finally, the apparent 
1 Sm-Nd isotope ages and high equilibrium temperatures suggest that the mantle sources of the

2 garnet peridotite xenoliths from Prahuaniyeu have been thermally perturbed by a high-

3 temperature event (Bjerg et al., 2009).

4 Figure 10c shows that temperatures derived from the REE-in-garnet-clinopyroxene

5 thermobarometer are systematically lower than those calculated using the garnet-clinopyroxene

6 Fe-Mg thermometer of Krogh (1988) for these samples (see Supplementary Fig. S4 for individual

7 temperature and pressure inversions). (One possible exception is the Group B eclogite from the

8 Slave Craton). This further demonstrates that the Fe-Mg exchange thermometer can be easily

9 reset to the high ambient temperature during heating, while the REE-based thermometer

10 potentially records former low temperatures at an early stage of heating or perhaps before heating.

11 The temperature differences between the REE and the Fe-Mg thermometers may be used to infer

12 thermal histories (i.e., cooling vs. heating) of mafic and ultramafic rocks from various tectonic

13 settings. For subduction-derived eclogites and peridotites, temperatures and pressures calculated

14 using the REE-in-garnet-clinopyroxene thermobarometer may be used to deduce subduction

15 trajectories (Fig. 10d). When coupled with Sm-Nd isotope ages, the REE-in-garnet-clinopyroxene

16 thermobarometer may be used to constrain the rates of subduction, delamination, or heating. Thus,

17 the REE-in-garnet-clinopyroxene thermobarometer would be particularly useful to study large-

18 scale tectonic processes.

\section{Summary and Further Discussion}

21 We have developed a REE-in-garnet-clinopyroxene thermobarometer for garnet- and

22 clinopyroxene-bearing mafic and ultramafic rocks. This new thermobarometer is based on the 23 temperature- and pressure-dependent REE and Y partitioning between garnet and clinopyroxene,

24 and is tested against measured partition coefficients from experimentally determined mineral-melt

25 partition coefficients and from field samples, including eclogites and granulites with quartz,

26 graphite or diamond, and well-equilibrated mantle eclogite xenoliths. Taken collectively, these 
1 experimental and field data establishes the accuracy and reliability of the REE-in-garnet-

2 clinopyroxene thermobarometer at magmatic and subsolidus conditions. Applications of the REE-

3 in-garnet-clinopyroxene thermobarometer to garnet- and clinopyroxene-bearing mafic and

4 ultramafic rocks from active tectonic environments demonstrate that the REE-in-garnet-

5 clinopyroxene thermobarometer records temperatures higher than those from the $\mathrm{Fe}-\mathrm{Mg}$

6 thermometer for samples from cooling tectonic settings, but lower than those from the Fe-Mg

7 thermometer for samples from thermally perturbed regions. (Note that the thermal histories

8 (cooling or heating) of these samples were suggested in the literature or could be inferred directly

9 according to the interpretations in the literature.) We attribute the systematic temperature

10 differences to the differences in diffusion rates, and hence closure temperatures, between the

11 trivalent REEs and divalent Fe-Mg in garnet and clinopyroxene. Thus, when coupled with Fe-Mg

12 thermometers, the REE-in-garnet-clinopyroxene thermobarometer is capable of revealing thermal

13 histories of garnet- and clinopyroxene-bearing rocks.

14 Because garnet and clinopyroxene used in our model calibrations are mostly Mg-rich,

15 cautions should be exercised when applying the REE-in-garnet-clinopyroxene thermobarometer

16 to field samples with grossular-rich garnet or Fe-rich garnet and clinopyroxene (e.g., $\mathrm{Mg \#}<40$,

17 and $>50 \%$ grossular in garnet). Additional REE partitioning experiments with coexisting garnet

18 and clinopyroxene in more mafic systems are needed to further test and calibrate the REE-in-

19 garnet-clinopyroxene thermobarometer in the future.

20 The distribution of $\mathrm{Fe}^{2+}-\mathrm{Mg}^{2+}$ in the M2 and M1 sites in clinopyroxene becomes highly

21 ordered at lower temperatures (e.g., McCallister et al., 1976; Dal Negro et al., 1982; Ganguly,

22 1982; Brizi et al., 2000). In our parameterized lattice model, REE partitioning in clinopyroxene

23 depends on $X_{\mathrm{Mg}}^{\mathrm{M} 2}$ which was calculated by assuming random distribution of $\mathrm{Fe}^{2+}-\mathrm{Mg}^{2+}$ in

24 clinopyroxene (Eq. 7a). The ordering of $\mathrm{Fe}^{2+}-\mathrm{Mg}^{2+}$ over the M1 and M2 sites in clinopyroxene

25 might lead to significant uncertainties in the temperature estimation for field samples. Here, we 
1 assessed the effect of $\mathrm{Fe}^{2+}-\mathrm{Mg}^{2+}$ ordering in clinopyroxene on temperatures derived from the

2 REE-based thermobarometer using the relation between temperature and $\mathrm{Fe}^{2+}-\mathrm{Mg}^{2+}$ distribution

3 in clinopyroxene quantified by Brizi et al. (2000; their Eq. 4). We first calculated the amount of

$4 \mathrm{Mg}$ in the M2 site of clinopyroxene from the experiments compiled in Sun and Liang (2012), and

5 re-calibrated the lattice strain parameters in Eqs. (7a-c). The new coefficients differ from those in

6 Eqs. (7a-c) within the $2 \sigma$ errors, but slightly decrease the model reproducibility for the compiled

7 clinopyroxene-melt REE and Y partitioning data. Provided the ordering distribution of $\mathrm{Fe}^{2+}-\mathrm{Mg}^{2+}$

8 in clinopyroxene, we then re-calculated temperatures for the 35 well-equilibrated mantle eclogite

9 xenoliths using the new lattice strain parameters for clinopyroxene. The temperatures increase by

$101-20{ }^{\circ} \mathrm{C}$ (Supplementary Fig. S5), indicating negligible influence of the ordering of $\mathrm{Fe}^{2+}-\mathrm{Mg}^{2+}$ in

11 clinopyroxene. The small effect of $\mathrm{Fe}^{2+}-\mathrm{Mg}^{2+}$ ordering in clinopyroxene can be understood by the

12 small coefficient of $X_{\mathrm{Mg}}^{\mathrm{M} 2}$ in Eq. (7a) and low abundance of $\mathrm{Mg}$ in the $\mathrm{M} 2$ site in clinopyroxene.

13 Another important source of uncertainties is the trade-off between the temperature and

14 pressure in the garnet-clinopyroxene REE partitioning model (Eq. 2). Through Monte Carlo

15 simulations, we found that the inverted temperatures and pressures show a weak but positive

16 correlation (Supplementary Fig. S6). The accuracy of the REE-in-garnet-clinopyroxene

17 thermobarometer also depends on analytical errors in major element and REE compositions of

18 garnet and clinopyroxene. Analytical errors in major element concentrations of garnet and

19 clinopyroxene are typically small, i.e., less than $1 \%$ errors in electron microprobe analysis, while

20 those in REE abundances of garnet and clinopyroxene may be up to $20 \%$ or perhaps greater by

21 the Laser Ablation Inductively Coupled Plasma Mass Spectrometry analysis. The effects of

22 analytical errors on the accuracy of the REE-in-garnet-clinopyroxene thermobarometer can also

23 be illustrated through Monte Carlo simulations.

24 For example, $1 \%$ relative errors in major element compositions of garnet and clinopyroxene 25 result in less than $15{ }^{\circ} \mathrm{C}$ uncertainties in the inverted temperature and less than $0.25 \mathrm{GPa}$ 
1 uncertainties in the calculated pressure. These uncertainties are comparable to those from $10 \%$

2 analytical error in REEs in garnet and clinopyroxene (Fig. 11). The uncertainties in the estimated

3 temperatures and pressures increase with the analytical errors in the REE abundances, while the

4 uncertainties in the estimated temperature also increase with the equilibrium temperature (Fig.

5 11). The number of REEs used in the inversion is also an important factor. When all REEs are

6 included in the inversion, a 20\% analytical error in REEs results in less than $50{ }^{\circ} \mathrm{C}$ uncertainties

7 in temperature and $0.5 \mathrm{GPa}$ uncertainties in pressures. When certain REEs are below detection

8 limits or altered by secondary processes (e.g., light REE enrichments), one has to exclude them to

9 obtain a reliable temperature and pressure (Figs. 3c-d). Without heavy REEs, the temperature

10 uncertainty for the low temperature eclogite $\left(801{ }^{\circ} \mathrm{C}\right)$ increases from $30{ }^{\circ} \mathrm{C}$ to $40{ }^{\circ} \mathrm{C}$ for $20 \%$

11 analytical errors in REEs; however, without light REEs, it increases to $60{ }^{\circ} \mathrm{C}$ for the same

12 uncertainty in REE abundances. The pressure uncertainty increases up to $0.8 \mathrm{GPa}$ for $20 \%$ errors

13 in REE analysis, if heavy REEs are excluded in the inversion. Therefore, accurate analysis of

14 REEs in garnet and clinopyroxene is a prerequisite in the application of the REE-in-garnet-

15 clinopyroxene thermobarometer.

\section{Acknowledgements}

18 We thank Lijing Yao for useful discussion and Seigei Simakov for his help with his garnet-

19 clinopyroxene barometer. We are grateful to Cin-Ty Lee for his constructive review. This work

20 was supported in part by the NSF grant EAR-1220076 and NASA grant NNX13AH07G.

\section{Appendix A. Supplementary Data}

23 Supplementary data to this manuscript can be found online. 


\section{References}

2 Adam J. and Green T. (2006) Trace element partitioning between mica-and amphibole-bearing 3 garnet lherzolite and hydrous basanitic melt: 1. Experimental results and the investigation of controls on partitioning behaviour. Contributions to Mineralogy and Petrology 152, 1-17.

5 Ai Y. (1994) A revision of the garnet-clinopyroxene $\mathrm{Fe}^{2+}-\mathrm{Mg}$ exchange geothermometer. Contributions to Mineralogy and Petrology 115, 467-473.

Barth M. G., Rudnick R. L., Horn I., McDonough W. F., Spicuzza M. J., Valley J. W. and

Brizi E., Molin G. and Zanazzi P. F. (2000) Experimental study of intracrystalline $\mathrm{Fe}^{2+}-\mathrm{Mg}$ Haggerty S. E. (2001) Geochemistry of xenolithic eclogites from West Africa, Part I: a link between low $\mathrm{MgO}$ eclogites and Archean crust formation. Geochimica et Cosmochimica Acta 65, 1499-1527.

Bjerg E. A., Ntaflos T., Thöni M., Aliani P. and Labudia C. H. (2009) Heterogeneous lithospheric mantle beneath northern Patagonia: evidence from Prahuaniyeu garnet-and spinel-peridotites. Journal of Petrology 50, 1267-1298.

Blundy J. and Wood B. (1994) Prediction of crystal melt partition coefficients from elastic moduli. Nature 372, 452-454.

Bohlen S. R. and Boettcher A. L. (1982) The quartz $\leftrightarrows$ coesite transformation: a precise determination and the effects of other components. Journal of Geophysical Research: Solid Earth 87, 7073-7078.

Brey G. P., Bulatov V. K. and Girnis, A. V. (2008) Geobarometry for peridotites: experiments in simple and natural systems from 6 to $10 \mathrm{GPa}$. Journal of Petrology 49, 3-24.

Brey G. P., Nickel K. G. and Kogarko L. (1986) Garnet-pyroxene equilibria in the system CaO$\mathrm{MgO}-\mathrm{Al}_{2} \mathrm{O}_{3}-\mathrm{SiO}_{2}$ (CMAS): prospects for simplified ('T-independent') lherzolite barometry and an eclogite-barometer. Contributions to Mineralogy and Petrology 92, 448-455.

exchange in three augite crystals: Effect of composition on geothermometric calibration. American Mineralogist 85, 1375-1382. 
1 Carlson W. D. 2012. Rates and mechanism of Y, REE, and Cr diffusion in garnet. American $2 \quad$ Mineralogist, 97, 1598-1618.

3 Cherniak D. J. and Dimanov A. (2010) Diffusion in pyroxene, mica and amphibole. Reviews in $4 \quad$ Mineralogy and Geochemistry 72, 641-690.

5 Chin E. J., Lee C. T. A., Luffi P. and Tice M. (2012) Deep lithospheric thickening and 6 refertilization beneath continental arcs: Case study of the P, T and compositional evolution 7 of peridotite xenoliths from the Sierra Nevada, California. Journal of Petrology 53, 477-511.

8 Corgne A., Armstrong L. S., Keshav S., Fei Y., McDonough W. F., Minarik W. G. and Moreno K. 9 (2012) Trace element partitioning between majoritic garnet and silicate melt at 10-17GPa: 10 Implications for deep mantle processes. Lithos 148, 128-141.

11 Dal Negro A., Carbonin S., Molin G. M., Cundari A. and Piccirillo E. M. (1982) Intracrystalline 12 cation distribution in natural clinopyroxenes of tholeiitic, transitional, and alkaline basaltic 13 rocks. In Advances in physical geochemistry (pp. 117-150). Springer New York.

14 Day H. W. (2012) A revised diamond-graphite transition curve. American Mineralogist 97, 52-62.

15 Draper D. S. and van Westrenen W. (2007) Quantifying garnet-melt trace element partitioning 16 using lattice-strain theory: assessment of statistically significant controls and a new 17 predictive model. Contributions to Mineralogy and Petrology 154, 731-746.

18 Ellis D. J. and Green D. H. (1979) An experimental study of the effect of Ca upon garnet19 clinopyroxene Fe-Mg exchange equilibria. Contributions to Mineralogy and Petrology 71, $20 \quad 13-22$.

21 Freer R. and Edwards A. (1999) An experimental study of $\mathrm{Ca}-(\mathrm{Fe}, \mathrm{Mg})$ interdiffusion in silicate 22 garnets. Contributions to Mineralogy and Petrology 134, 370-379.

23 Ganguly J. (1979) Garnet and clinopyroxene solid solutions, and geothermometry based on Fe24 Mg distribution coefficient. Geochimica et Cosmochimica Acta 43, 1021-1029.

25 Ganguly J. (1982) Mg-Fe order-disorder in ferromagnesian silicates: II. Thermodynamics, 26 kinetics and geological applications. Advances in physical geochemistry 2, 58-99. 
1 Ganguly J. and Tazzoli V. (1994) $\mathrm{Fe}^{2+}-\mathrm{Mg}$ interdiffusion in orthopyroxene; retrieval from the 2 data on intracrystalline exchange reaction. American Mineralogist 79, 930-937.

3 Green T. H., Blundy J. D., Adam J. and Yaxley G. M. (2000) SIMS determination of trace 4 element partition coefficients between garnet, clinopyroxene and hydrous basaltic liquids at $5 \quad 2-7.5 \mathrm{GPa}$ and $1080-1200^{\circ} \mathrm{C}$. Lithos $53,165-187$.

6 Griffin W. L. and O'Reilly S. Y. (2007) Cratonic lithospheric mantle: is anything subducted? $7 \quad$ Episodes 30, 43.

8 Griffin W. L., O'Reilly S. Y., Natapov L. M. and Ryan C. G. (2003) The evolution of lithospheric 9 mantle beneath the Kalahari Craton and its margins. Lithos 71, 215-241.

10 Gysi A. P., Jagoutz O., Schmidt M. W. and Targuisti K. (2011) Petrogenesis of pyroxenites and 11 melt infiltrations in the ultramafic complex of Beni Bousera, Northern Morocco. Journal of $12 \quad$ Petrology 52, 1679-1735.

13 Harte B. and Kirkley M. B. (1997) Partitioning of trace elements between clinopyroxene and 14 garnet: data from mantle eclogites. Chemical Geology 136, 1-24.

15 Heaman L. M., Creaser R. A. and Cookenboo H. O. (2002) Extreme enrichment of high field 16 strength elements in Jericho eclogite xenoliths: A cryptic record of Paleoproterozoic 17 subduction, partial melting, and metasomatism beneath the Slave craton, Canada. Geology $18 \quad 30,507-510$.

19 Hofmann A. W. (1988) Chemical differentiation of the Earth: the relationship between mantle, 20 continental crust, and oceanic crust. Earth and Planetary Science Letters 90, 297-314.

21 Hölttä P. and Paavola J. (2000) P-T-t development of Archaean granulites in Varpaisjärvi, 22 Central Finland: I. Effects of multiple metamorphism on the reaction history of mafic rocks. 23 Lithos 50, 97-120.

24 Huang J. X., Gréau Y., Griffin W. L., O'Reilly S. Y. and Pearson N. J. (2012) Multi-stage origin 25 of Roberts Victor eclogites: Progressive metasomatism and its isotopic effects. Lithos 142, $26 \quad 161-181$. 
1 Jacob D. E. and Foley S. F. (1999) Evidence for Archean ocean crust with low high field strength 2 element signature from diamondiferous eclogite xenoliths. Lithos 48, 317-336.

3 Jacob D. E., Viljoen K. S. and Grassineau N. V. (2009) Eclogite xenoliths from Kimberley, South $4 \quad$ Africa-a case study of mantle metasomatism in eclogites. Lithos 112, 1002-1013.

5 Kennedy C. S. and Kennedy G. C. (1976) The equilibrium boundary between graphite and 6 diamond. Journal of Geophysical Research 81, 2467-2470.

7 Koreshkova M. Y., Downes H., Levsky L. K. and Vladykin N. V. (2011) Petrology and 8 geochemistry of granulite xenoliths from Udachnaya and Komsomolskaya kimberlite pipes, $9 \quad$ Siberia. Journal of Petrology 52, 1857-1885.

10 Krogh E. J. (1988) The garnet-clinopyroxene Fe-Mg geothermometer-a reinterpretation of 11 existing experimental data. Contributions to Mineralogy and Petrology 99, 44-48.

12 Lee C. T. A., Harbert A. and Leeman W. P. (2007) Extension of lattice strain theory to 13 mineral/mineral rare-earth element partitioning: an approach for assessing disequilibrium 14 and developing internally consistent partition coefficients between olivine, orthopyroxene, 15 clinopyroxene and basaltic melt. Geochimica et Cosmochimica Acta 71, 481-496.

16 Liang Y., Sun, C. and Yao L. (2013) A REE-in-two-pyroxene thermometer for mafic and 17 ultramafic rocks. Geochimica et Cosmochimica Acta 102, 246-260.

18 Liang Y. (2014) Time scales of diffusive re-equilibration in bi-mineralic systems with and 19 without a fluid or melt phase. Geochimica et Cosmochimica Acta 132, 274-287.

20 Matjuschkin V., Brey G. P., Höfer H. E. and Woodland A. B. (2014) The influence of Fe3+ on 21 garnet-orthopyroxene and garnet-olivine geothermometers. Contributions to Mineralogy 22 and Petrology 167, 1-10.

23 McCallister R. H., Finger L. W. and Ohashi Y. (1976) Intracrystalline $\mathrm{Fe}^{2+}-\mathrm{Mg}$ equilibria in three 24 natural Ca-rich clinopyroxenes. American Mineralogist 61, 671-676.

25 Mukhopadhyay B. (1991) Garnet-clinopyroxene geobarometry; the problems, a prospect, and an 26 approximate solution with some applications. American Mineralogist 76, 512-529. 
1 Nakamura D. (2009) A new formulation of garnet-clinopyroxene geothermometer based on 2 accumulation and statistical analysis of a large experimental data set. Journal of 3 Metamorphic Geology 27, 495-508.

4 Nehring F., Foley S. F. and Hölttä P. (2010) Trace element partitioning in the granulite facies.

5 Contributions to Mineralogy and Petrology 159, 493-519.

6 Nimis P. and Grütter H. (2010) Internally consistent geothermometers for garnet peridotites and 7 pyroxenites. Contributions to Mineralogy and Petrology 159, 411-427.

8 Powell R. (1985) Regression diagnostics and robust regression in geothermometer / geobarometer 9 calibration: the garnet-clinopyroxene geothermometer revisited. Journal of Metamorphic $10 \quad$ Geology 3, 231-243.

11 Råheim A. and Green D. H. (1974) Experimental determination of the temperature and pressure 12 dependence of the Fe-Mg partition coefficient for coexisting garnet and clinopyroxene. 13 Contributions to Mineralogy and Petrology 48, 179-203.

14 Ravna E. K. and Paquin J. (2003) Thermobarometric methodologies applicable to eclogites and 15 garnet ultrabasites. EMU notes in mineralogy 5, 229-259.

16 Ravna K. (2000) The garnet-clinopyroxene $\mathrm{Fe}^{2+}-\mathrm{Mg}$ geothermometer: an updated calibration. 17 Journal of Metamorphic Geology 18, 211-219.

18 Saxena S. K. (1979) Garnet-clinopyroxene geothermometer. Contributions to Mineralogy and 19 Petrology 70, 229-235.

20 Scambelluri M., Pettke T. and Van Roermund H. L. M. (2008) Majoritic garnets monitor deep 21 subduction fluid flow and mantle dynamics. Geology 36, 59-62.

22 Seitz H. M., Altherr R. and Ludwig T. (1999) Partitioning of transition elements between 23 orthopyroxene and clinopyroxene in peridotitic and websteritic xenoliths: new empirical 24 geothermometers. Geochimica et Cosmochimica Acta 63, 3967-3982.

25 Shannon R. D. (1976) Revised effective ionic radii and systematic studies of interatomic 26 distances in halides and chalcogenides. Acta Crystallographica Section A: Crystal Physics, 
Diffraction, Theoretical and General Crystallography 32, 751-767.

2 Shatsky V., Ragozin A., Zedgenizov D. and Mityukhin S. (2008) Evidence for multistage

3 evolution in a xenolith of diamond-bearing eclogite from the Udachnaya kimberlite pipe.

$4 \quad$ Lithos $105,289-300$.

5 Simakov S. K. (2008) Garnet-clinopyroxene and clinopyroxene geothermobarometry of deep 6 mantle and crust eclogites and peridotites. Lithos 106, 125-136.

7 Simakov S. K. and Taylor L. A. (2000) Geobarometry for mantle eclogites: Solubility of Ca-

8 Tschermaks in clinopyroxene. International Geology Review 42, 534-544.

9 Smart K. A., Heaman L. M., Chacko T., Simonetti A., Kopylova M., Mah D. and Daniels D. 10 (2009) The origin of high-MgO diamond eclogites from the Jericho Kimberlite, Canada. 11 Earth and Planetary Science Letters 284, 527-537.

12 Spengler D., Van Roermund H. L., Drury M. R., Ottolini L., Mason P. R. and Davies G. R. (2006)

13 Deep origin and hot melting of an Archaean orogenic peridotite massif in Norway. Nature $14 \quad 440,913-917$.

15 Stosch H. G. (1982) Rare earth element partitioning between minerals from anhydrous spinel 16 peridotite xenoliths. Geochimica et Cosmochimica Acta 46, 793-811.

17 Sun C. and Liang Y. (2012) Distribution of REE between clinopyroxene and basaltic melt along a 18 mantle adiabat: effects of major element composition, water, and temperature. Contributions 19 to Mineralogy and Petrology 163, 807-823.

20 Sun C. and Liang Y. (2013a) The importance of crystal chemistry on REE partitioning between 21 mantle minerals (garnet, clinopyroxene, orthopyroxene, and olivine) and basaltic melts. 22 Chemical Geology 358, 23-36.

23 Sun C. and Liang Y. (2013b) Distribution of REE and HFSE between low-Ca pyroxene and lunar 24 picritic melts around multiple saturation points. Geochimica et Cosmochimica Acta 119, $25 \quad 340-358$.

26 Sun C. and Liang Y. (2014) An assessment of subsolidus re-equilibration on REE distribution 
among mantle minerals olivine, orthopyroxene, clinopyroxene, and garnet in peridotites. Chemical Geology 372, 80-91.

3 Suzuki T., Hirata T., Yokoyama T. D., Imai T. and Takahashi, E. (2012) Pressure effect on 4 element partitioning between minerals and silicate melt: Melting experiments on basalt up to 5 20GPa. Physics of the Earth and Planetary Interiors 208, 59-73.

6 Tang H. F., Liu C. Q., Nakai S. I. and Orihashi Y. (2007) Geochemistry of eclogites from the 7 Dabie-Sulu terrane, eastern China: new insights into protoliths and trace element behaviour 8 during UHP metamorphism. Lithos 95, 441-457.

9 Tuff J. and Gibson S. A. (2007) Trace-element partitioning between garnet, clinopyroxene and 10 Fe-rich picritic melts at 3 to $7 \mathrm{GPa}$. Contributions to Mineralogy and Petrology 153, 369-387.

11 Van Orman J. A., Grove T. L., Shimizu N. and Layne G. D. (2002) Rare earth element diffusion 12 in a natural pyrope single crystal at $2.8 \mathrm{GPa}$. Contributions to Mineralogy and Petrology 142 , $13 \quad 416-424$.

14 Van Orman J. A., Grove T. L. and Shimizu N. (2001) Rare earth element diffusion in diopside: 15 influence of temperature, pressure, and ionic radius, and an elastic model for diffusion in 16 silicates. Contributions to Mineralogy and Petrology 141, 687-703.

17 van Westrenen W. and Draper D. S. (2007) Quantifying garnet-melt trace element partitioning 18 using lattice-strain theory: new crystal-chemical and thermodynamic constraints. 19 Contributions to Mineralogy and Petrology 154, 717-730.

20 van Westrenen W., Van Orman J. A., Watson H., Fei Y. and Watson E. B. (2003) Assessment of 21 temperature gradients in multianvil assemblies using spinel layer growth kinetics. 22 Geochemistry, Geophysics, Geosystems 4.

23 van Westrenen W., Wood B. J. and Blundy J. D. (2001) A predictive thermodynamic model of 24 garnet-melt trace element partitioning. Contributions to Mineralogy and Petrology 142, 219254 . 234

26 Watson E. B. and Cherniak D. J. (2013) Simple equations for diffusion in response to heating. 
$1 \quad$ Chemical Geology 335, 93-104.

2 Witt-Eickschen G. and O'Neill H. S. C. (2005) The effect of temperature on the equilibrium 3 distribution of trace elements between clinopyroxene, orthopyroxene, olivine and spinel in $4 \quad$ upper mantle peridotite. Chemical Geology 221, 65-101.

5 Wood B. J. and Banno S. (1973) Garnet-orthopyroxene and orthopyroxene-clinopyroxene 6 relationships in simple and complex systems. Contributions to Mineralogy and Petrology 42, $7 \quad 109-124$

8 Wood B. J. and Blundy J. D. (1997) A predictive model for rare earth element partitioning 9 between clinopyroxene and anhydrous silicate melt. Contributions to Mineralogy and $10 \quad$ Petrology $129,166-181$.

11 Wood B. J. and Blundy J. D. (2002) The effect of $\mathrm{H}_{2} \mathrm{O}$ on crystal-melt partitioning of trace 12 elements. Geochimica et Cosmochimica Acta 66, 3647-3656.

13 Wood B. J. and Blundy J. D. (2003) Trace element partitioning under crustal and uppermost 14 mantle conditions: the influences of ionic radius, cation charge, pressure and temperature, in 15 Treatise on Geochemistry, vol. 2, The Mantle and Core, edited by R. W. Carlson, H. D. 16 Holland, and K. K. Turekian, pp. 392-424, Elsevier, New York.

17 Yao L., Sun C. and Liang Y. (2012) A parameterized model for REE distribution between low-Ca 18 pyroxene and basaltic melts with applications to REE partitioning in low-Ca pyroxene along 19 a mantle adiabat and during pyroxenite-derived melt and peridotite interaction. 20 Contributions to Mineralogy and Petrology 164, 261-280.

21 Yao, L., Liang, Y., 2014. Closure temperature in cooling bi-mineralic systems: I. Definition and 22 application to REE-in-two-pyroxene thermometer. Geochimica et Cosmochimica Acta, in 23 revision. 


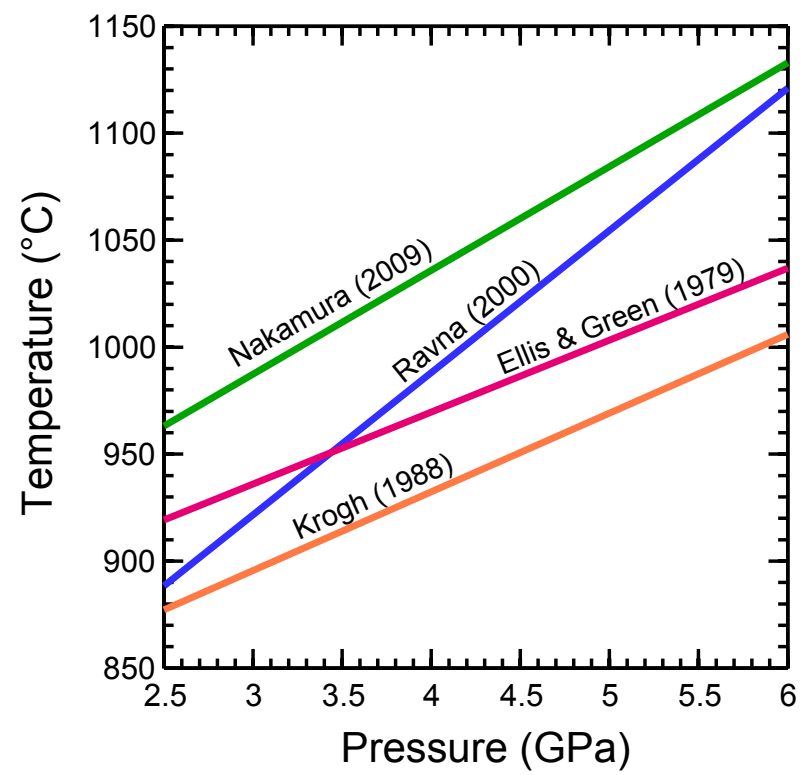

9

10 Figure 1 Temperature variations as functions of pressure derived from different garnet-

11 clinopyroxene Fe-Mg thermometers. Major element compositions of garnet and clinopyroxene

12 are from Huang et al. (2012; sample RV07-12).

13 


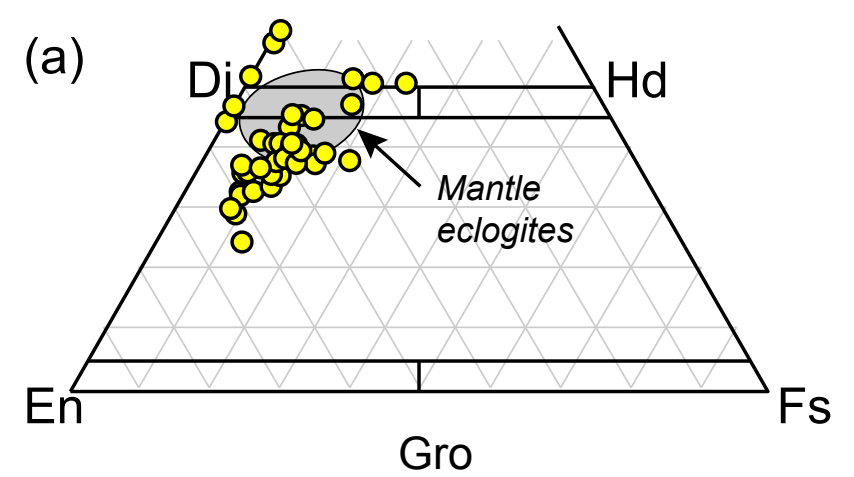

(b)

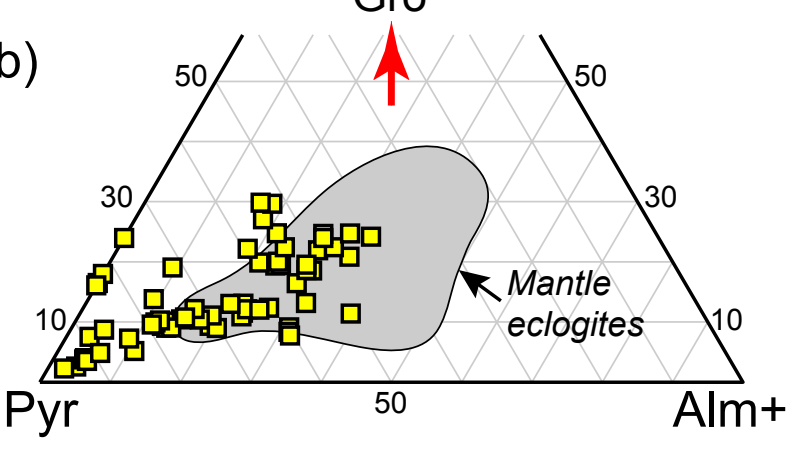

7 Figure 2 Quadrilateral and ternary diagrams showing compositions of clinopyroxenes (a) and 8 garnets (b) used in the clinopyroxene-melt REE partitioning model (Sun and Liang, 2012) and

9 the garnet-melt REE partitioning model (Sun and Liang, 2013a, 2014). Di, En, Hd and Fs denote

10 pyroxene end-members, diopside, enstatite, hedenbergite, and ferrosilite, respectively. Py, Gross,

11 and $A l m+$ represent garnet end-members, pyrope, grossular, almandine (+ spessartine),

12 respectively. Gray areas denote the clinopyroxene and garnet compositions from well-

13 equilibrated mantle eclogite xenoliths. See Section 3.2 in the text for details of the well14 equilibrated mantle eclogites. 

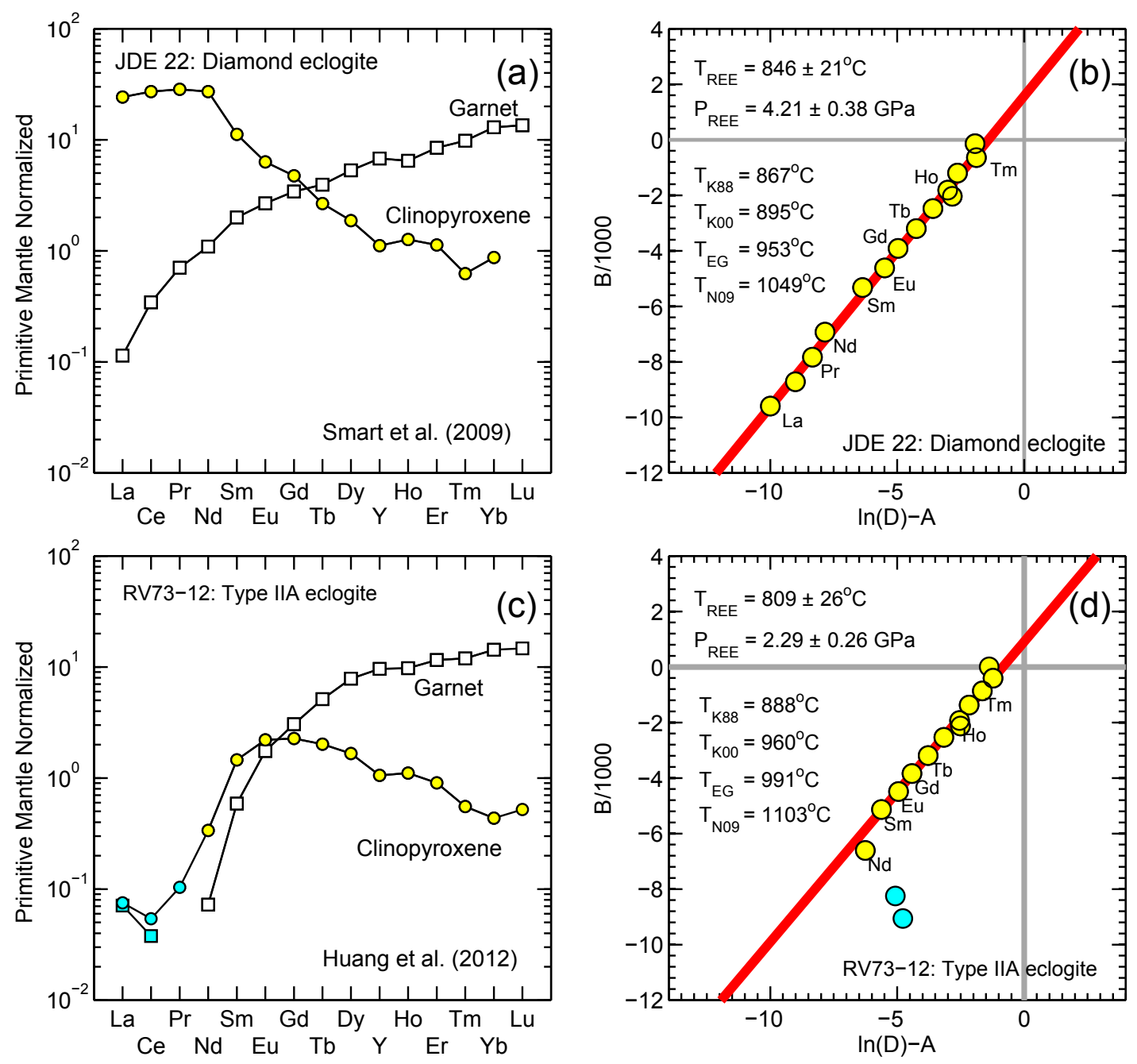

3 Figure 3 Inversions of temperature and pressure from REE abundances in garnet and

4 clinopyroxene for a well-equilibrated diamond eclogite $(\mathrm{a}, \mathrm{b})$ and a light REE-altered eclogite (c,

5 d). The mineral compositions of the diamond eclogite are from Smart et al. (2009) and those of

6 the light REE-altered eclogite are from Huang et al. (2012). (a, c) display the primitive mantle

7 normalized REE abundances in garnet and clinopyroxene, and (b, d) show the inversions of the

8 temperature and pressure through linear least squares regression analysis. The coefficients $A$ and

$9 \quad B$ are calculated using Eqs. (9b-c). Primitive mantle compositions are from Hofmann (1988).

10 Symbols with light blue colors highlight the REEs that may be altered and were excluded in the 11 temperature and pressure inversion. 

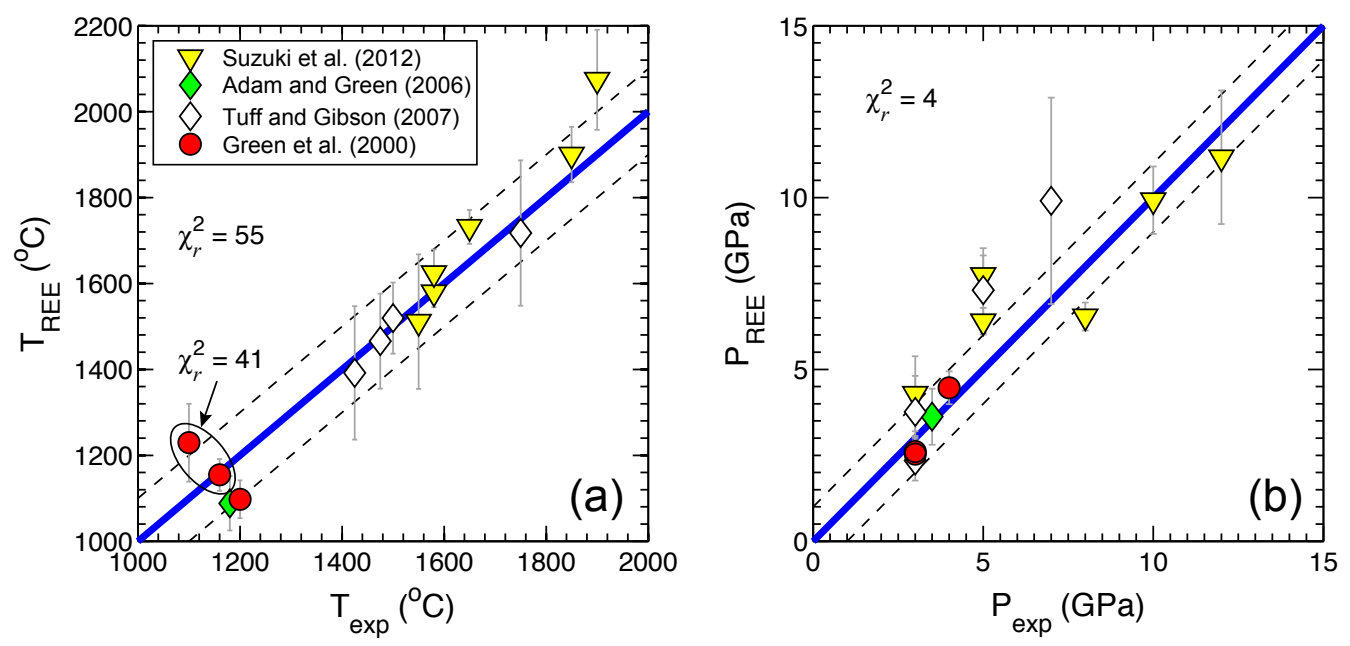

5

6

7 Figure 4 Comparisons of the temperatures and pressures derived from the REE-in-garnet-

8 clinopyroxene thermobarometer and those from the partitioning experiments. Solid blue lines are

$9 \quad$ 1:1 lines, and dashed lines denote $\pm 100^{\circ} \mathrm{C}$ in (a) and $\pm 1 \mathrm{GPa}$ in (b). The $\chi_{r}^{2}$ value in (a) becomes

1041 when the two experiments (Runs 1798 and 1807) from Green et al. (2000) were excluded.

11 

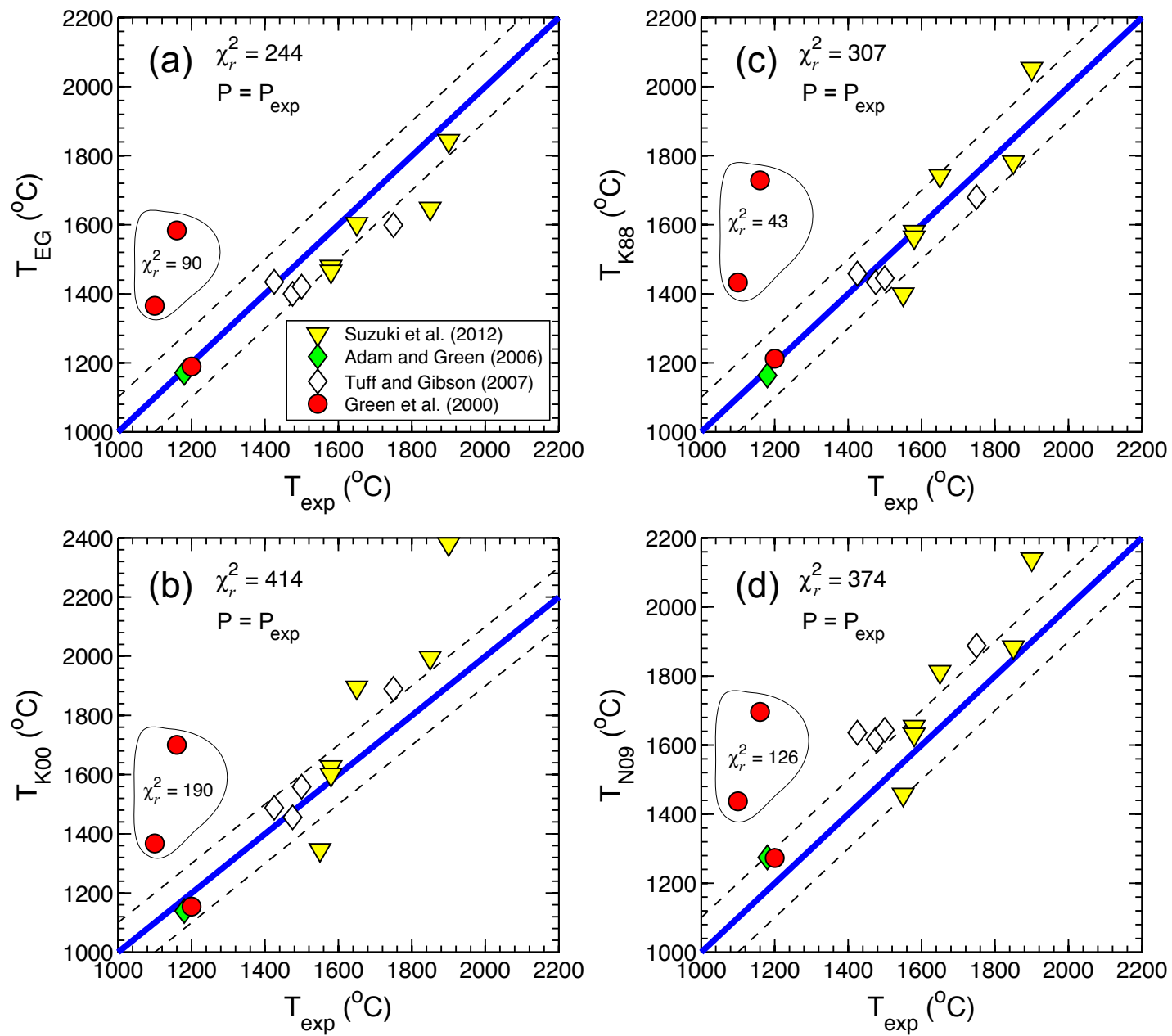

2 Figure 5 Comparisons of the calculated temperatures by the garnet-clinopyroxene Fe-Mg

3 thermometers and the experimental temperatures. The thermometers are from Ellis and Green

4 (1979; a), Ravna (2000; b), Krogh (1988; c) and Nakamura (2009; d). Pressures used in the

5 thermometers were the experimental pressures. The smaller $\chi_{r}^{2}$ values in each panel were

6 calculated by excluding the two experimental data within the circled regions [Runs 1798 and

71807 from Green et al. (2000)]. 

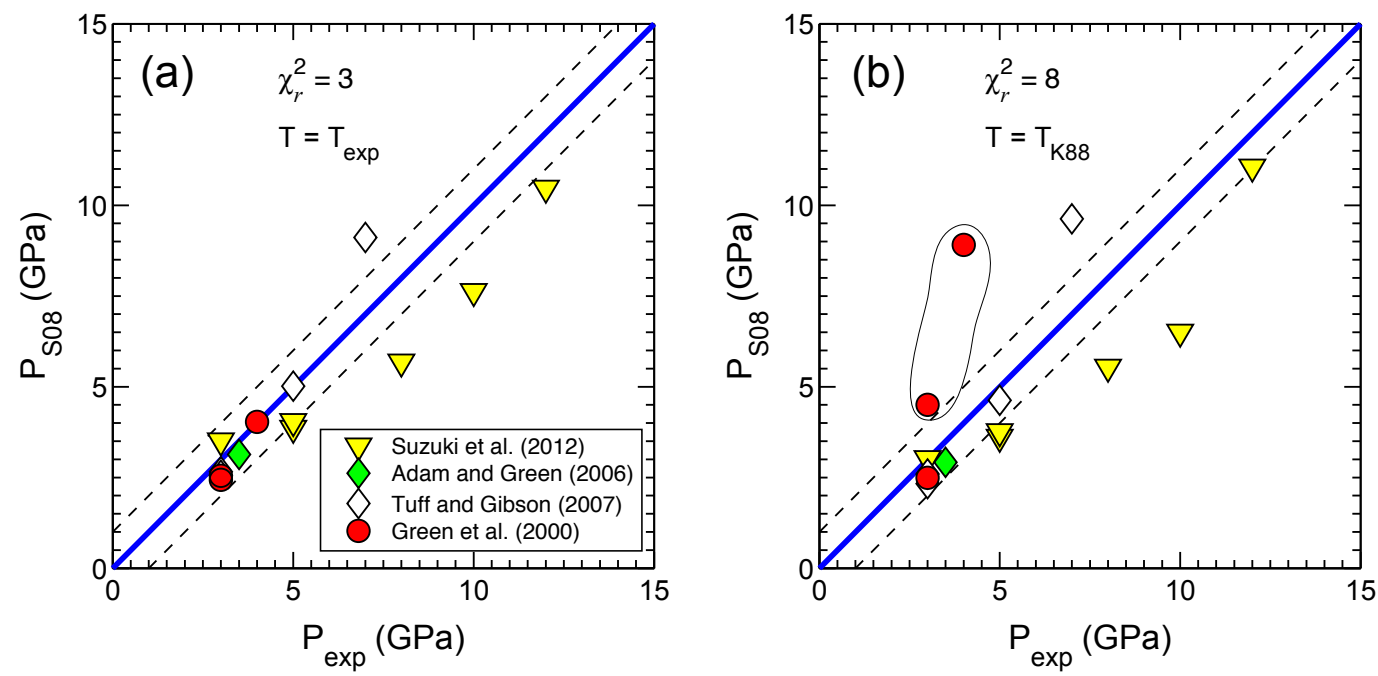

4

5 Figure 6 Comparisons of the estimated pressures and the experimental run pressures. To

6 calculate pressures, the experimental temperatures (a) and the thermometer of $\operatorname{Krogh}(1988 ; \mathrm{b})$

7 were used in the garnet-clinopyroxene barometer of Simakov (2008).

8 

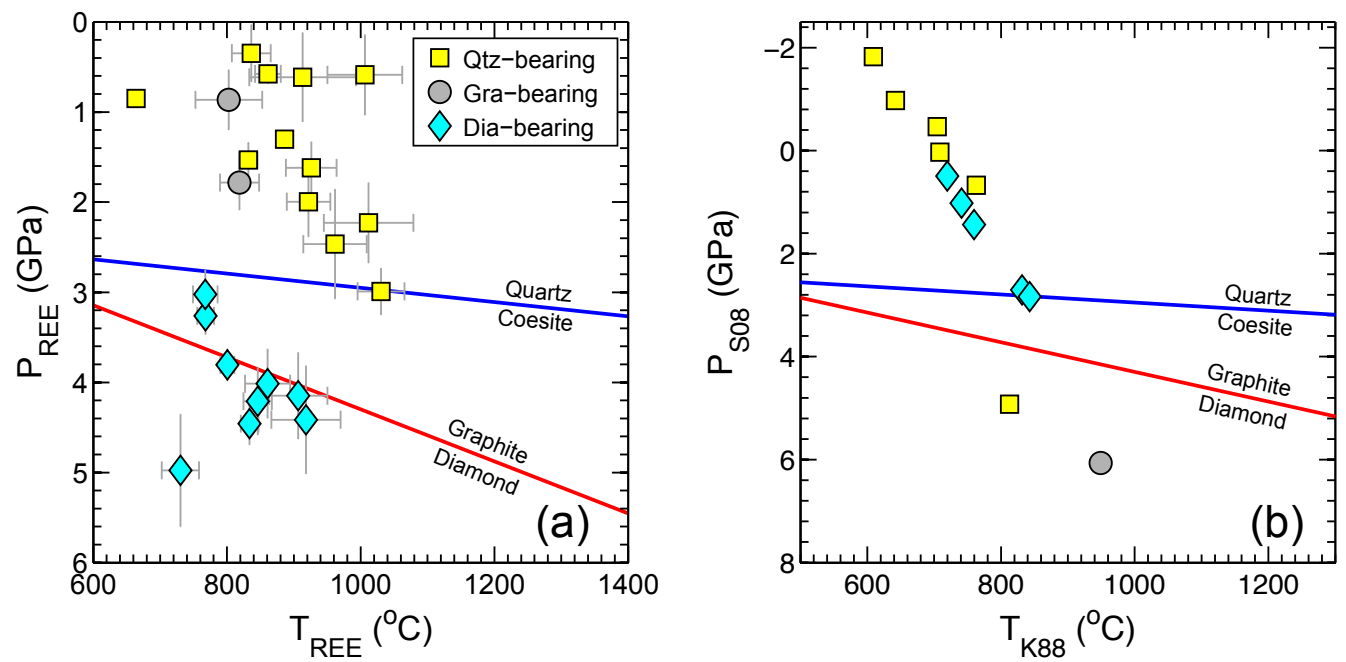

7

8 Figure 7 Temperatures and pressures for eclogites and granulites with quartz (qtz), graphite (gra)

9 and diamond (dia) estimated by the REE-in-garnet-clinopyroxene thermobarometer (a) and the

10 major element-based garnet-clinopyroxene thermometer and barometer of Krogh (1988) and

11 Simakov (2008) (b). The graphite-diamond phase boundary is from Day (2012), and the quartz-

12 coesite phase boundary is from Bohlen and Boettcher (1982). 

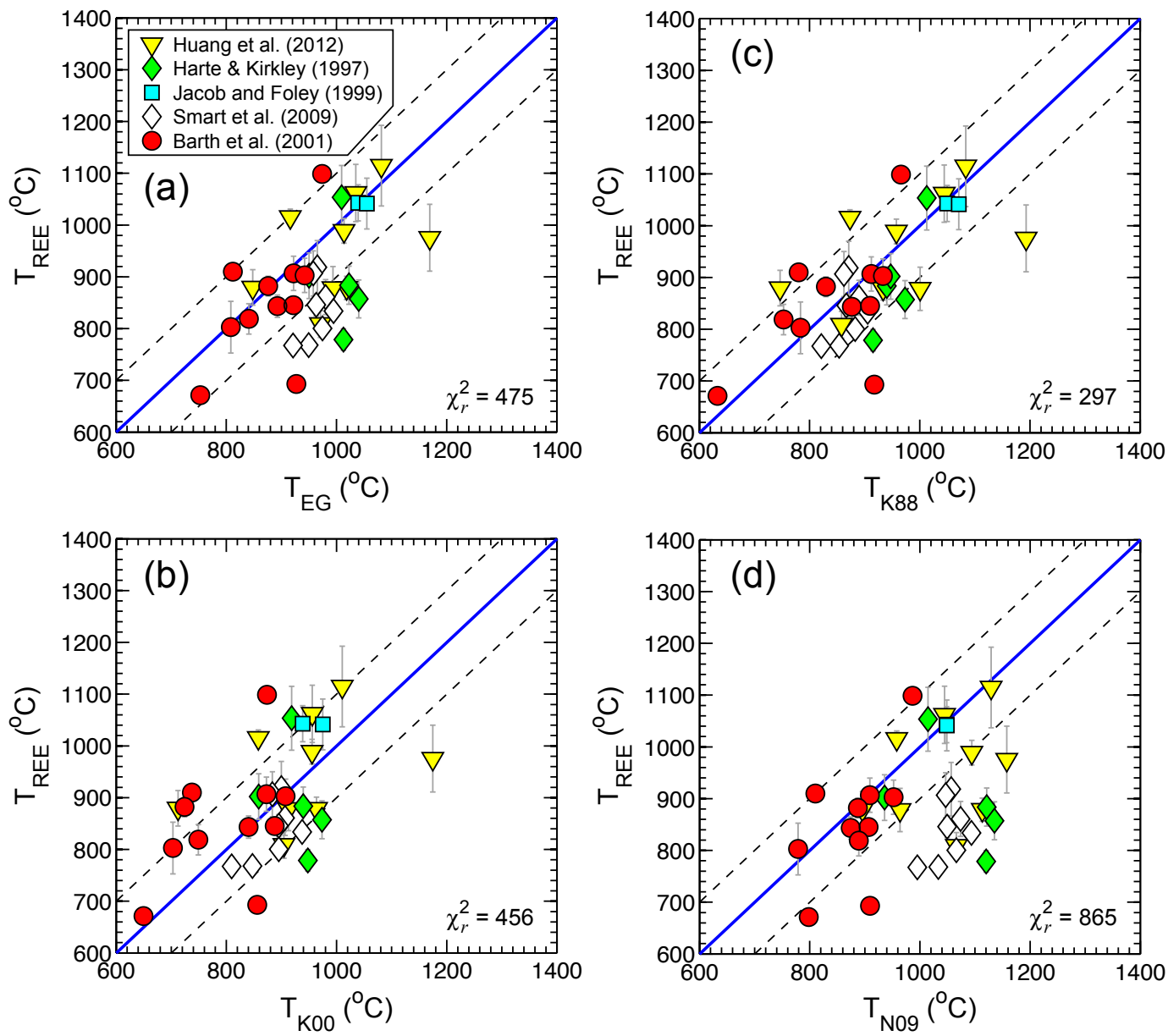

3 Figure 8 Comparisons of the temperatures derived from the REE-in-garnet-clinopyroxene

4 thermobarometer and those calculated by the Fe-Mg thermometers of Ellis and Green (1979; a),

5 Ravna (2000; b), Krogh (1988; c) and Nakamura (2009; d) for well-equilibrated mantle eclogite

6 xenoliths. The pressures used in the Fe-Mg thermometers were calculated by the REE-in-garnet-

7 clinopyroxene thermobarometer. Details of these eclogites samples are in the text. 

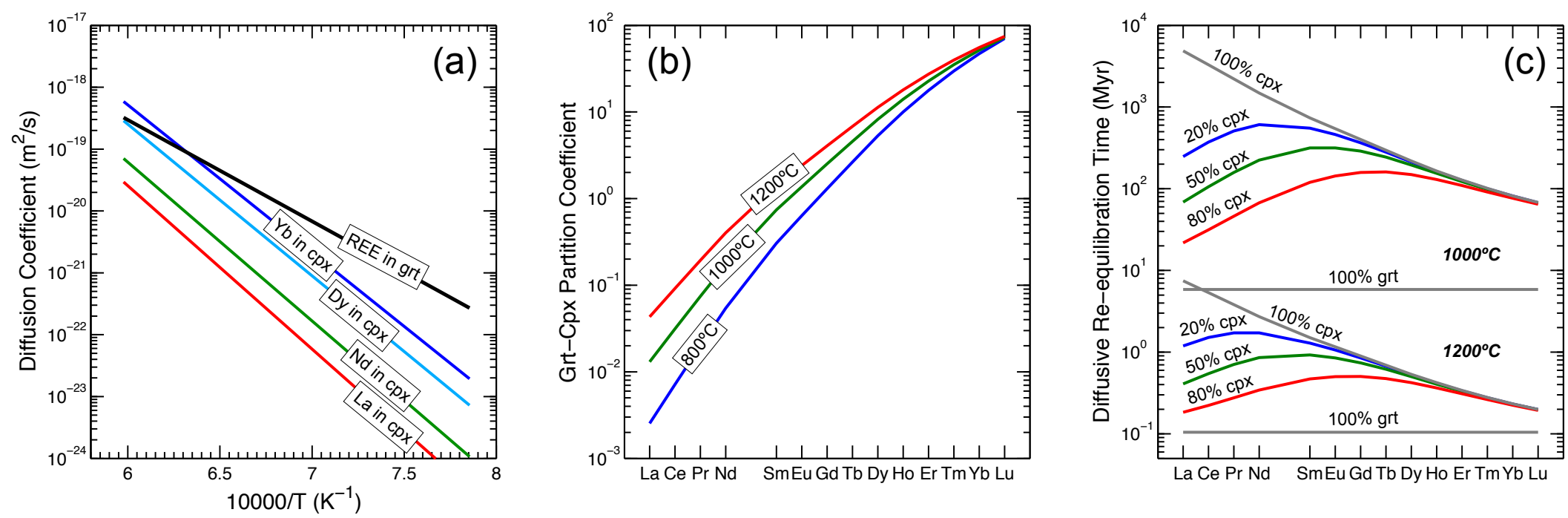

4 Figure 9 (a) Diffusion coefficients of REEs in clinopyroxene and garnet as a function of temperature (Van Orman et al., 2001, 2002). (b) Partition

5 coefficients of REEs between garnet and clinopyroxene at $1200^{\circ} \mathrm{C}, 1000^{\circ} \mathrm{C}, 800^{\circ} \mathrm{C}$ and $2.8 \mathrm{GPa}$. (c) Diffusive re-equilibration times for REEs in

6 garnet-clinopyroxene aggregates at $1200^{\circ} \mathrm{C}$ and $1000^{\circ} \mathrm{C}$ for three choices of clinopyroxene volume proportions $(20 \%, 50 \%, 80 \%)$. The garnet-

7 clinopyroxene REE partition coefficients were calculated using Eqs. (6, 7a-c, and 8a-c) and mineral major element compositions same as those

8 used in Fig. 1. 

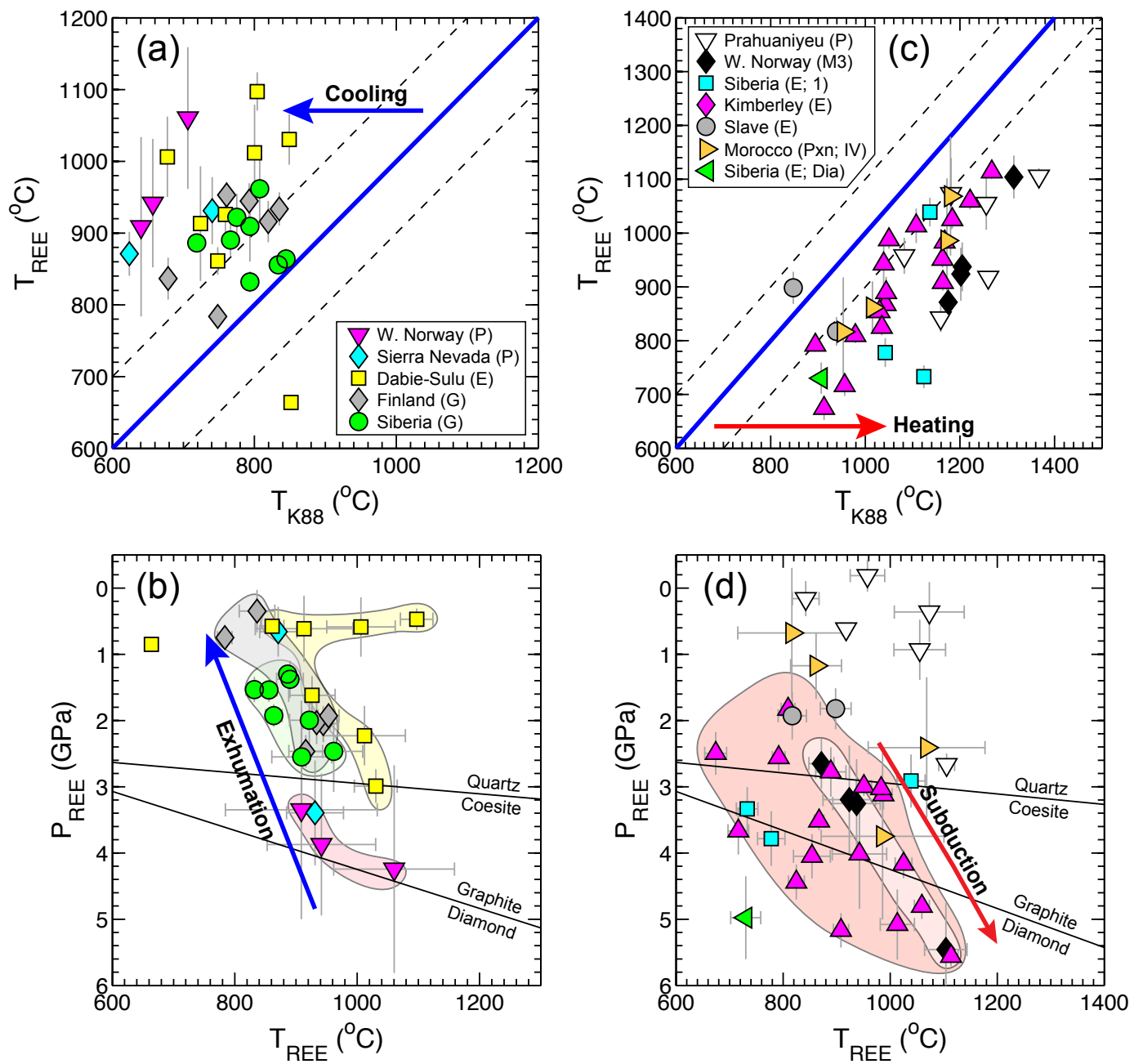

3 Figure 10 Calculated temperatures and pressures for garnet and clinopyroxene-bearing rocks

4 from cooling $(\mathrm{a}, \mathrm{b})$ and thermally perturbed $(\mathrm{c}, \mathrm{d})$ tectonic settings. (a, c) show the systematic

5 temperature differences between the REE-in-garnet-clinopyroxene thermobarometer and the

6 garnet-clinopyroxene Fe-Mg thermometer of Krogh (1988). (b, d) display the calculated pressures

7 and temperatures by the REE-in-garnet-clinopyroxene thermobarometer. In the legend, $P, E, G$

8 and Pxn represent peridotites, eclogites, granulites and pyroxenites, respectively. Eclogites from

9 Siberia include the Group-1 eclogites from Jacob and Foley (1999; squares) and the diamond-

10 bearing eclogite from Shatsky et al. (2008; triangle). Details of other samples are in the text. 

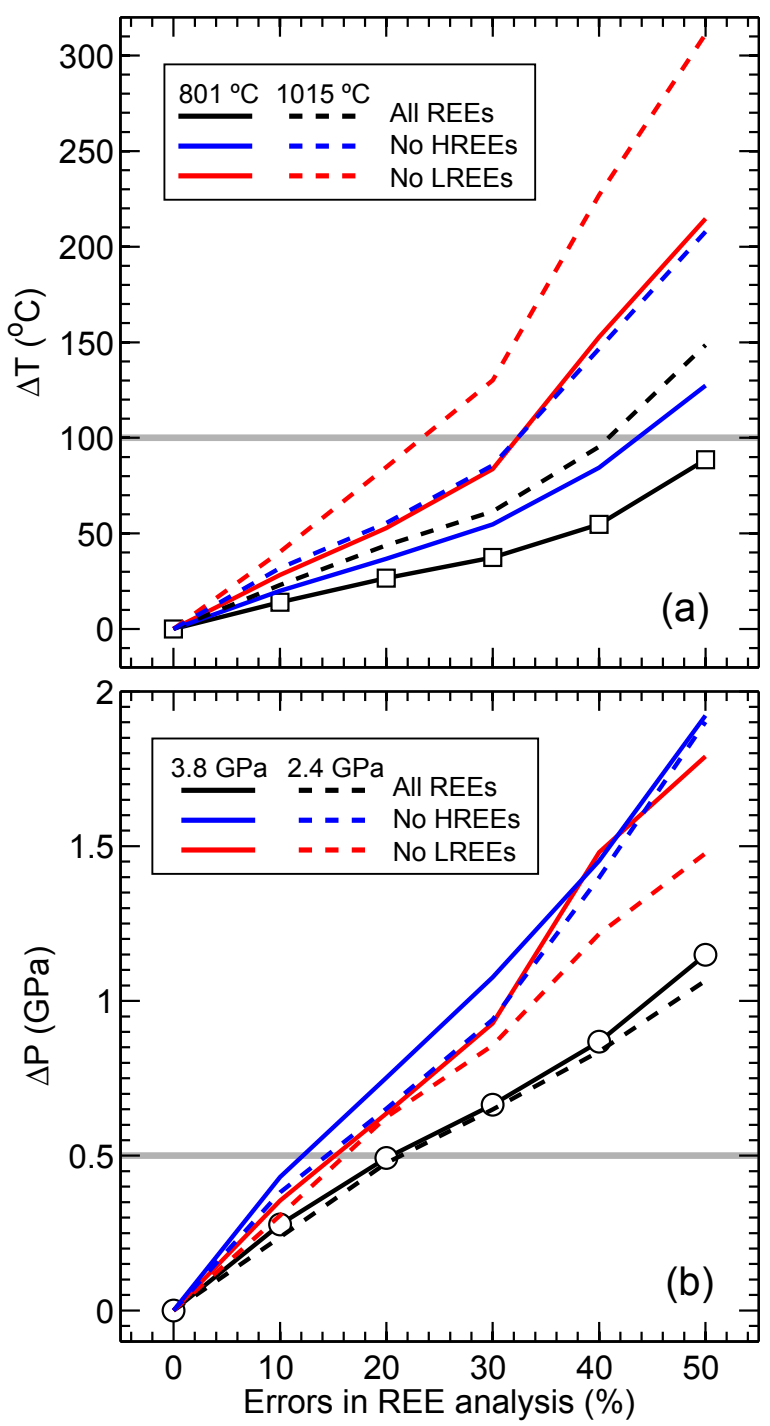

2 Figure 11 Uncertainties in the calculated temperatures and pressures using the REE-in-garnet-

3 clinopyroxene thermobarometer arising from analytical errors of REEs in garnet and

4 clinopyroxene. Here we consider analytical uncertainties in REE compositions from two eclogites

5 [RV07-12 from Huang et al. (2012); JDE 07 from Smart et al. (2009)] with different equilibrium

6 temperatures and pressures (RV07-12: $1015^{\circ} \mathrm{C}, 2.4 \mathrm{GPa}$, dashed curves; JDE07: $801{ }^{\circ} \mathrm{C}, 3.8 \mathrm{GPa}$,

7 solid curves). The temperature and pressure uncertainties are standard errors calculated from

8 Monte Carlo simulations for 1000 sets of garnet-clinopyroxene REE partition coefficients with

9 normally distributed random noise as the analytical errors. 


\title{
Electronic Supplementary Materials
}

\section{A REE-in-Garnet-Clinopyroxene Thermobarometer for Eclogites, Granulites and Garnet Peridotites}

\author{
Chenguang Sun* and Yan Liang \\ Department of Earth, Environmental and Planetary Sciences, Brown University \\ Box 1846, Providence, RI 02912, USA \\ * Corresponding author: Chenguang Sun \\ E-mail: csun@whoi.edu
}

Present address: Department of Geology and Geophysics, Woods Hole Oceanographic Institution Woods Hole, MA 02543, USA

Chemical Geology

2014 


\section{Further Test of the Garnet-Clinopyroxene REE Partitioning Model}

Here we compare garnet-clinopyroxene REE and Y partition coefficients predicted by Eqs. $(6,7 \mathrm{a}-\mathrm{c}$, and 8a-c) with those derived from mineral-melt partitioning experiments and with those measured in additional well-equilibrated mantle eclogite xenoliths from various locations. The partitioning experiments were conducted at $1100-1900{ }^{\circ} \mathrm{C}$ and $3-12 \mathrm{GPa}$, and produced clinopyroxene and garnet coexisting with melts (Green et al., 2000; Klemme et al., 2002; Adam and Green, 2006; Tuff and Gibson, 2007; Suzuki et al., 2012). Partitioning data from these experiments have been used to independently calibrate our clinopyroxene-melt and garnet-melt REE partitioning models except the clinopyroxene-melt partitioning data from Tuff and Gibson (2007) and Suzuki et al. (2012).

In addition to the well-equilibrated mantle xenoliths from the Roberts Victor kimberlite, South Africa (Type II eclogites; Harte and Kirkley, 1997; Huang et al., 2012) used in Sun and Liang (2013a), here we further expand our field test by considering well-equilibrated eclogites from the Udachnaya kimberlite, Siberia (Group 2 eclogites; Jacob and Foley, 1999), the Koidu kimberlite complex, West Africa (low-MgO eclogites; Barth et al., 2001), and the Jericho kimberlite, Canada (diamond eclogites; Smart et al., 2009). Note the garnets from these mantle eclogites are more Fe-rich than those used in the model calibrations (Fig. 2b). To calculate the garnet-clinopyroxene REE and Y partition coefficients, we used the reported final equilibrium temperatures for the partitioning experiments, and calculated the equilibrium temperatures of the eclogite xenoliths using the garnet-clinopyroxene Fe-Mg thermometer of Krogh (1988) at an assumed pressure of $3 \mathrm{GPa}$.

Supplementary Figs. S1a-b show that the garnet-clinopyroxene REE and Y partition coefficients derived from Eqs. (6, 7a-c, and 8a-c) are generally in very good agreement with those measured from the partitioning experiments and well-equilibrated mantle eclogite xenoliths, respectively. The outliers are light REEs and presumably can be attributed to poor analytical 
precisions or secondary alterations. Since the lattice strain parameters for REE partitioning in clinopyroxene and garnet were calibrated independently at magmatic conditions, the good agreement not only confirms their internal consistencies but also further justifies their extrapolation to subsolidus conditions and to more Fe-rich garnet (Fig. 2b).

\section{Additional Reference}

Klemme S., Blundy J. D. and Wood B. J. (2002) Experimental constraints on major and trace element partitioning during partial melting of eclogite. Geochimica et Cosmochimica Acta, $66,3109-3123$. 


\section{Supplementary Figures}

\section{Figure S1}
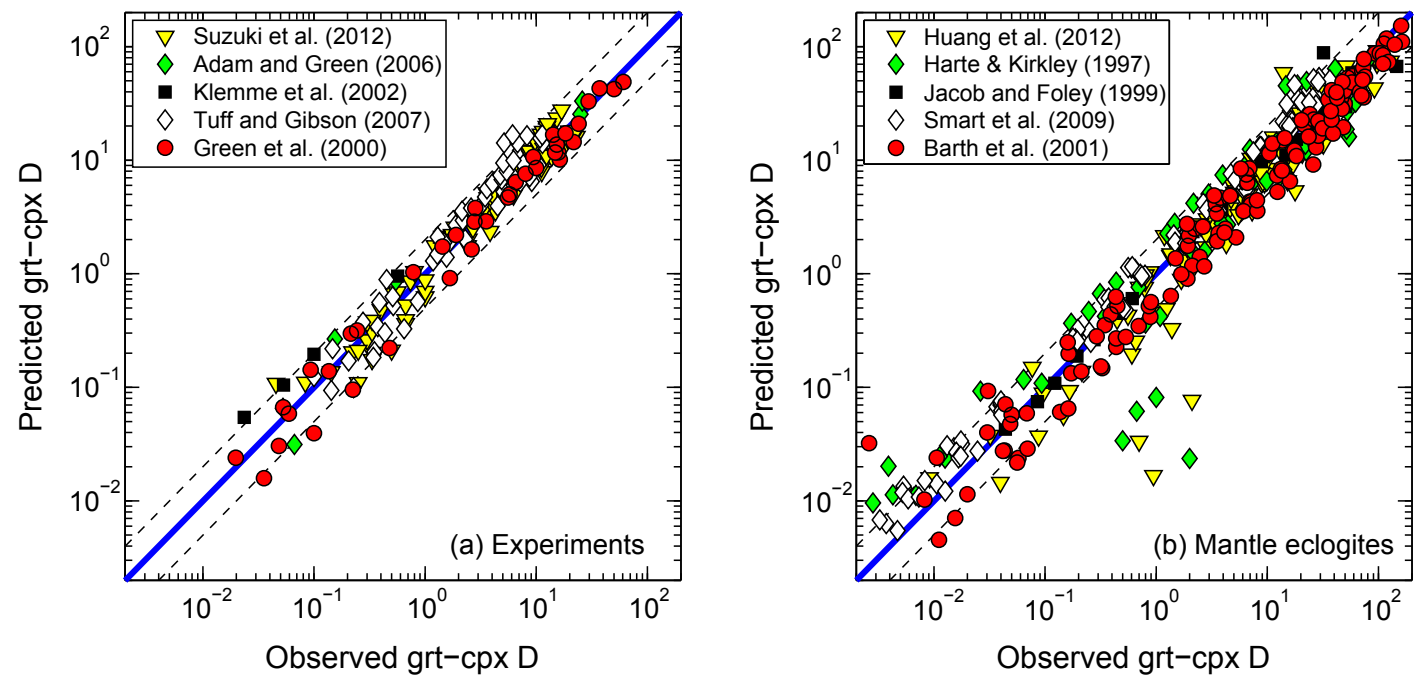

Figure S1 Comparisons of model-derived and measured REE and Y partition coefficients between garnet and clinopyroxene for partitioning experiments with coexisting garnet and clinopyroxene (a) and well-equilibrated mantle eclogite xenoliths (b) in the literature. Solid blue lines are 1:1 lines, and dashed lines are 1:2 and 2:1 lines. See text in the Supplementary Materials for details of these experiments and xenoliths. 


\section{Figure S2}
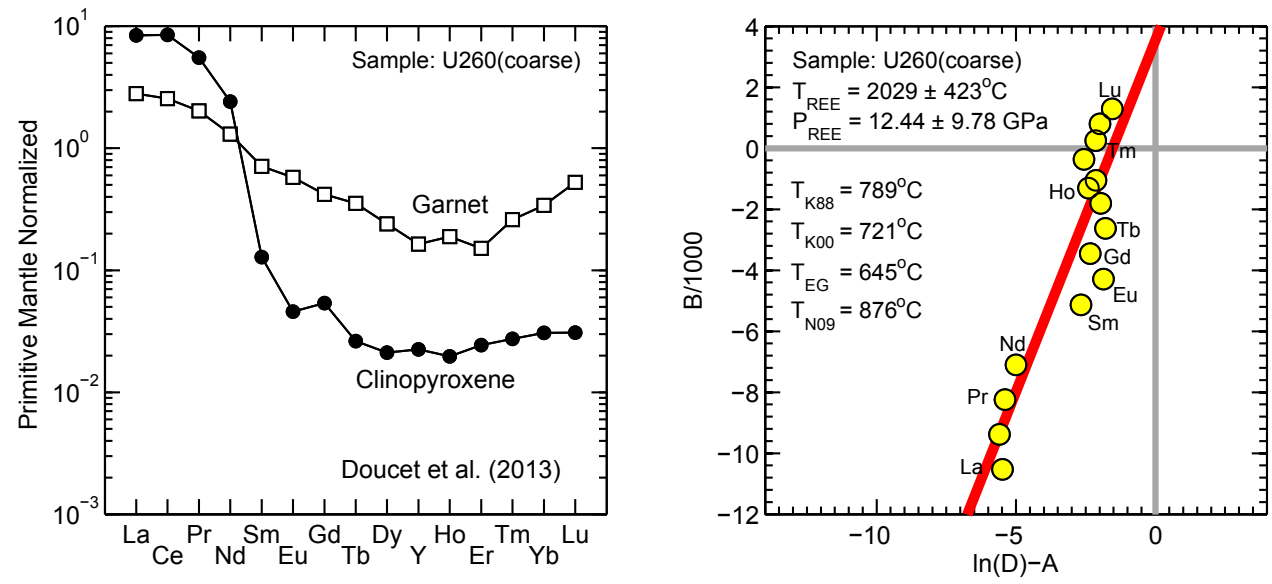

Figure S2 Inversion of the temperature and pressure from REE abundances in garnet and clinopyroxene for an eclogite with REEs in disequilibrium. The mineral compositions of the eclogite are from Doucet et al. (2013). (a) shows the primitive mantle normalized REE abundances in garnet and clinopyroxene, and (b) shows the inversion of the temperature and pressure through linear least squares regression analysis. 
Figure S3

Figure S3(1)

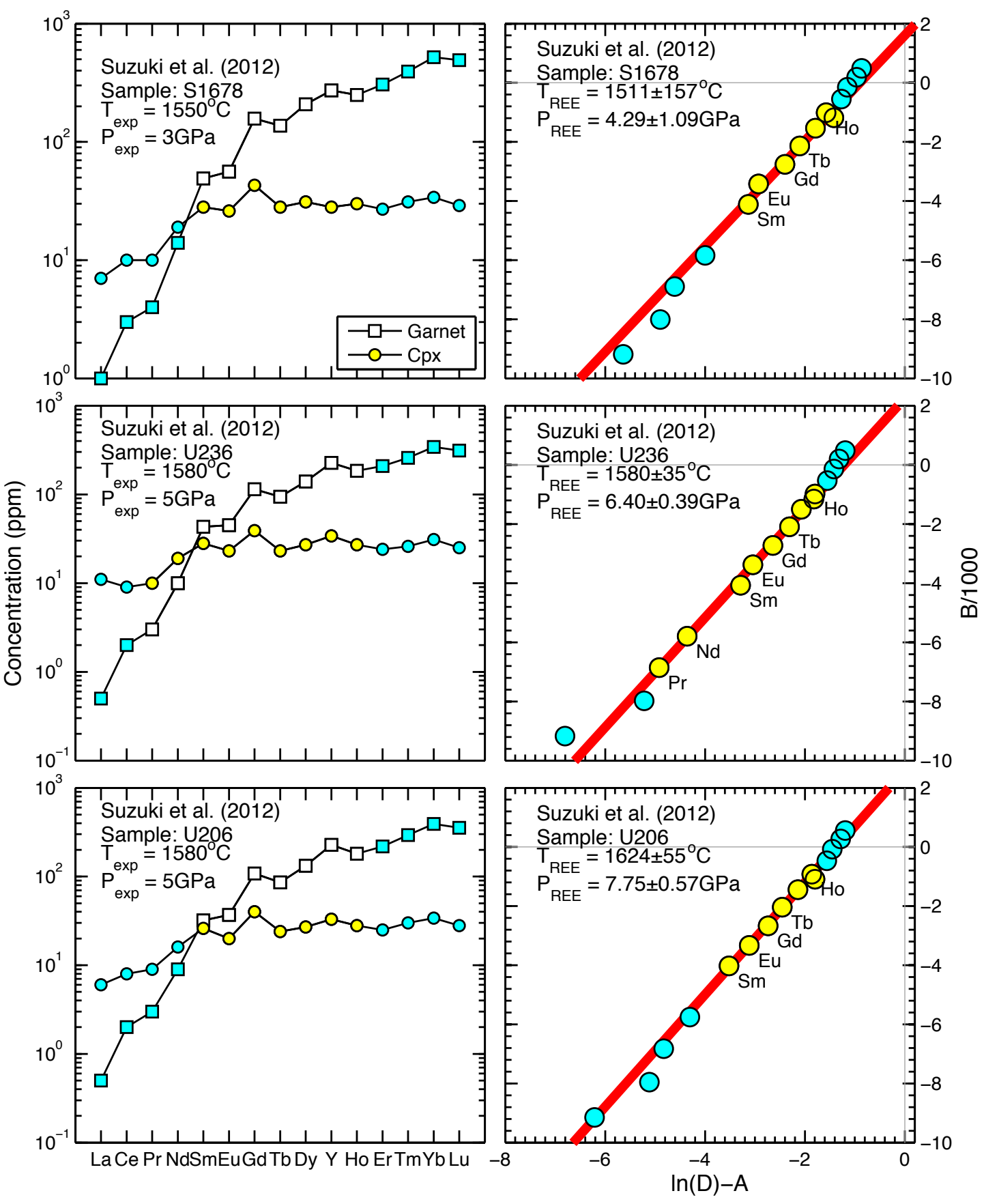


Figure S3(2)

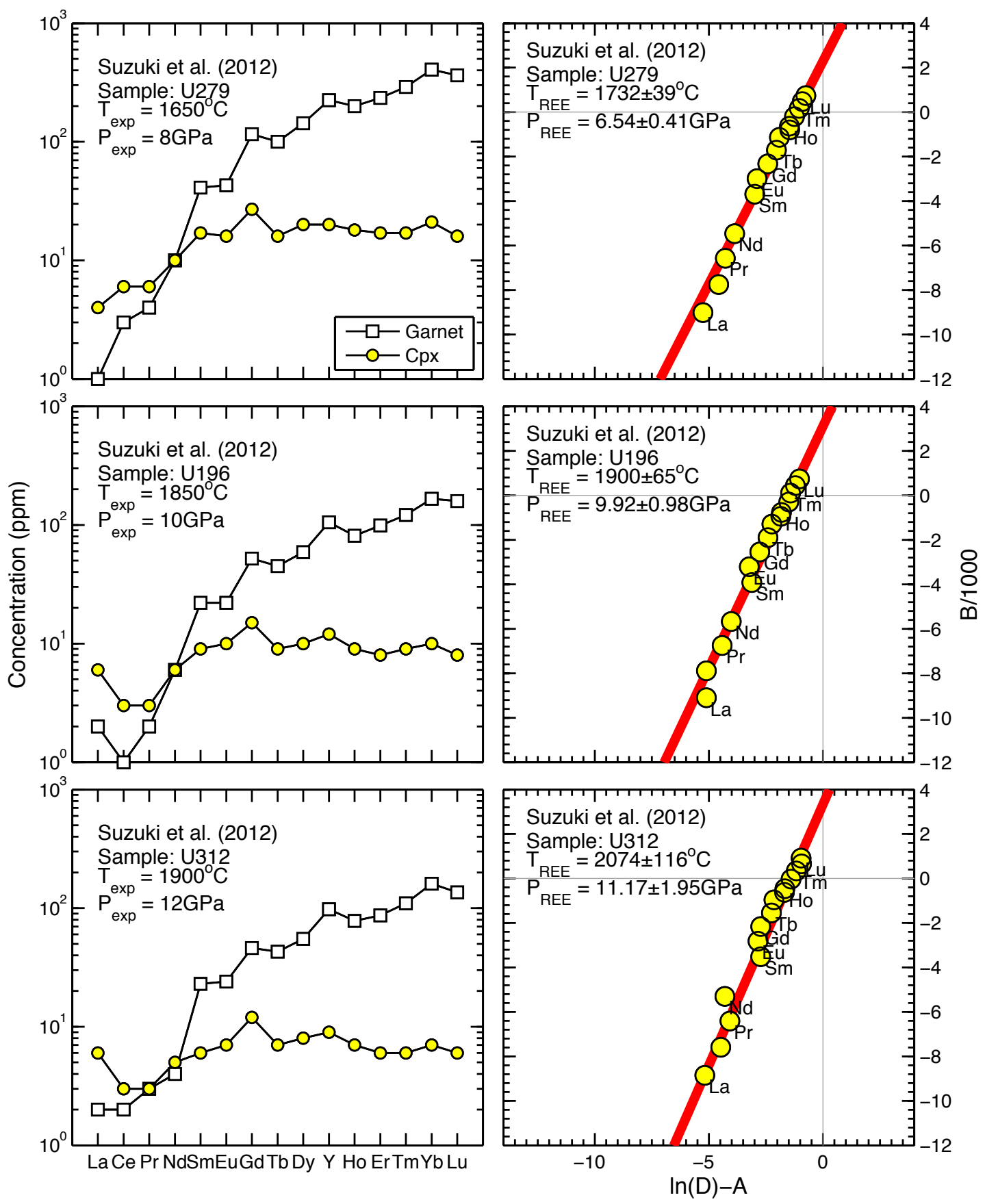


Figure S3(3)

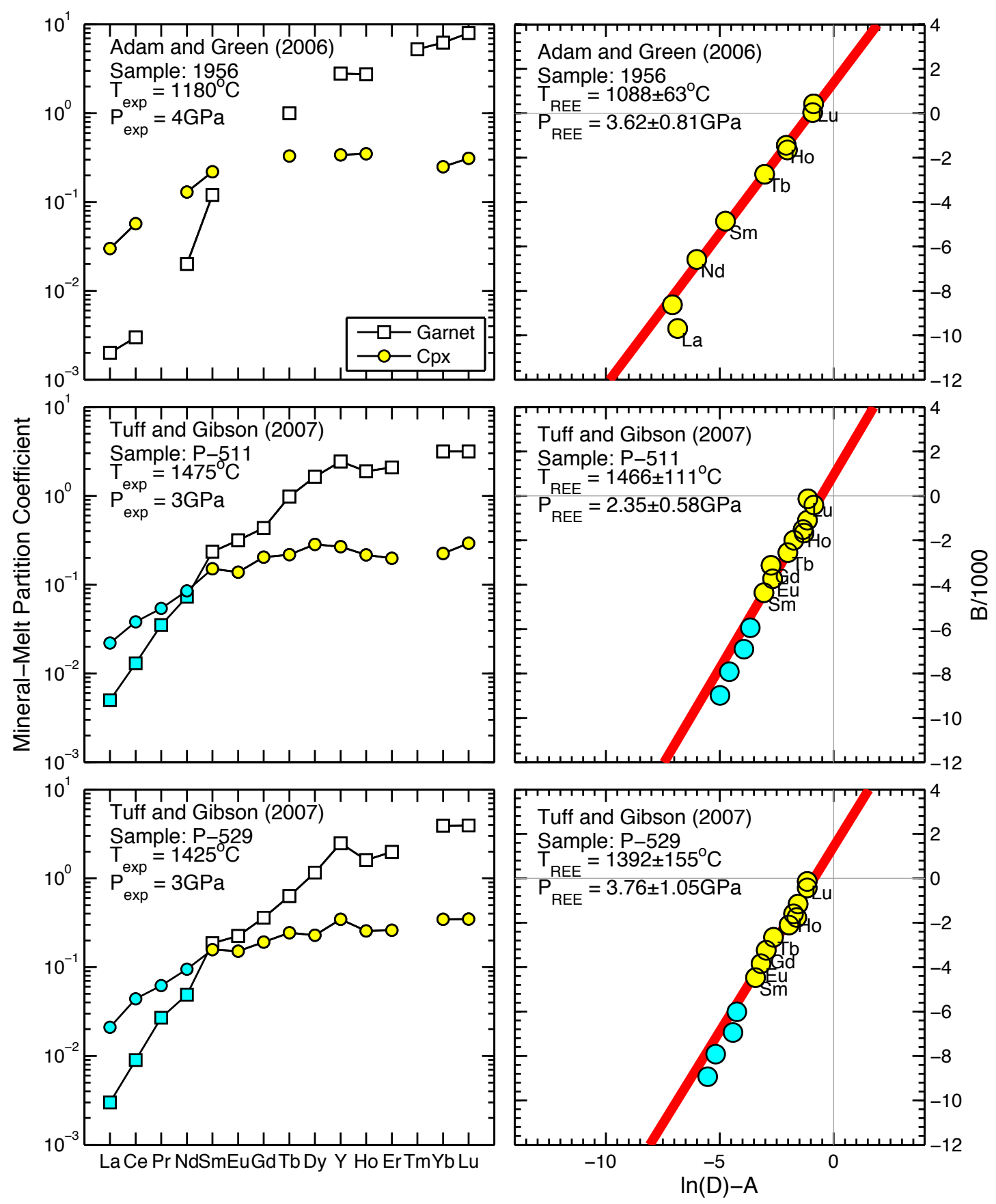


Figure S3(4)

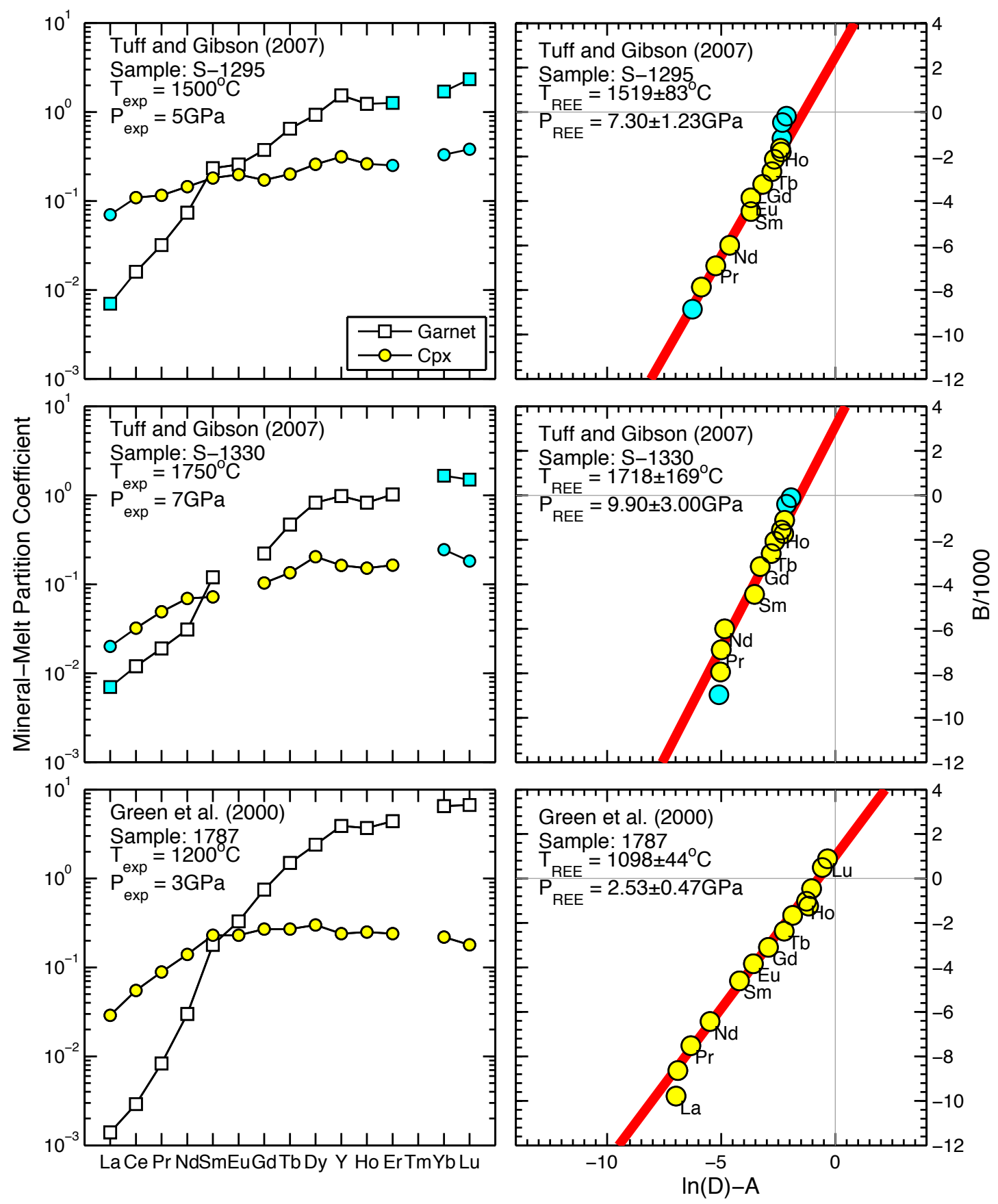


Figure S3(5)
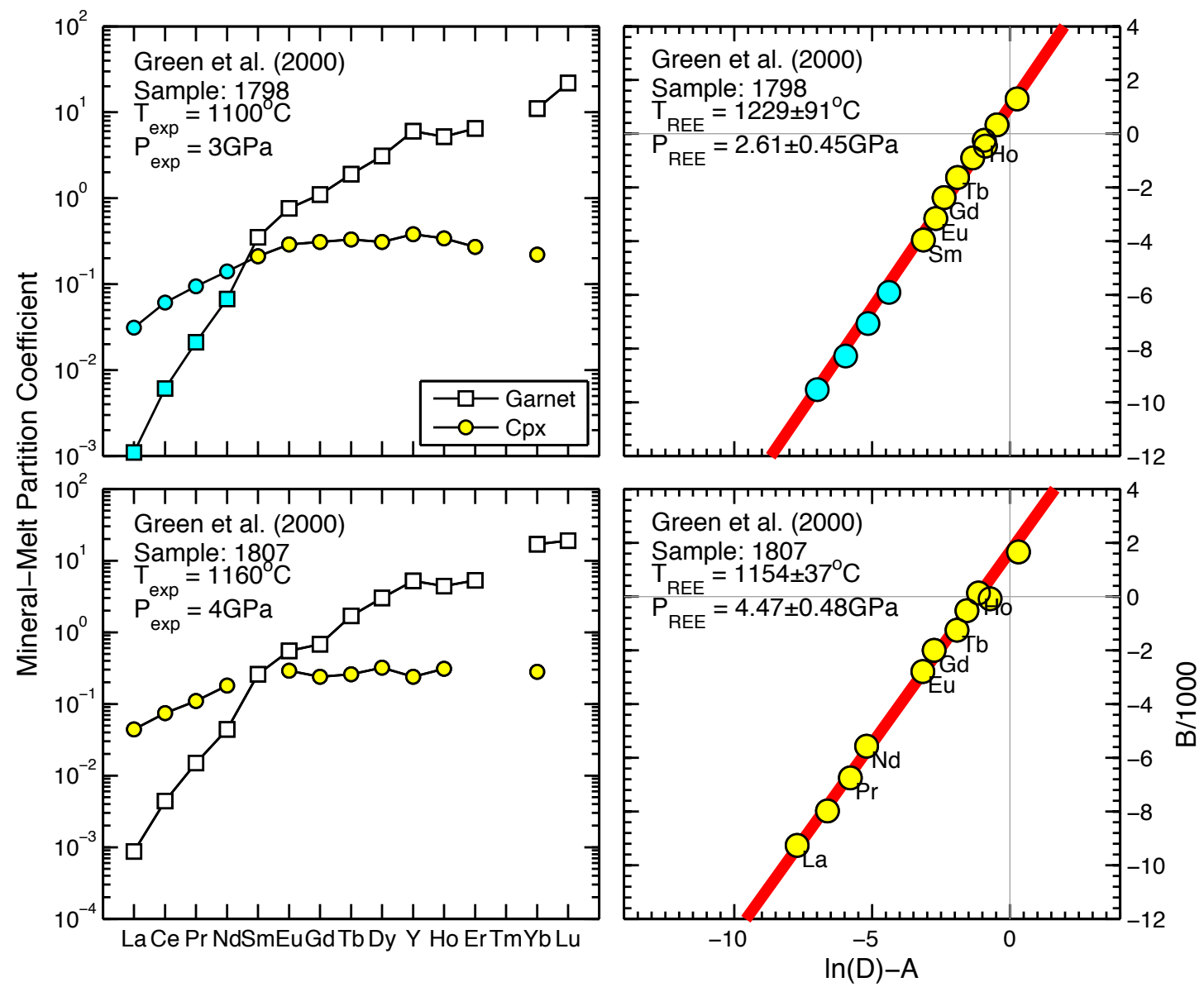

Figure S3 Inversions of the temperatures and pressures from REE abundances in garnet and clinopyroxene for the individual partitioning experiments from the literature. 
Figure S4

Figure S4(1)

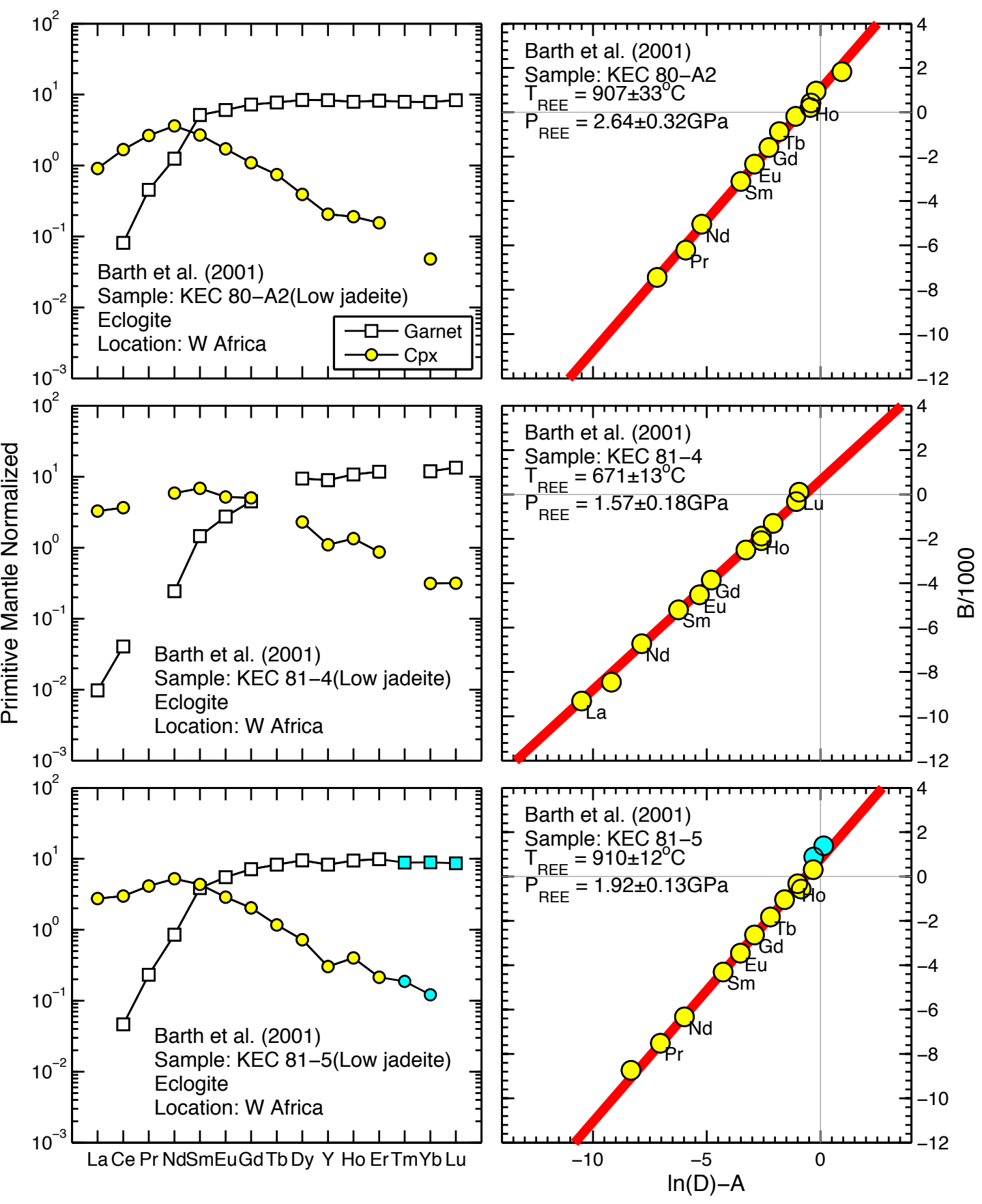


Figure S4(2)

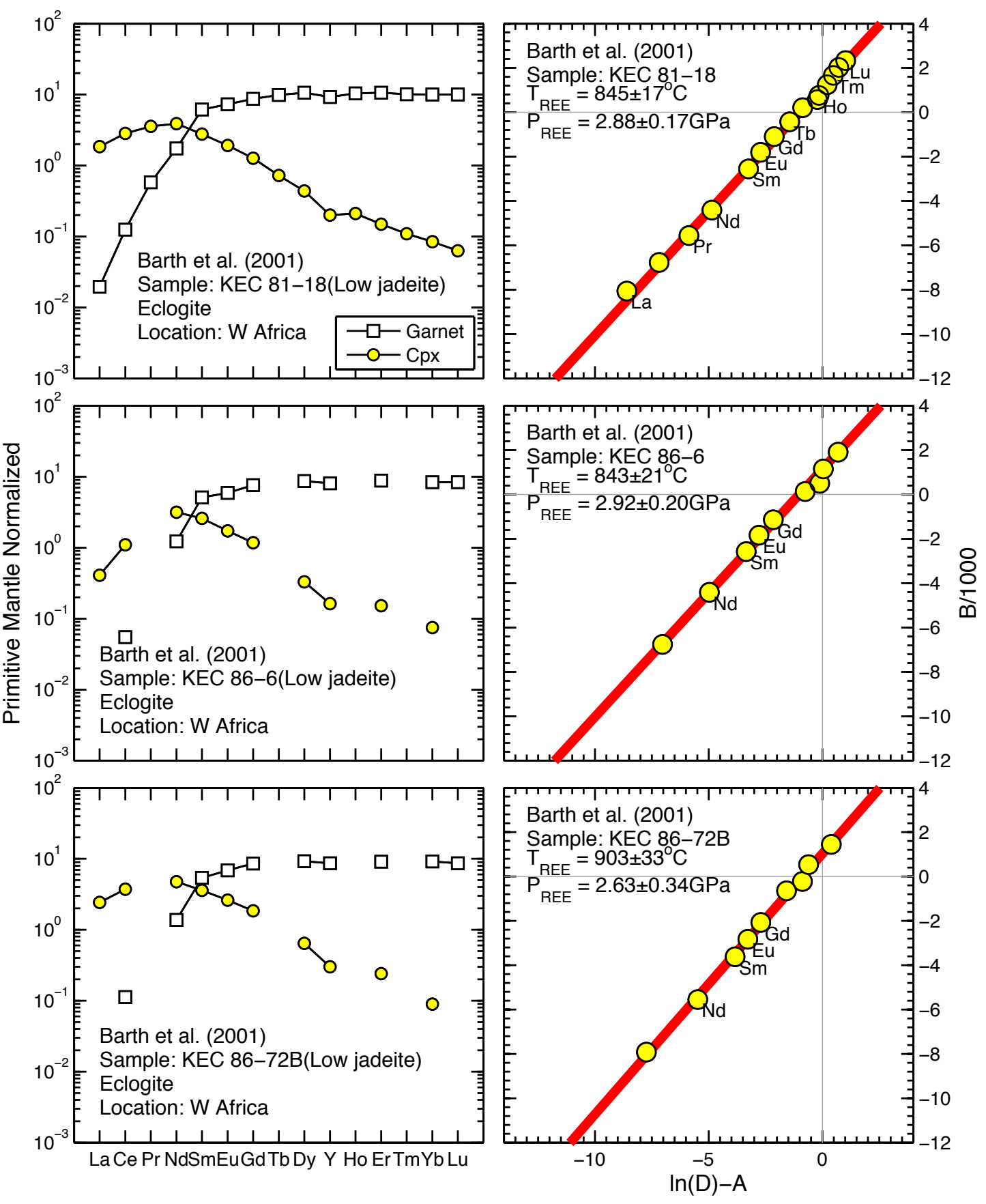


Figure S4(3)

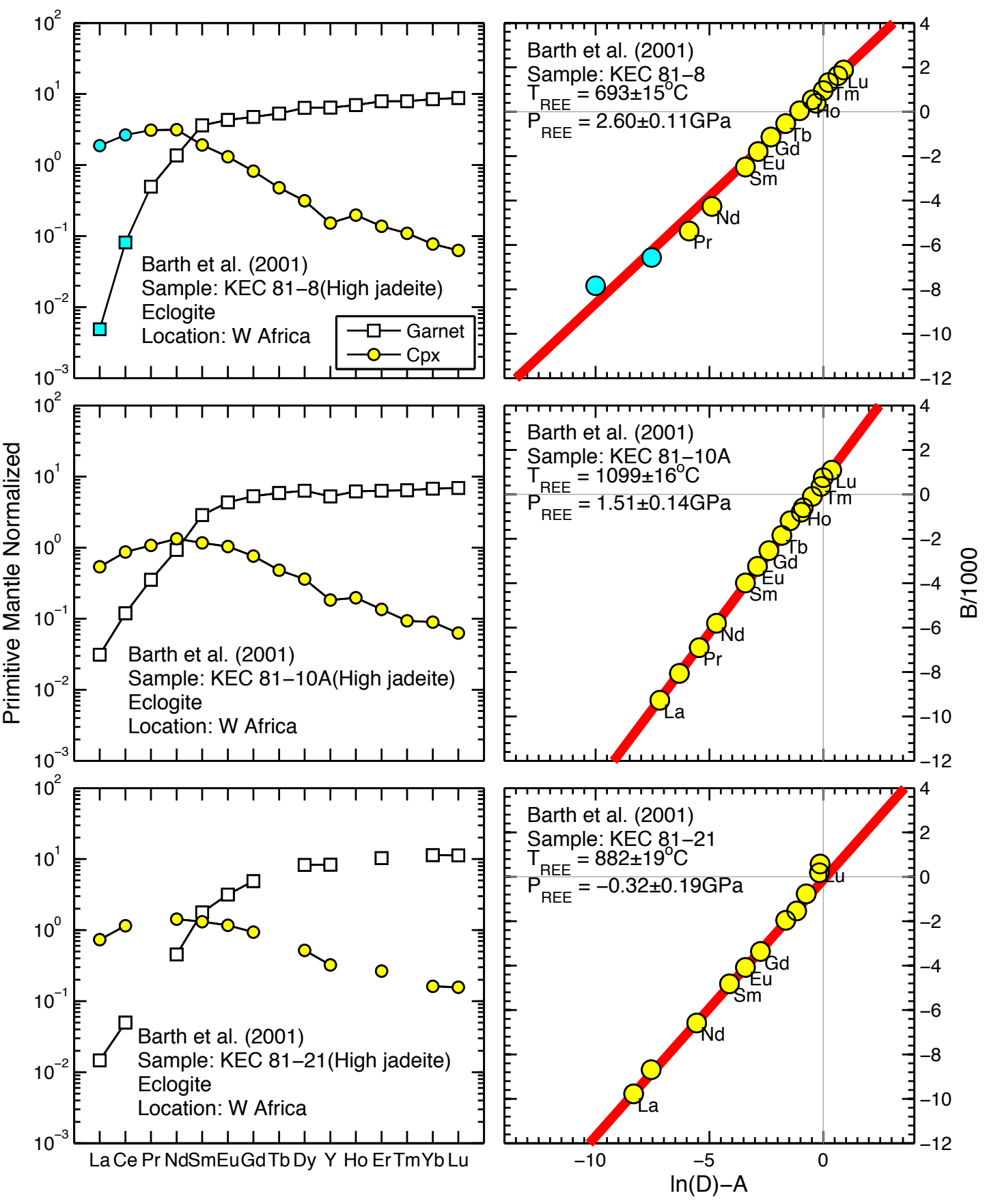


Figure S4(4)

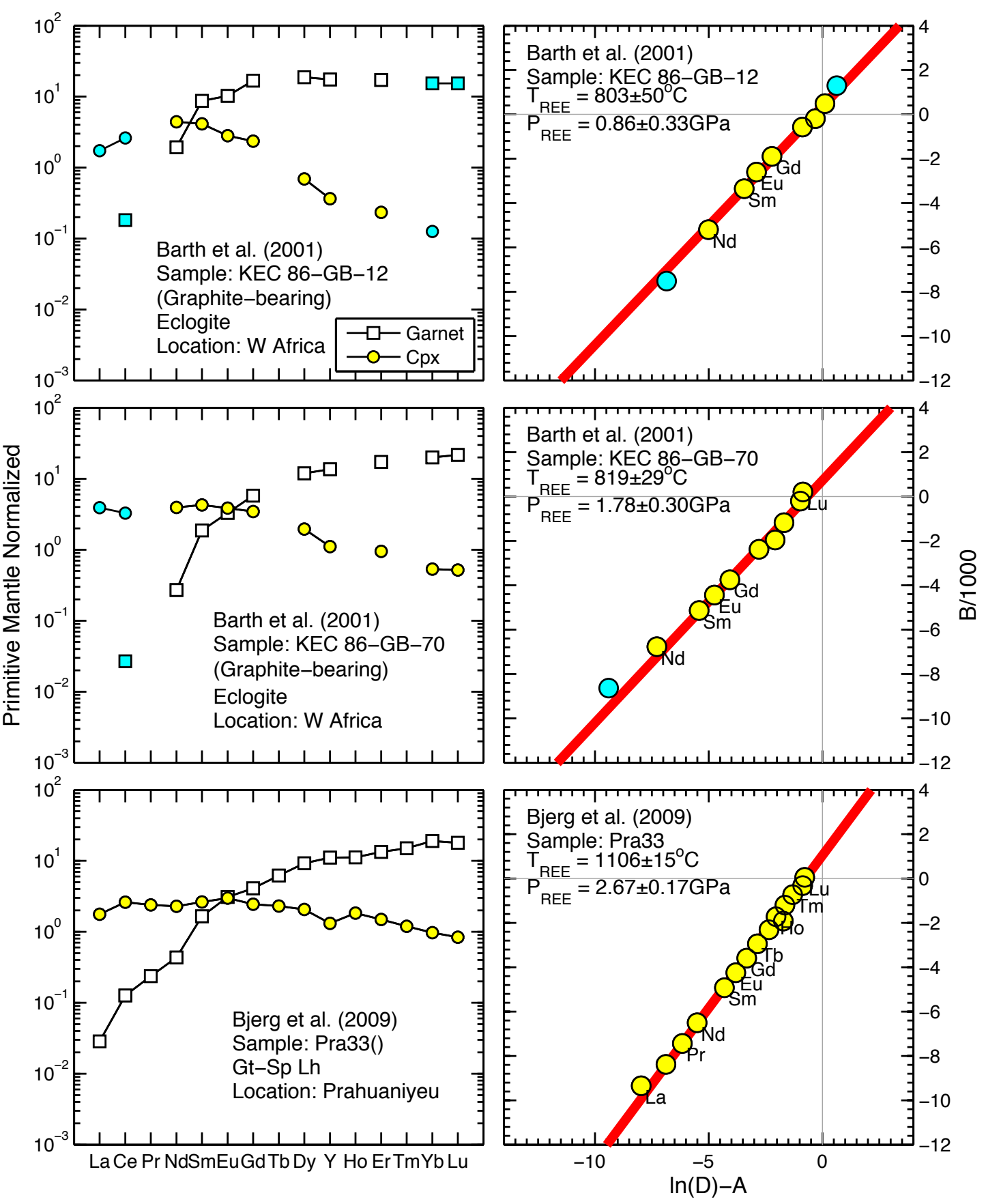


Figure S4(5)

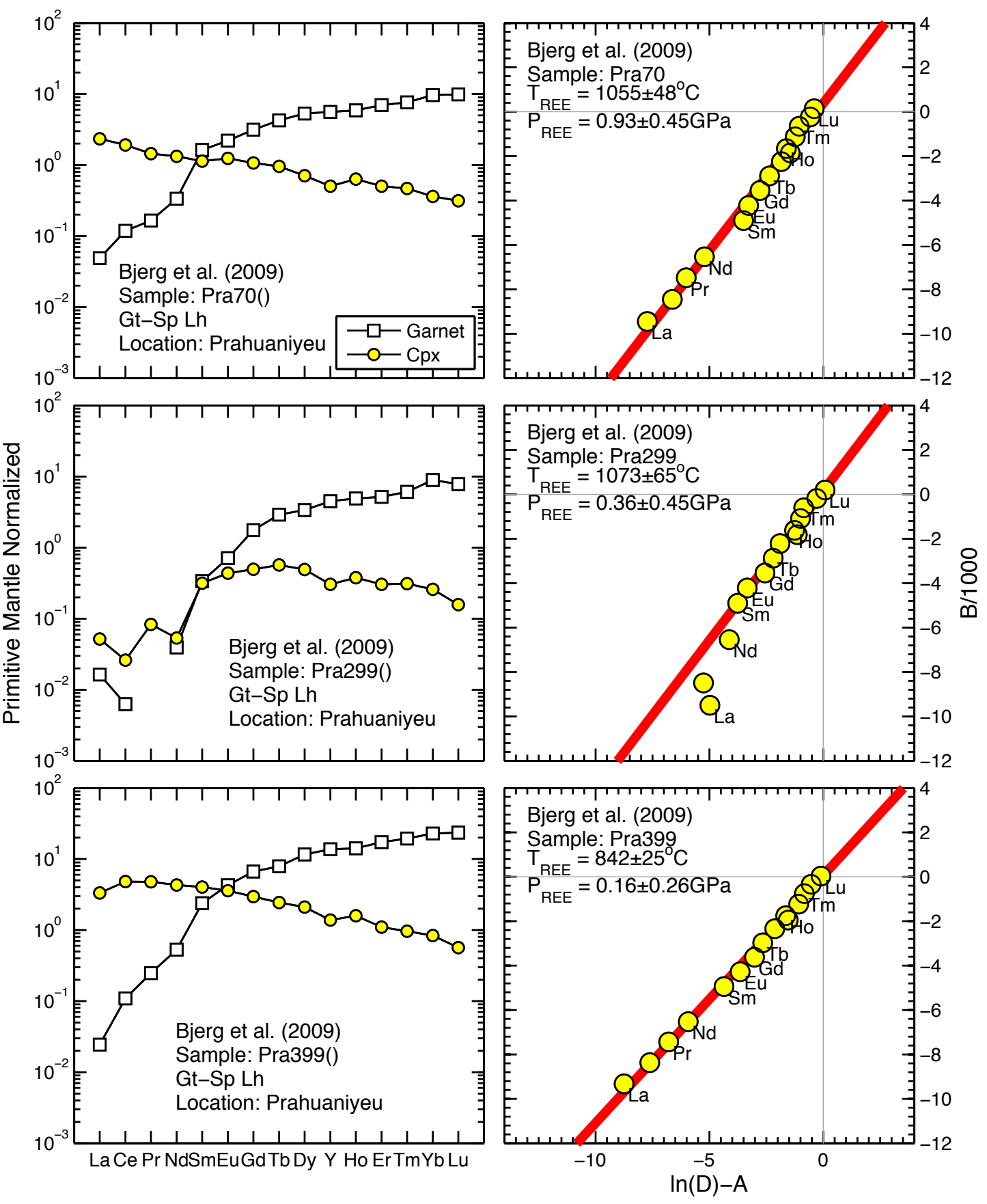


Figure S4(6)

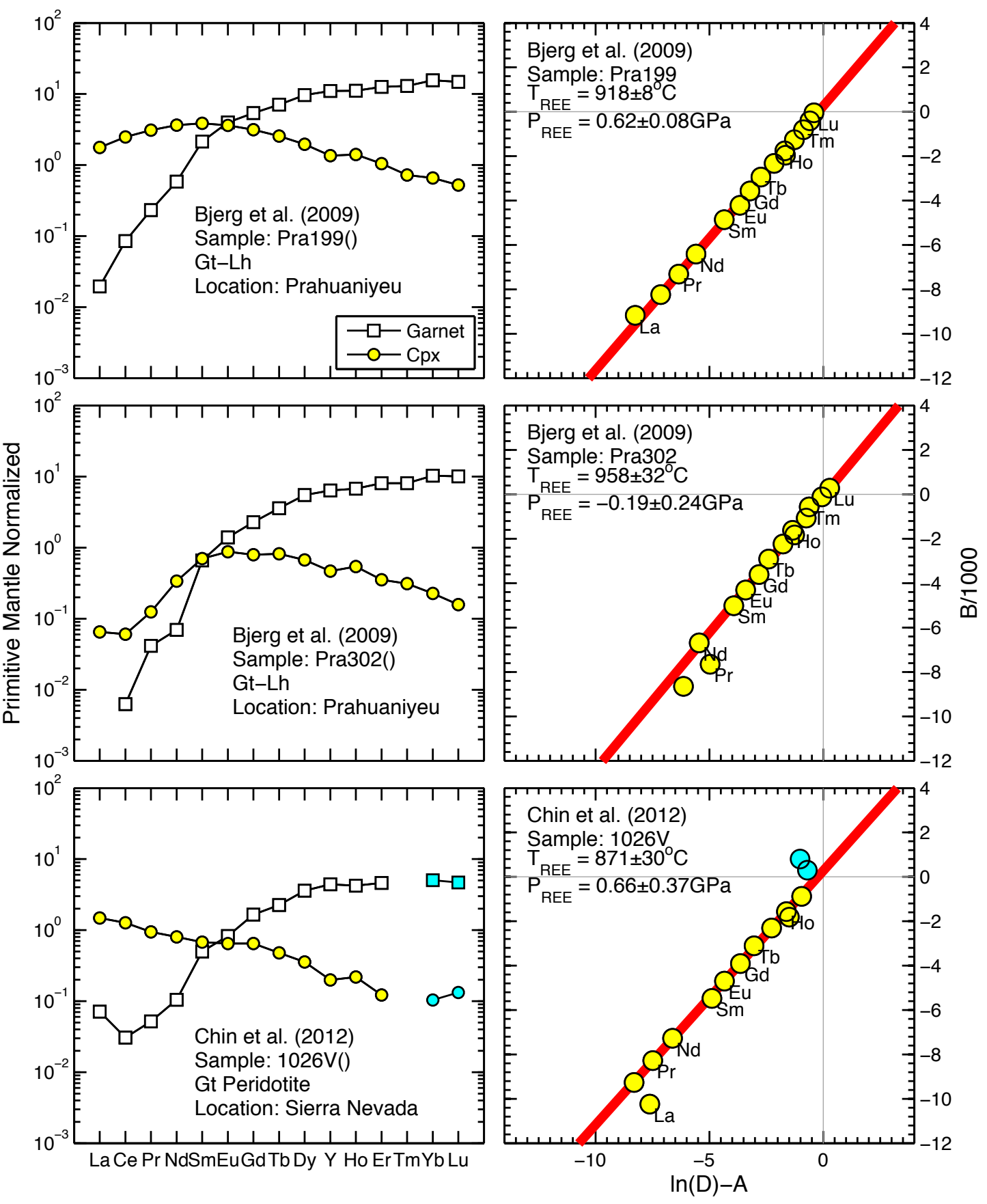


Figure S4(7)

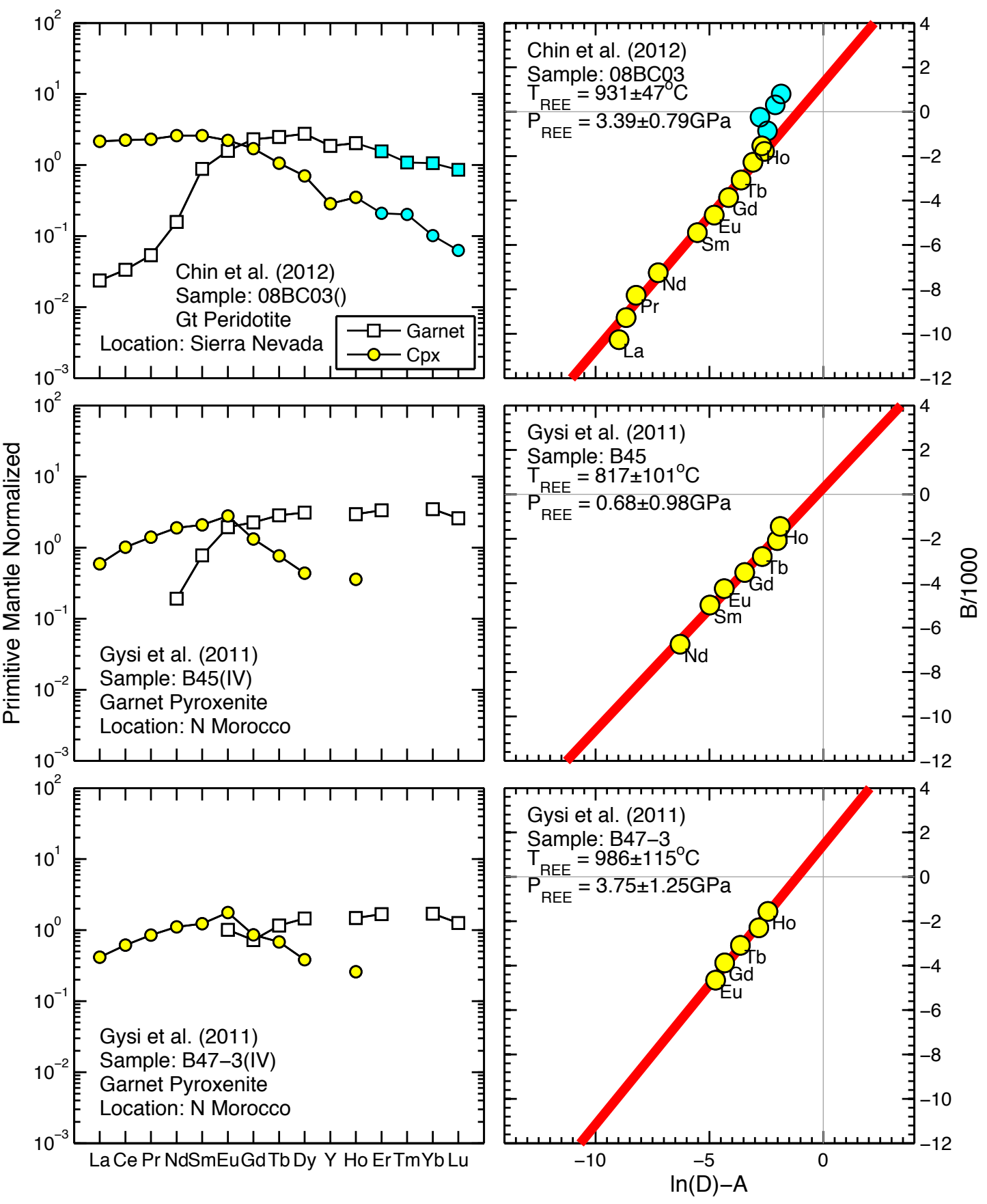


Figure S4(8)

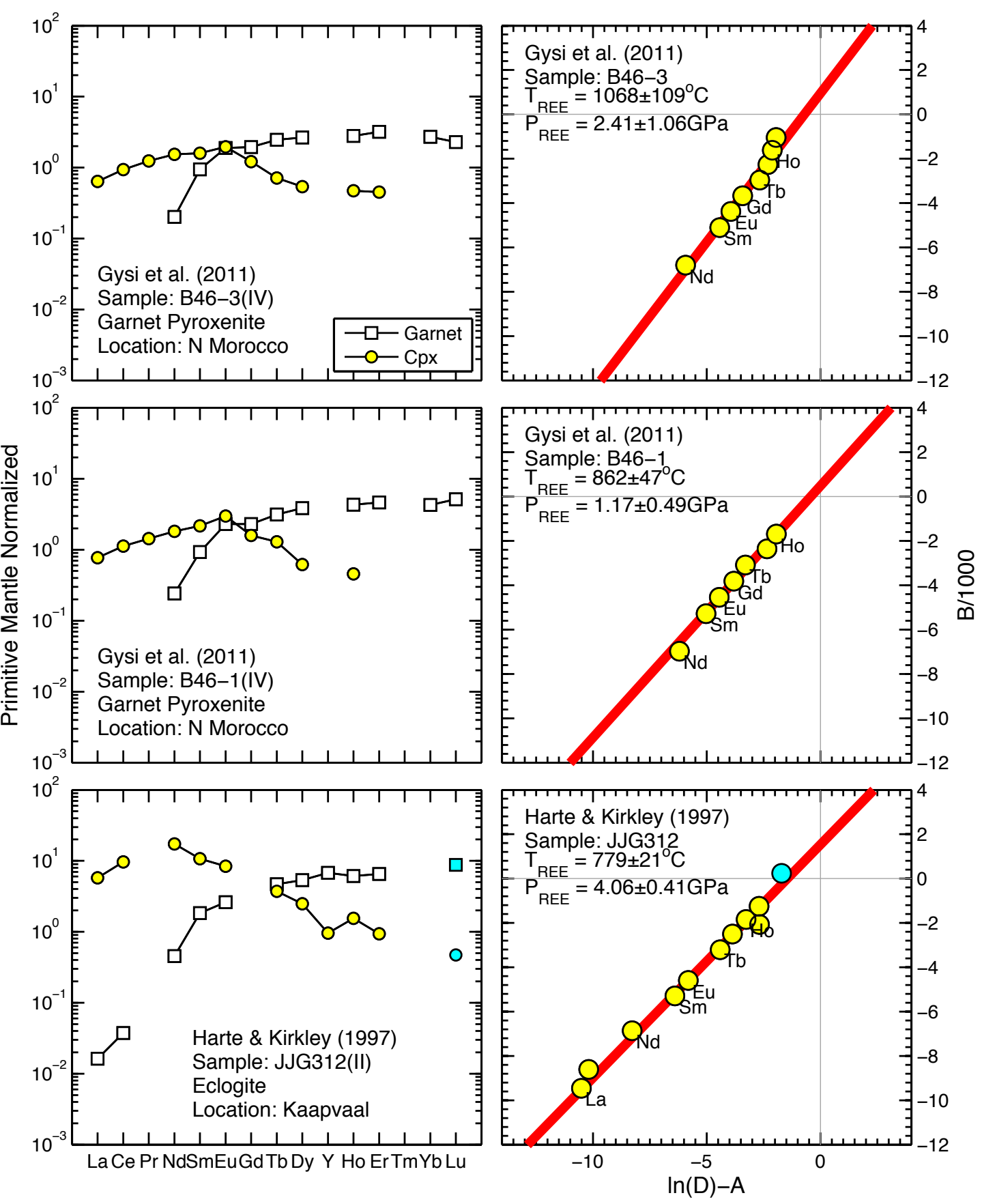


Figure S4(9)

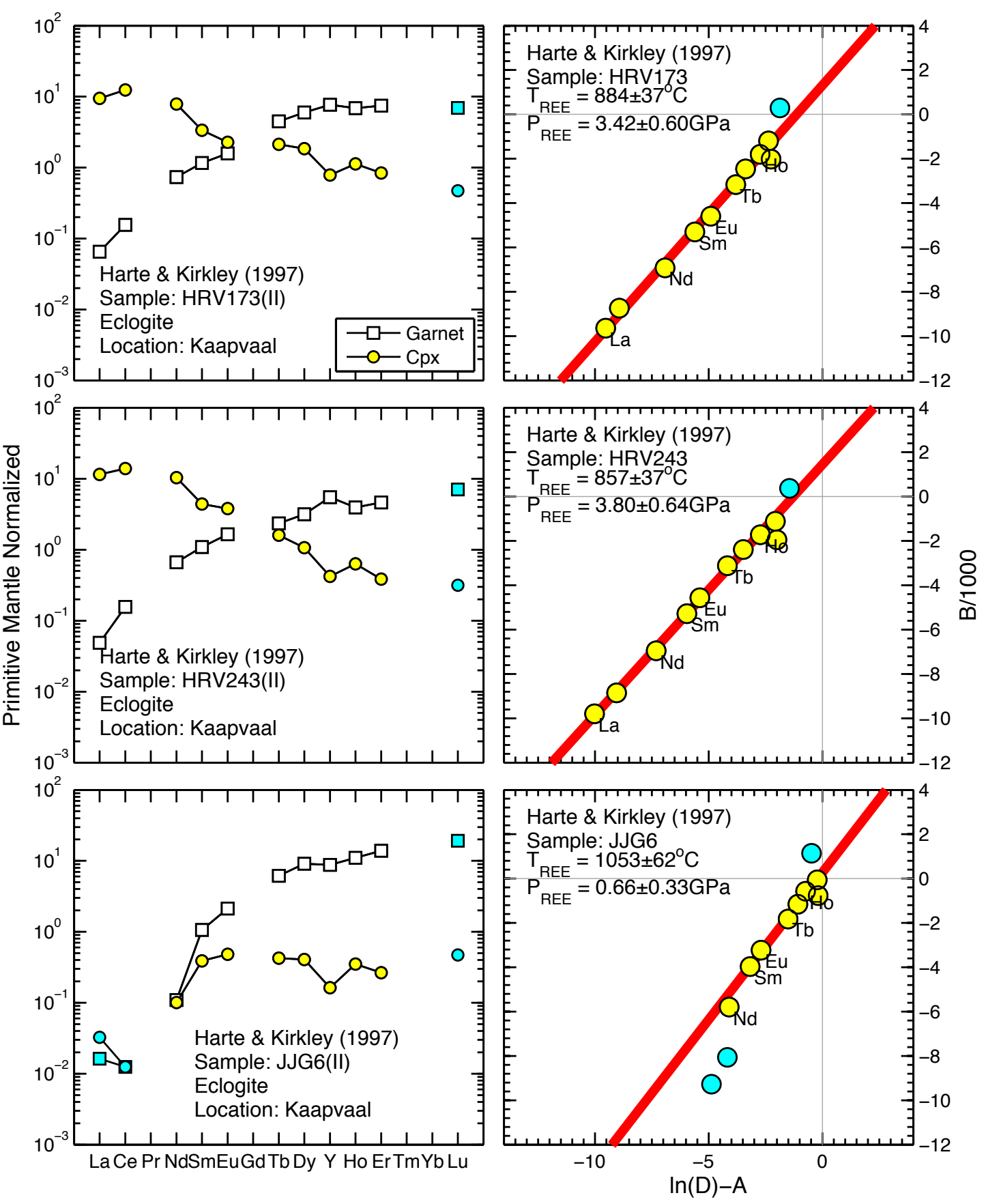


Figure S4(10)

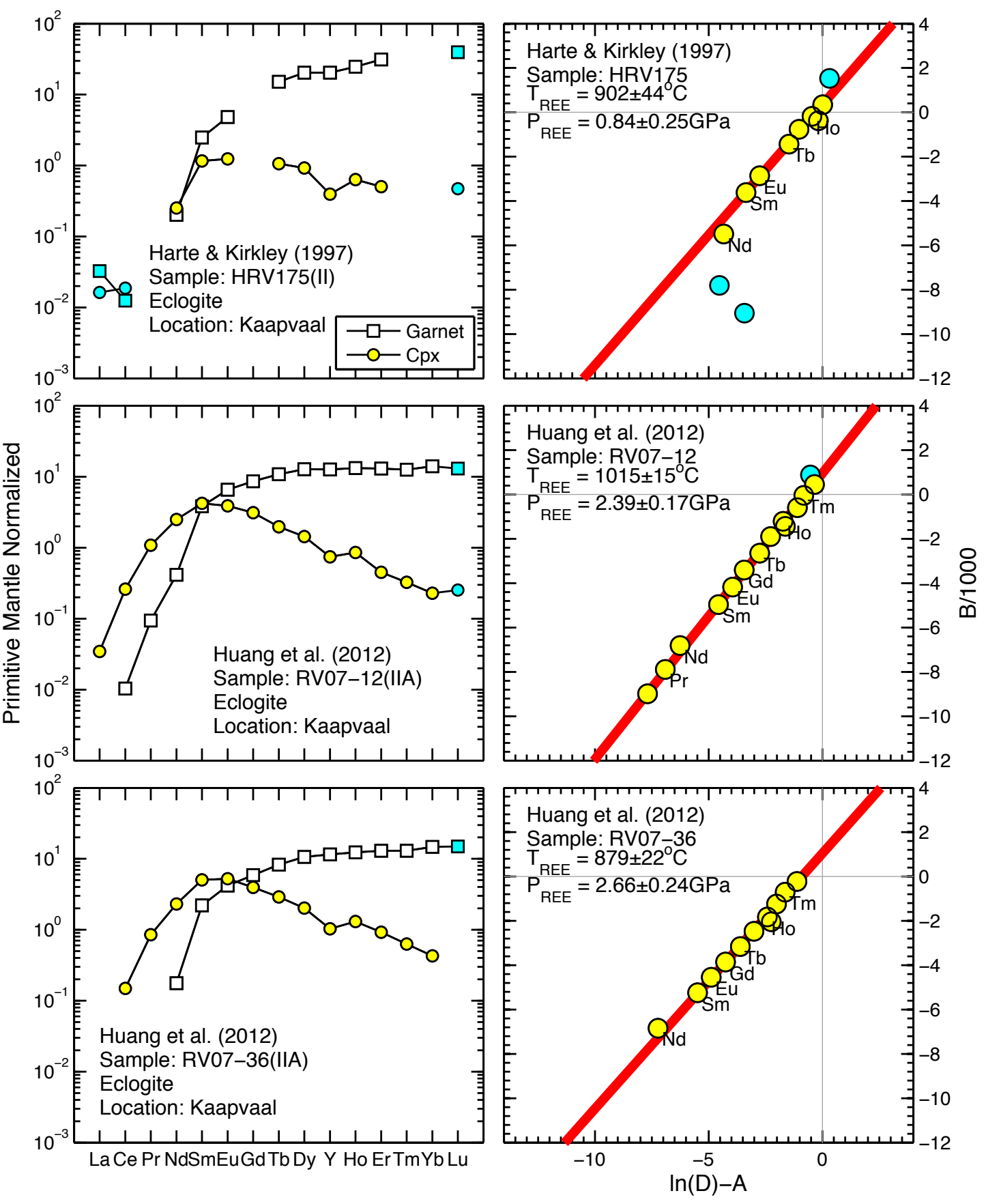


Figure S4(11)

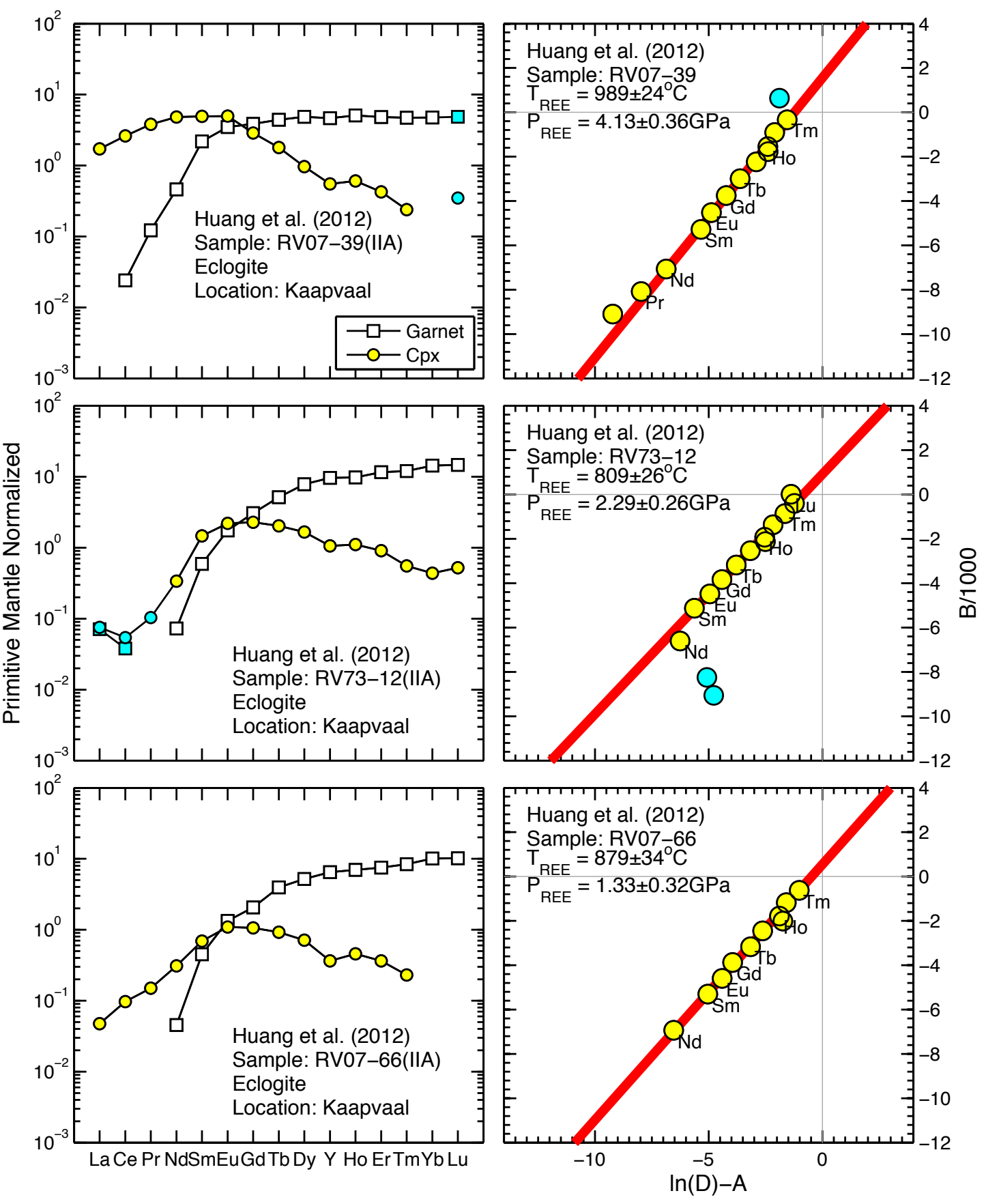


Figure S4(12)

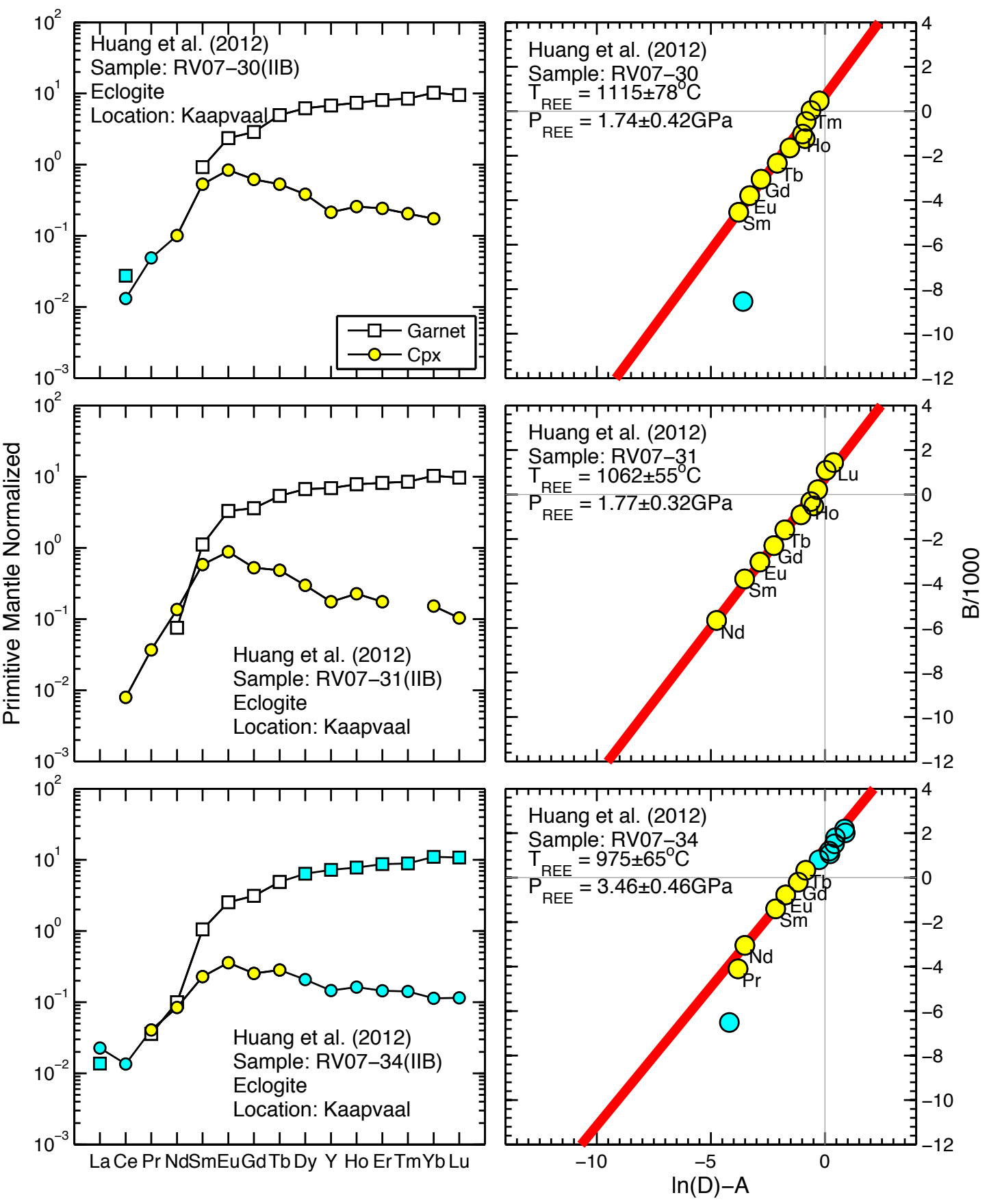


Figure S4(13)

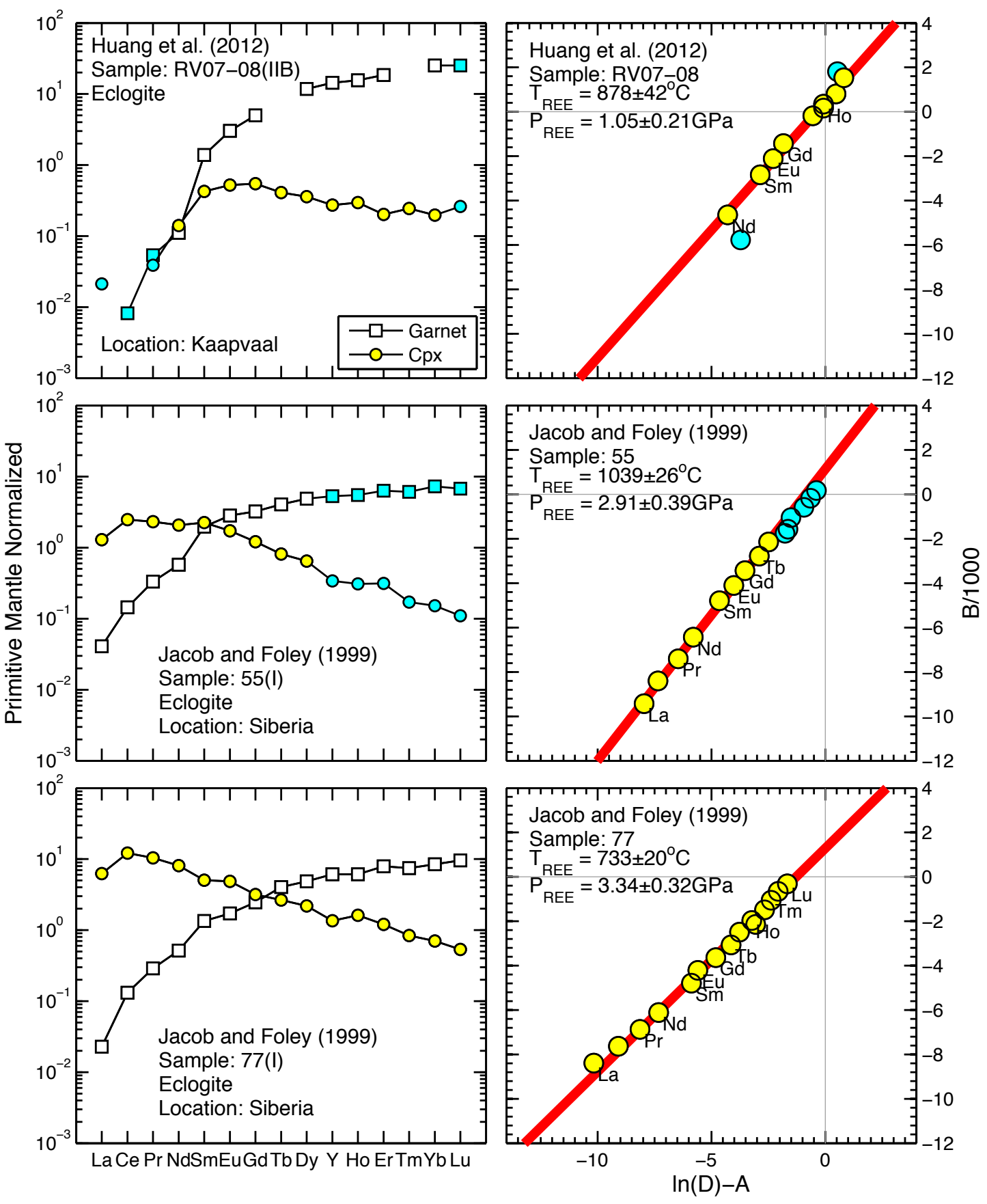


Figure S4(14)

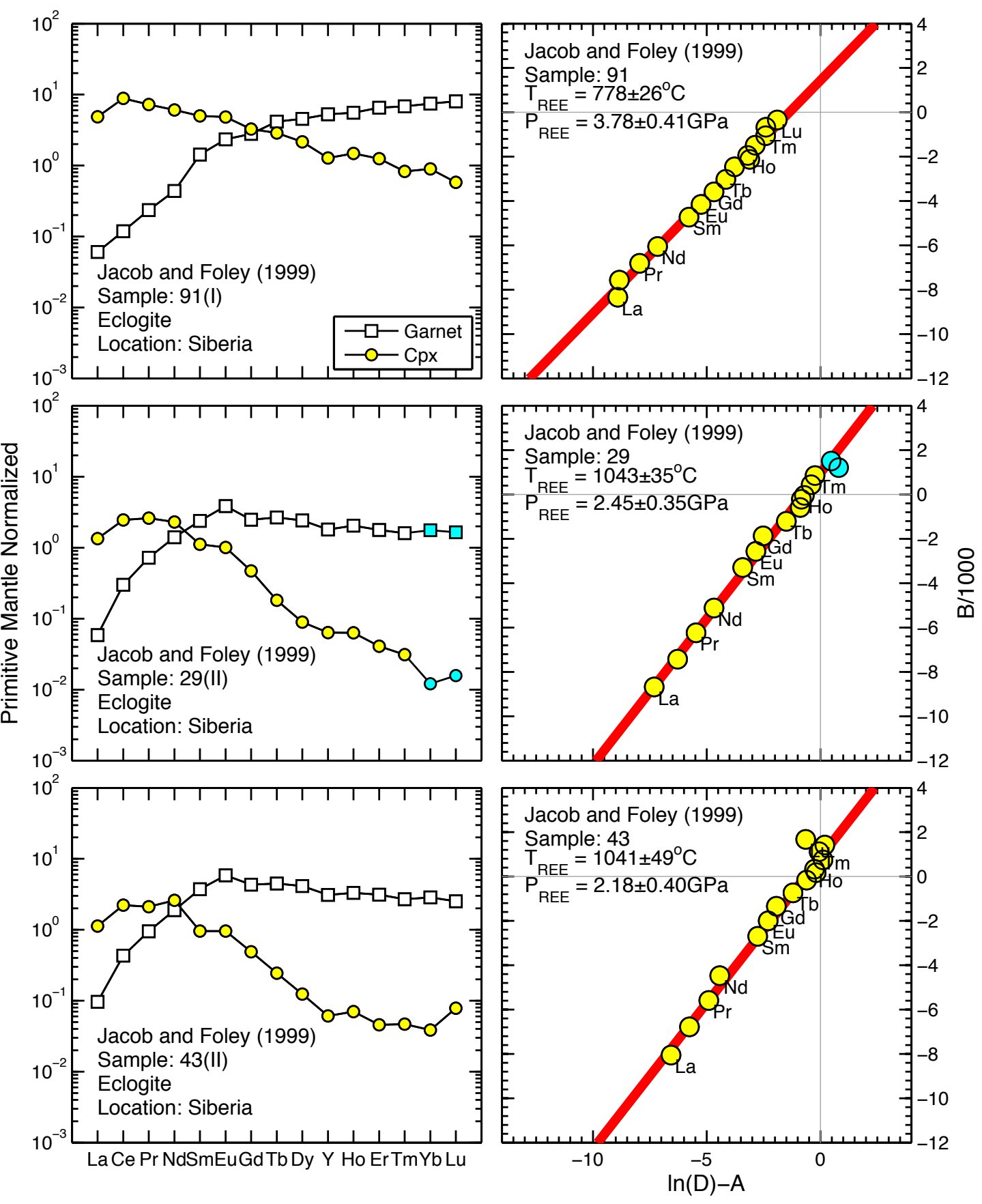


Figure S4(15)

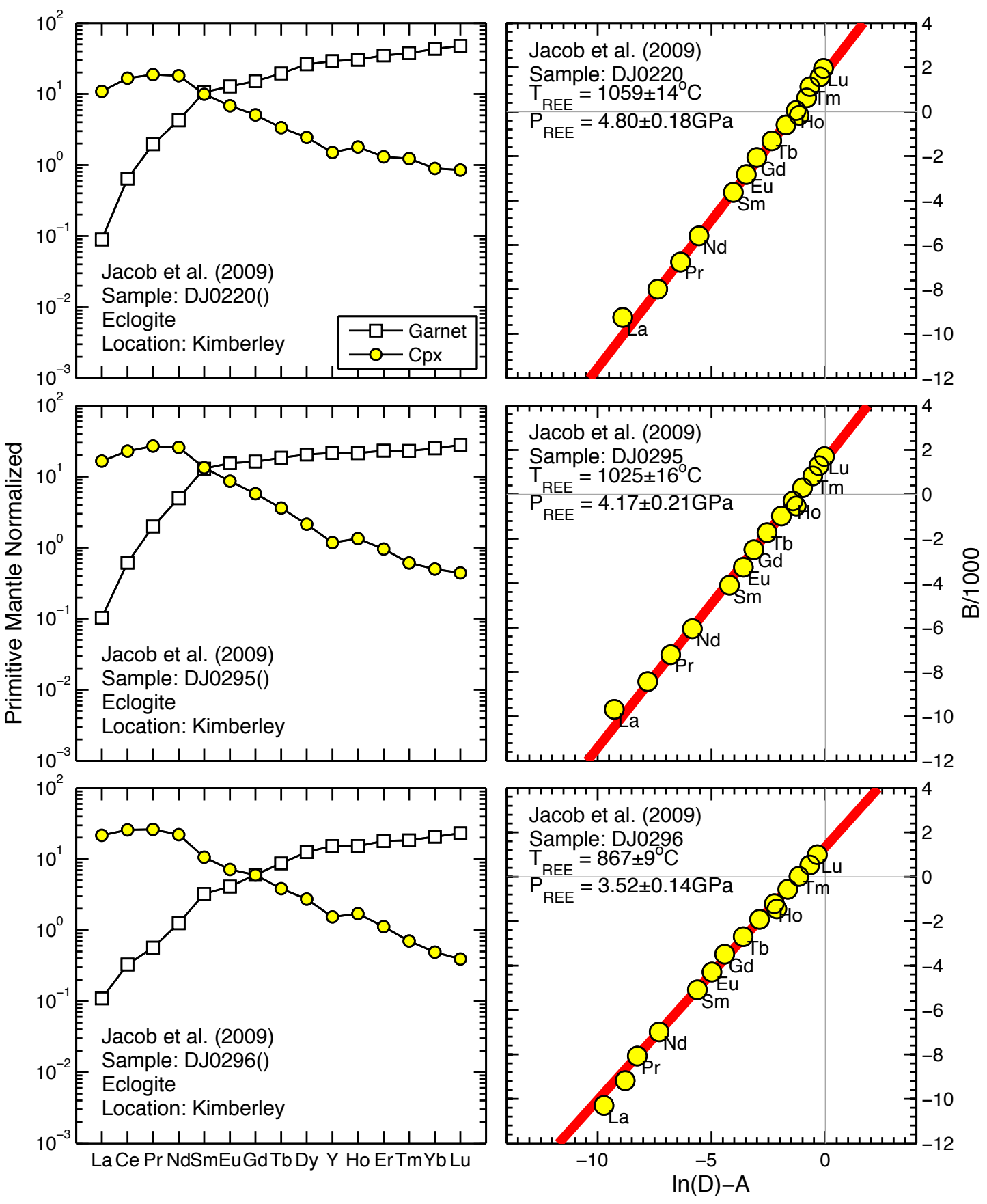


Figure S4(16)

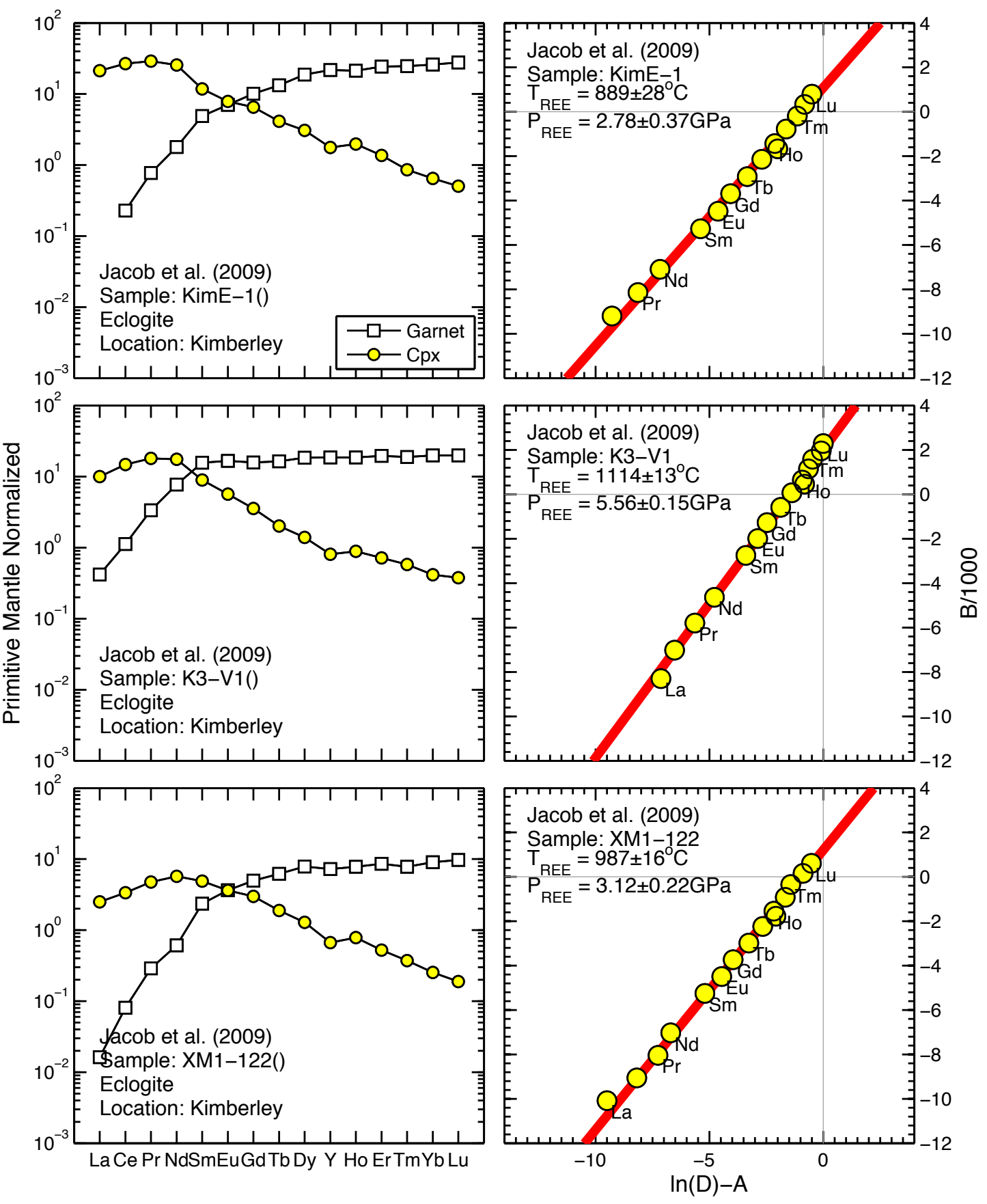


Figure S4(17)

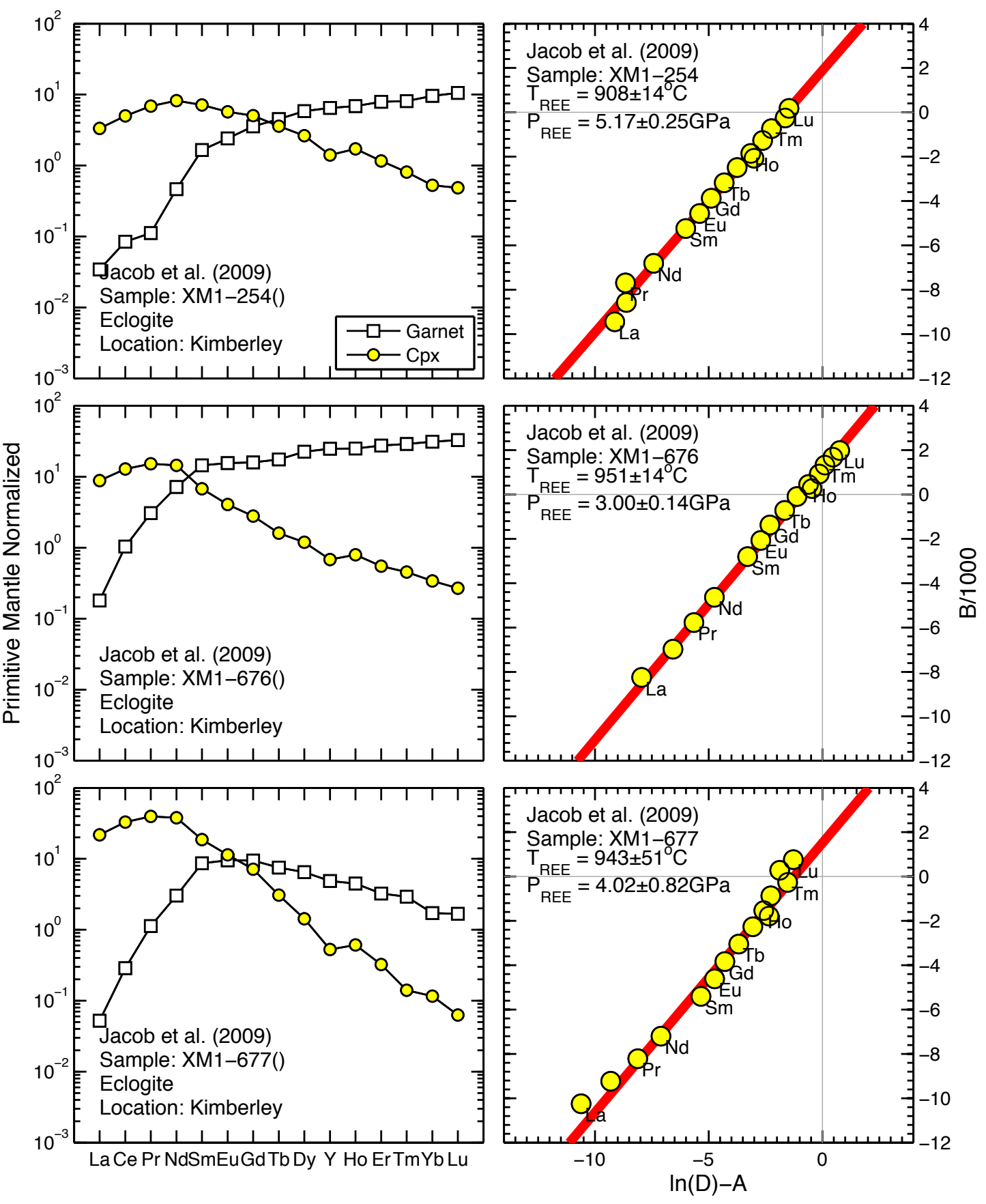


Figure S4(18)

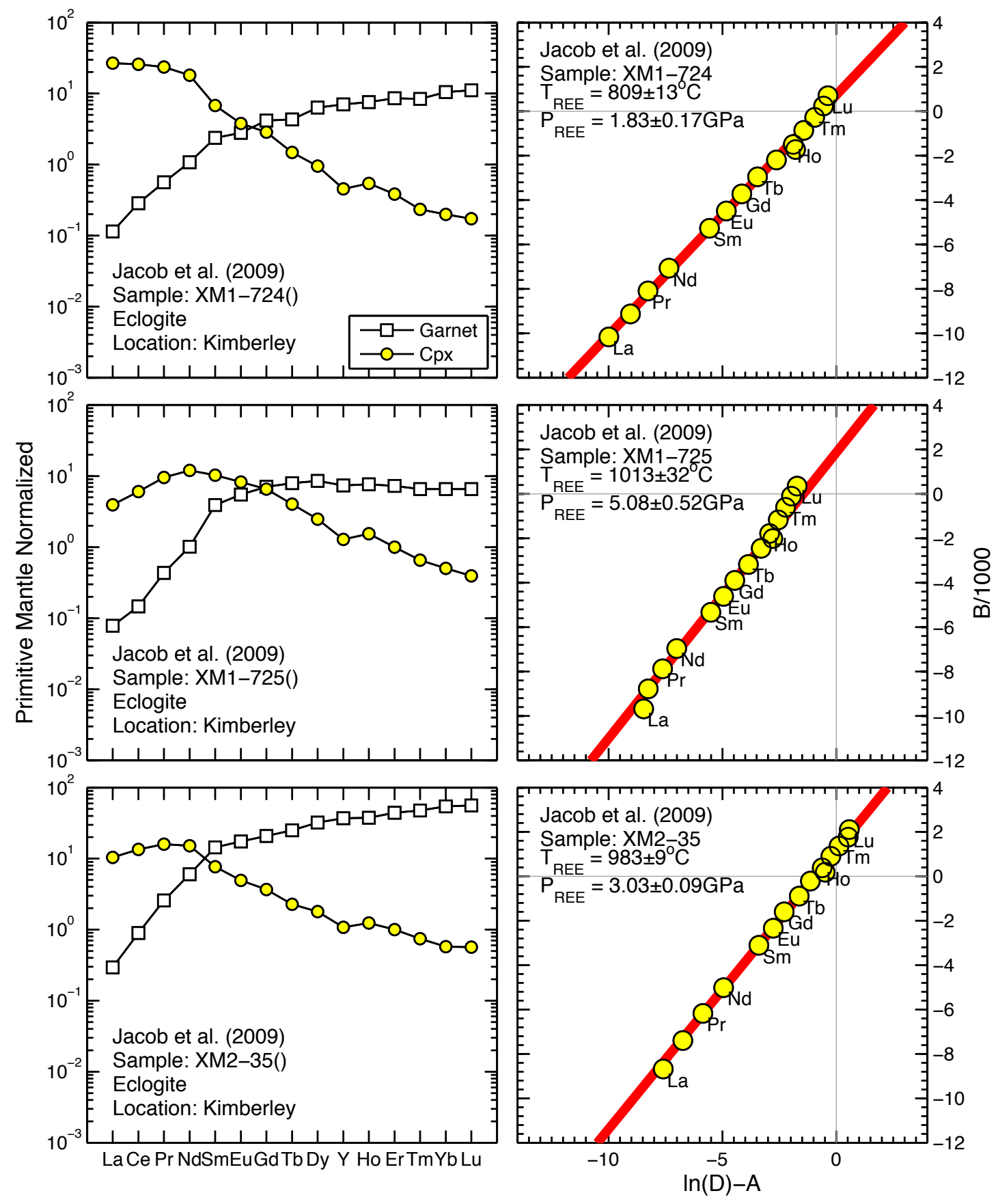


Figure S4(19)

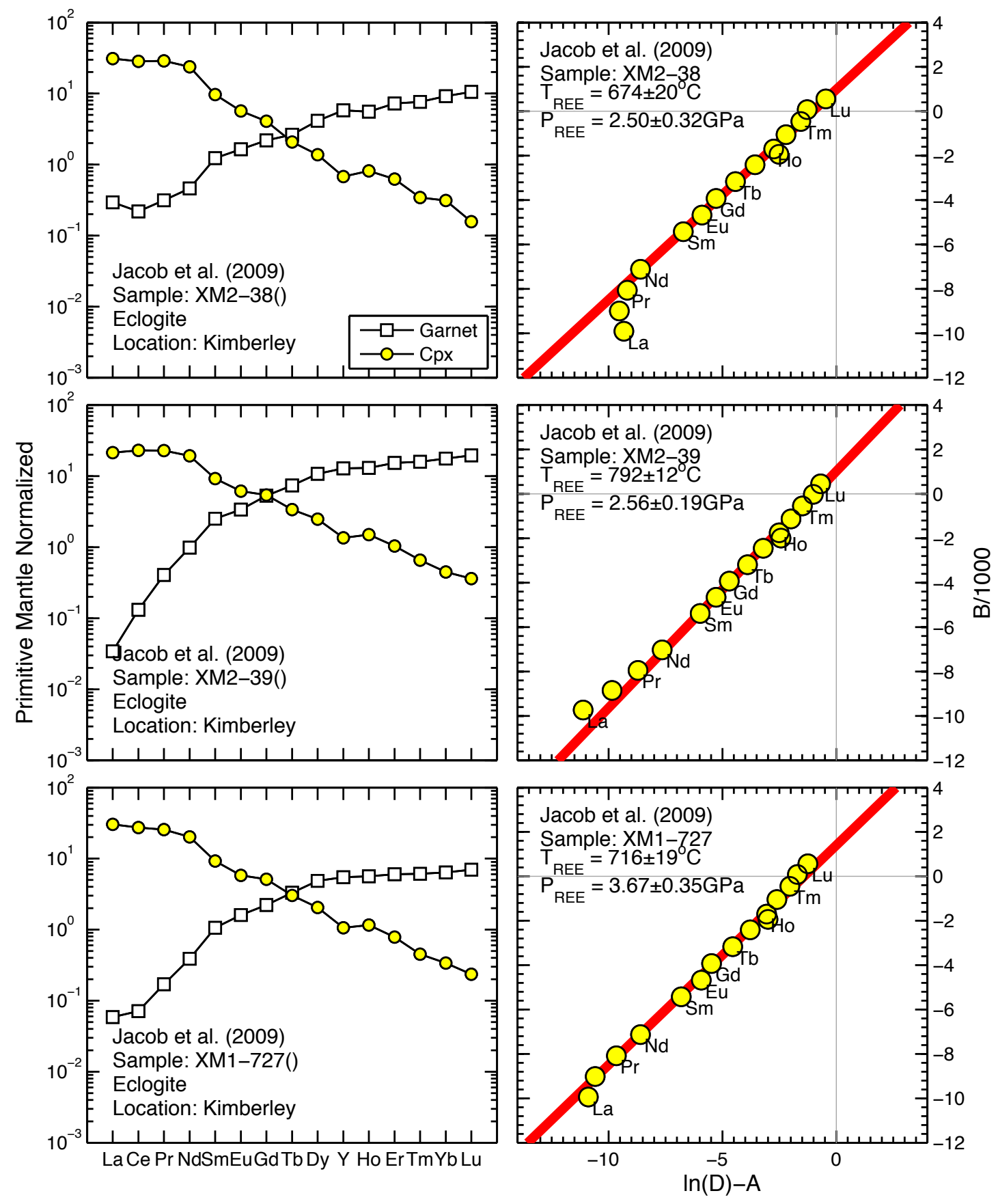


Figure S4(20)

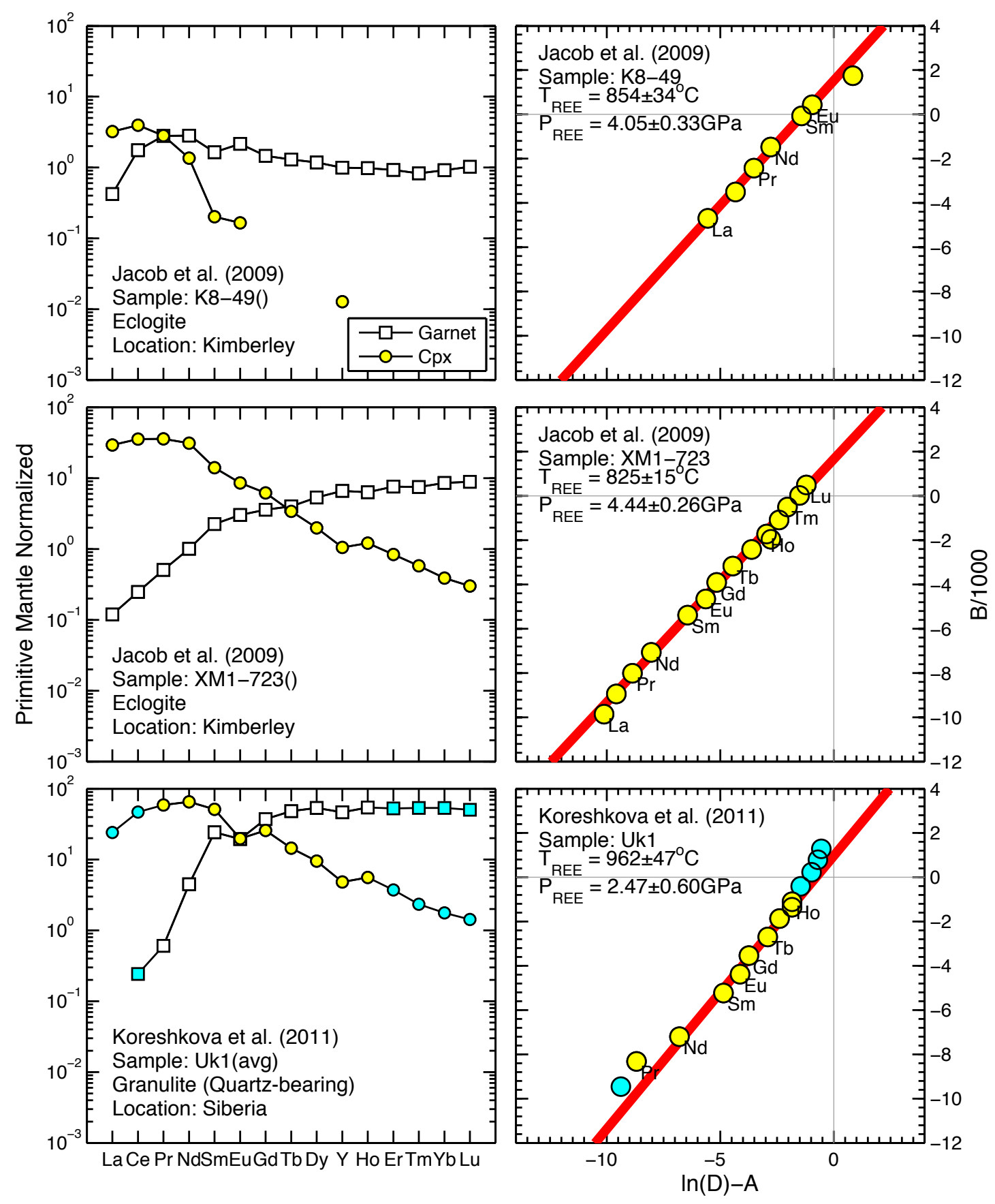


Figure S4(21)

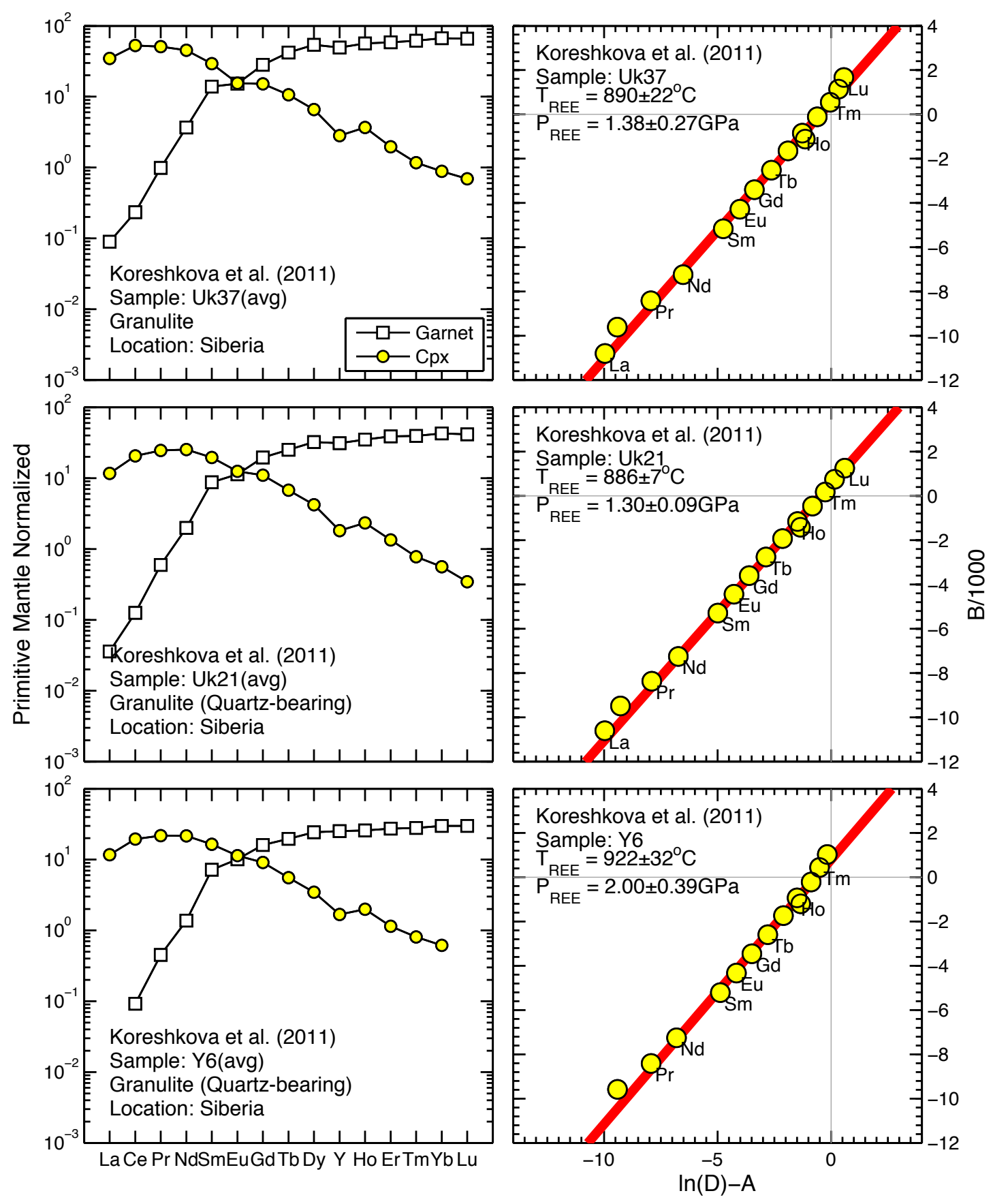


Figure S4(22)

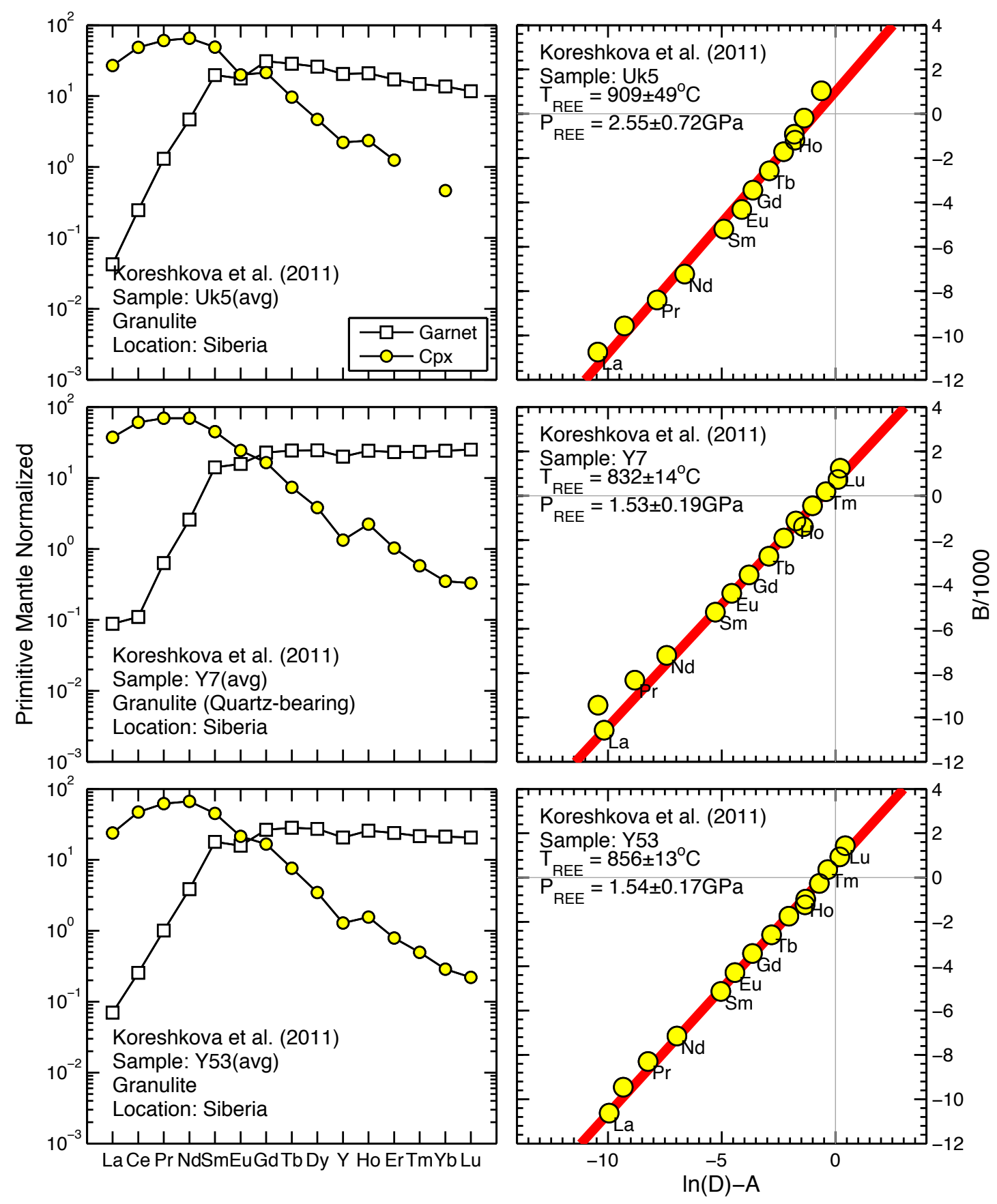


Figure S4(23)

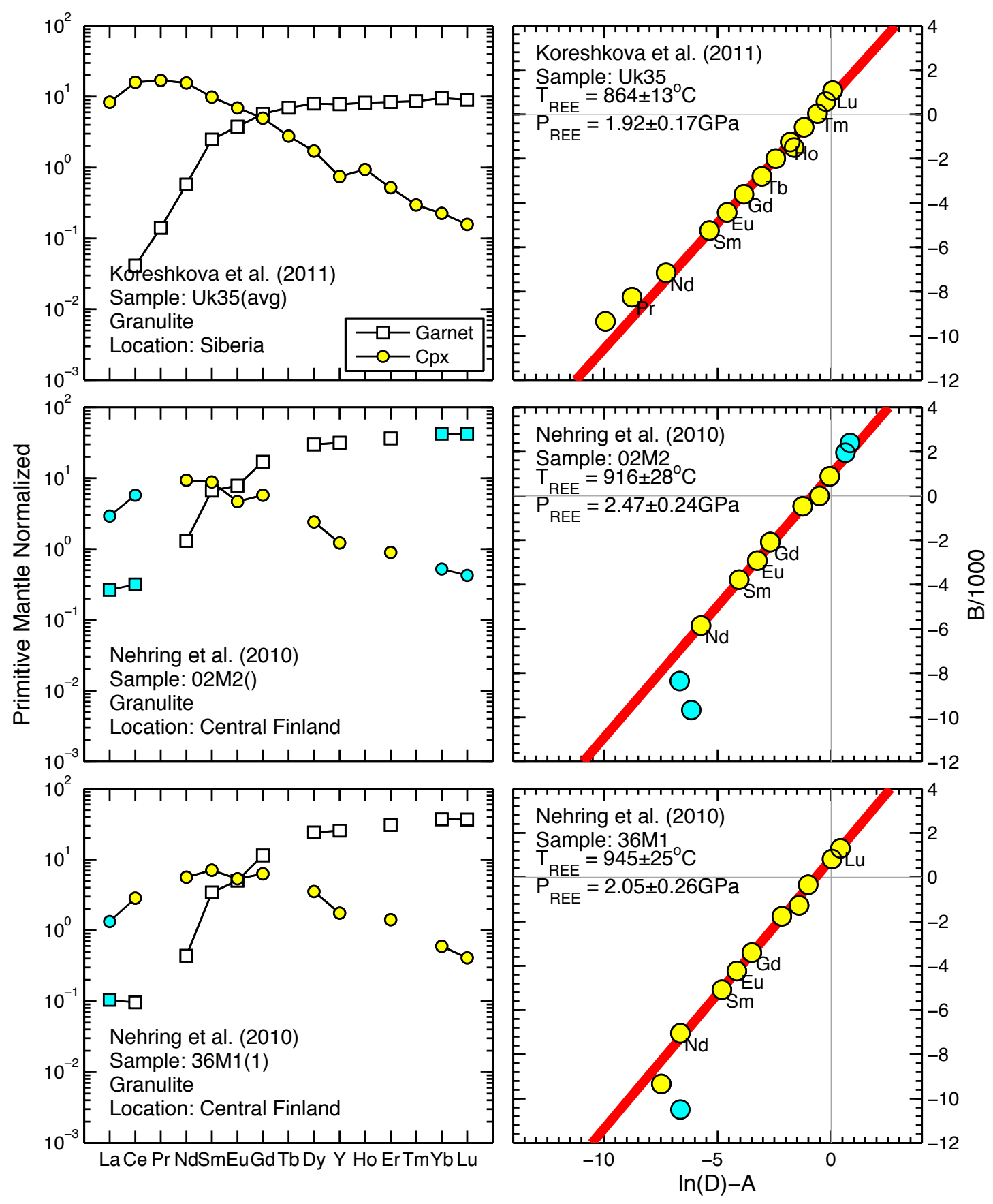


Figure S4(24)

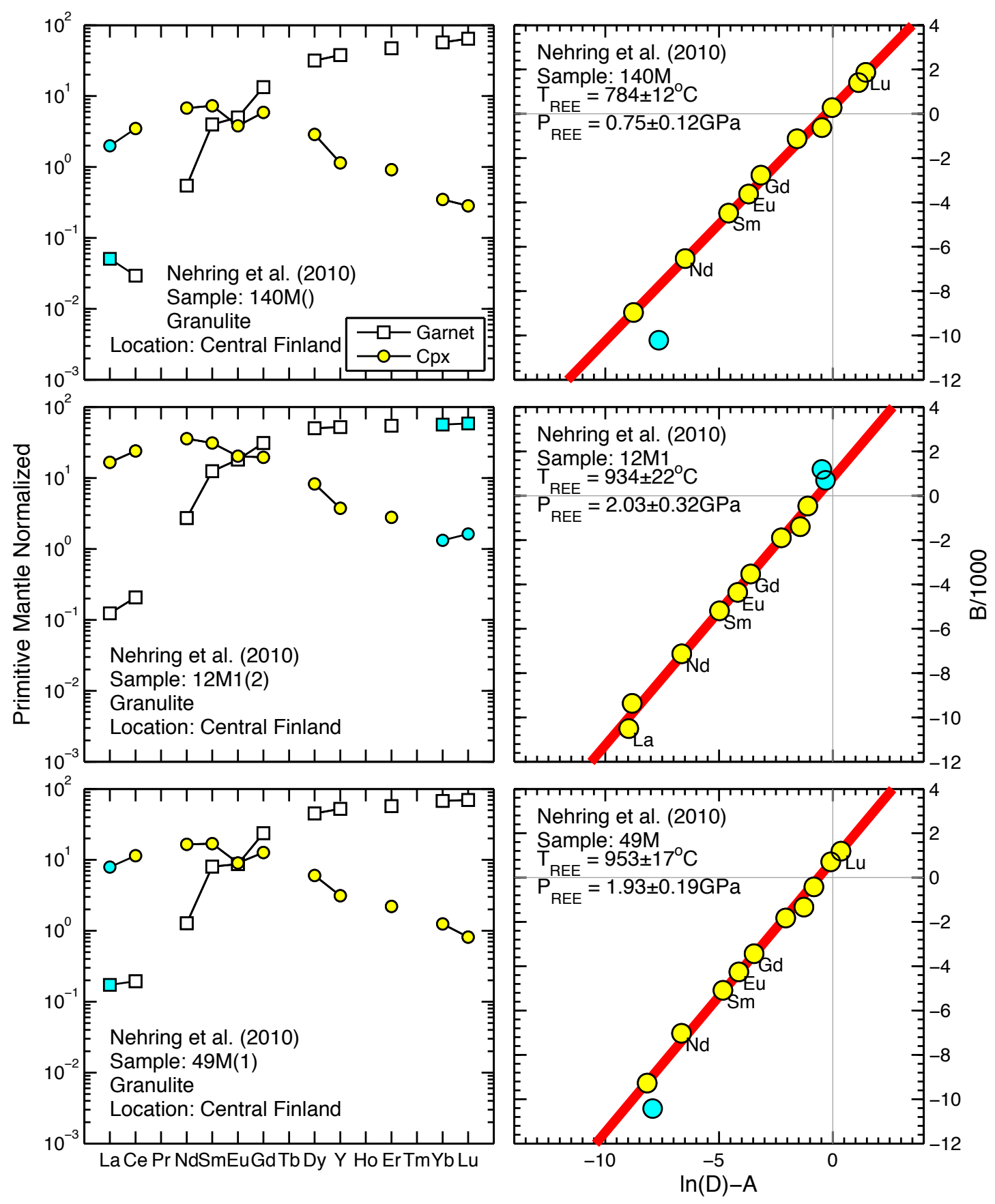


Figure S4(25)

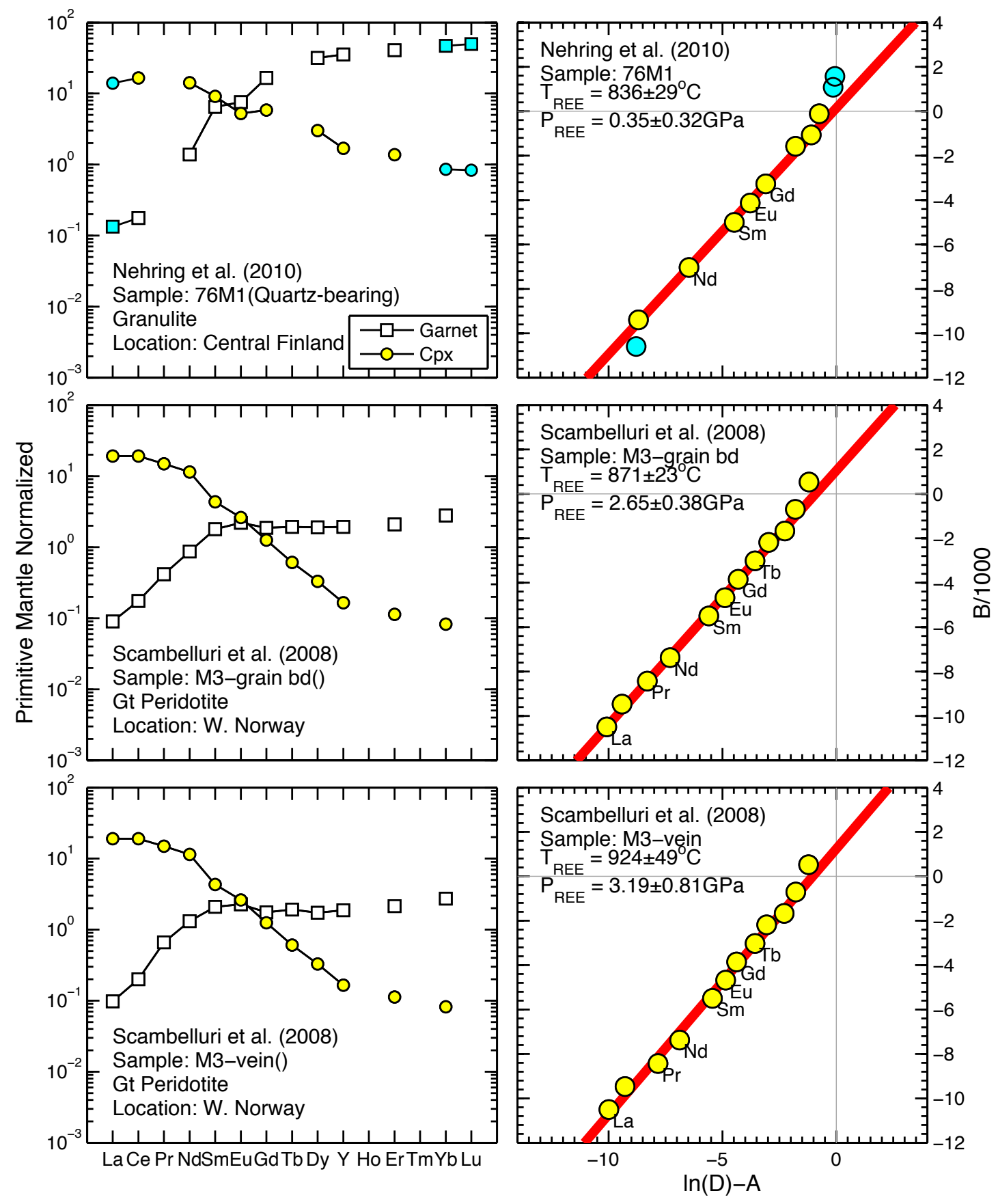


Figure S4(26)
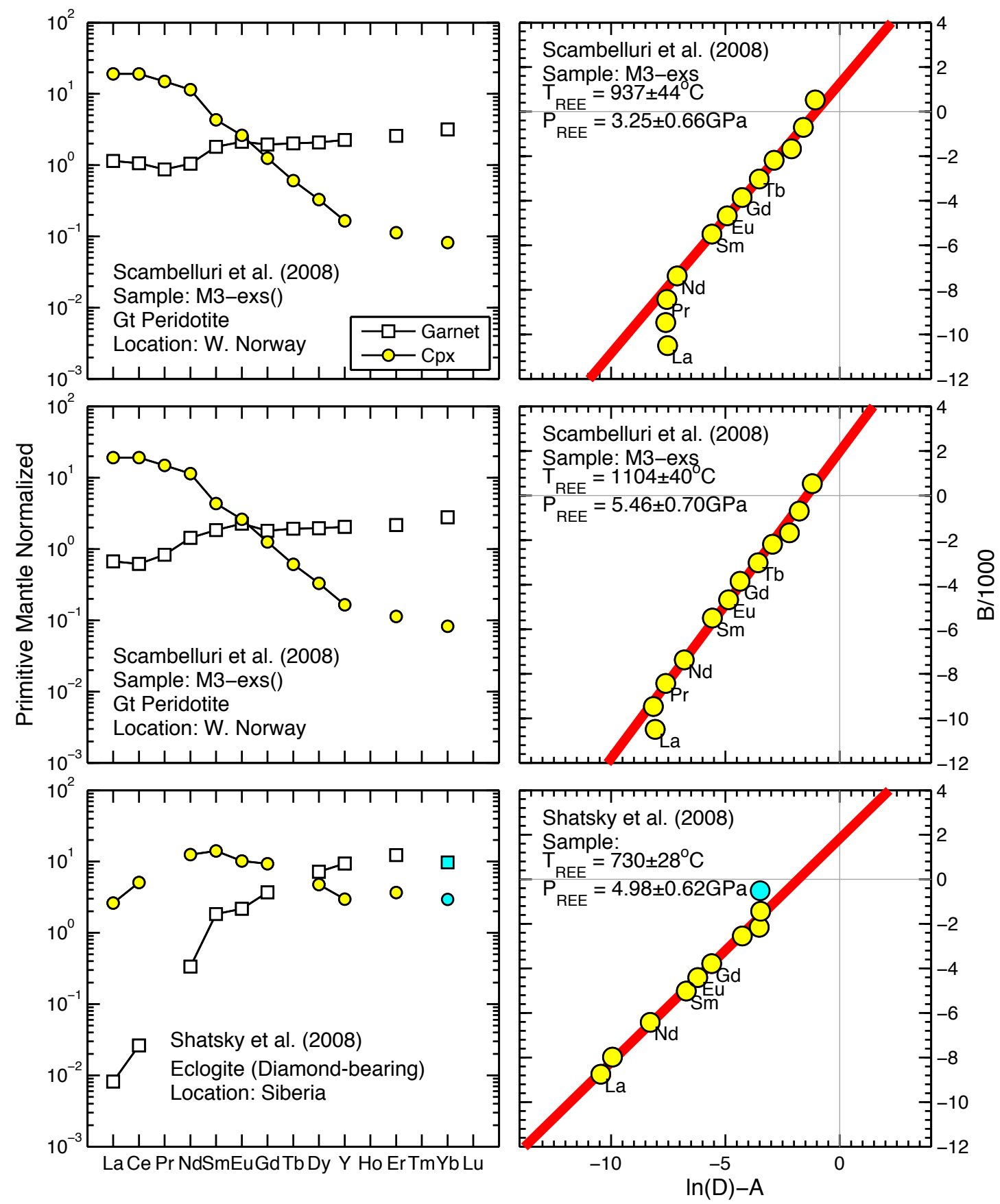
Figure S4(27)

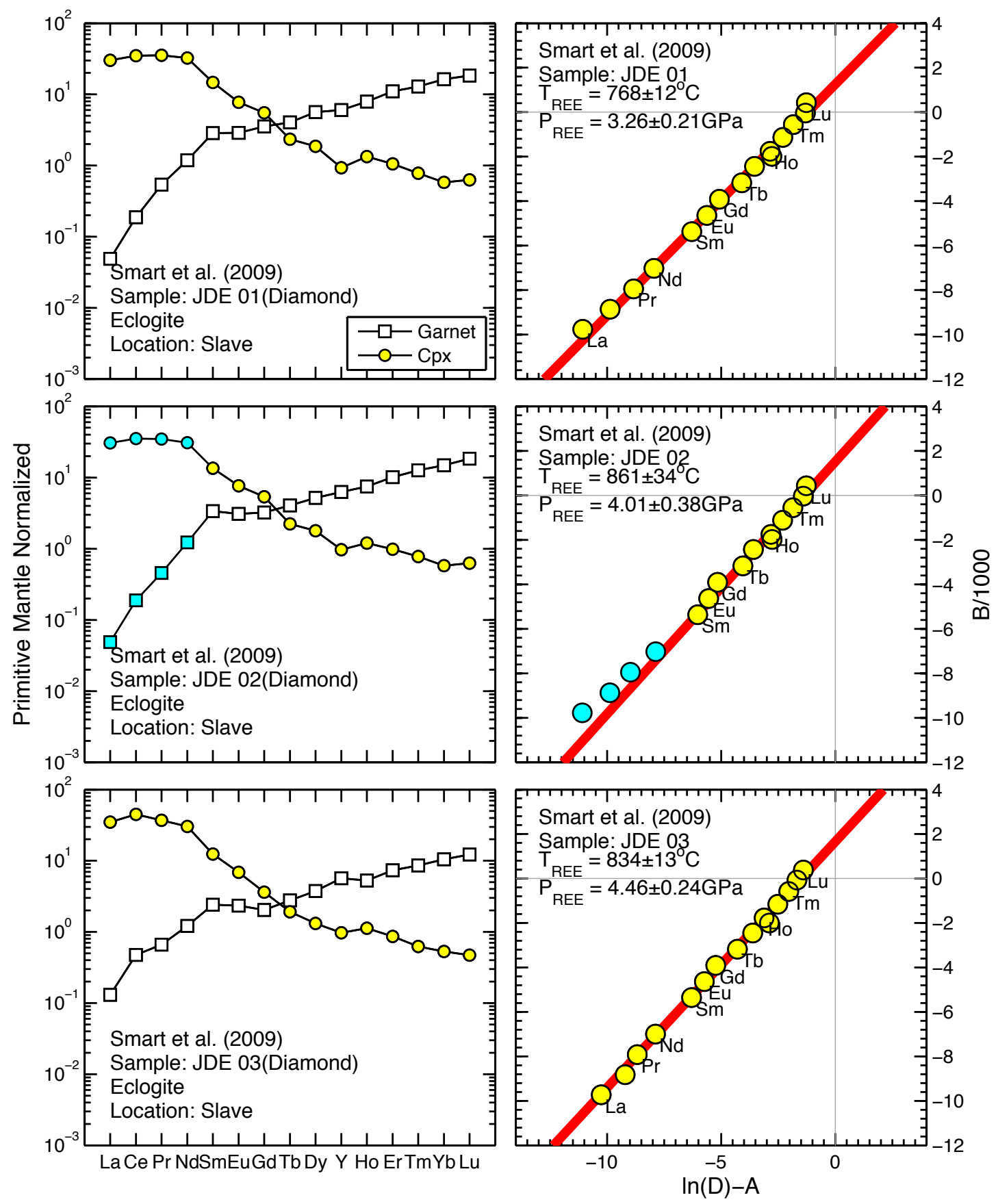


Figure S4(28)
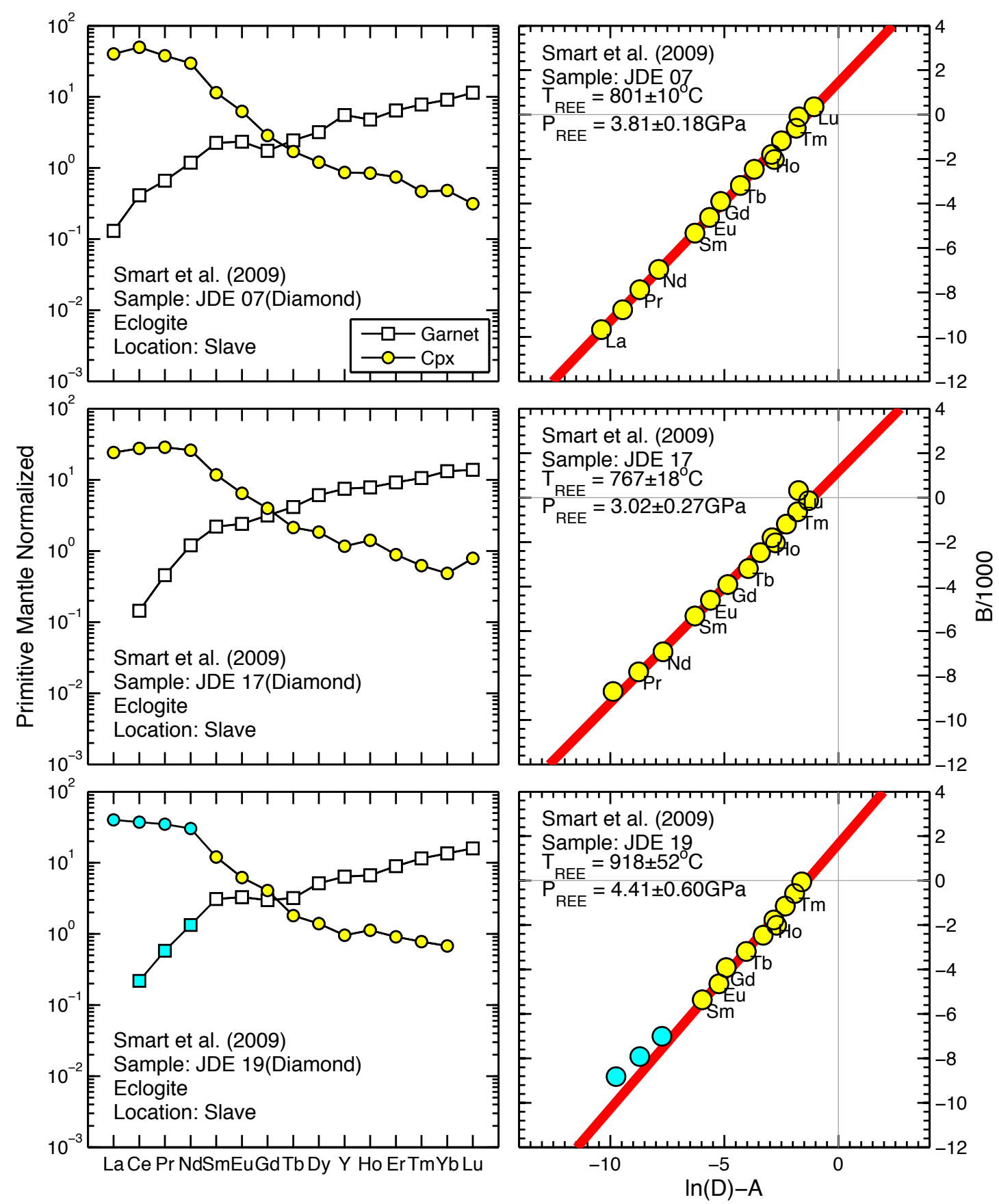
Figure S4(29)
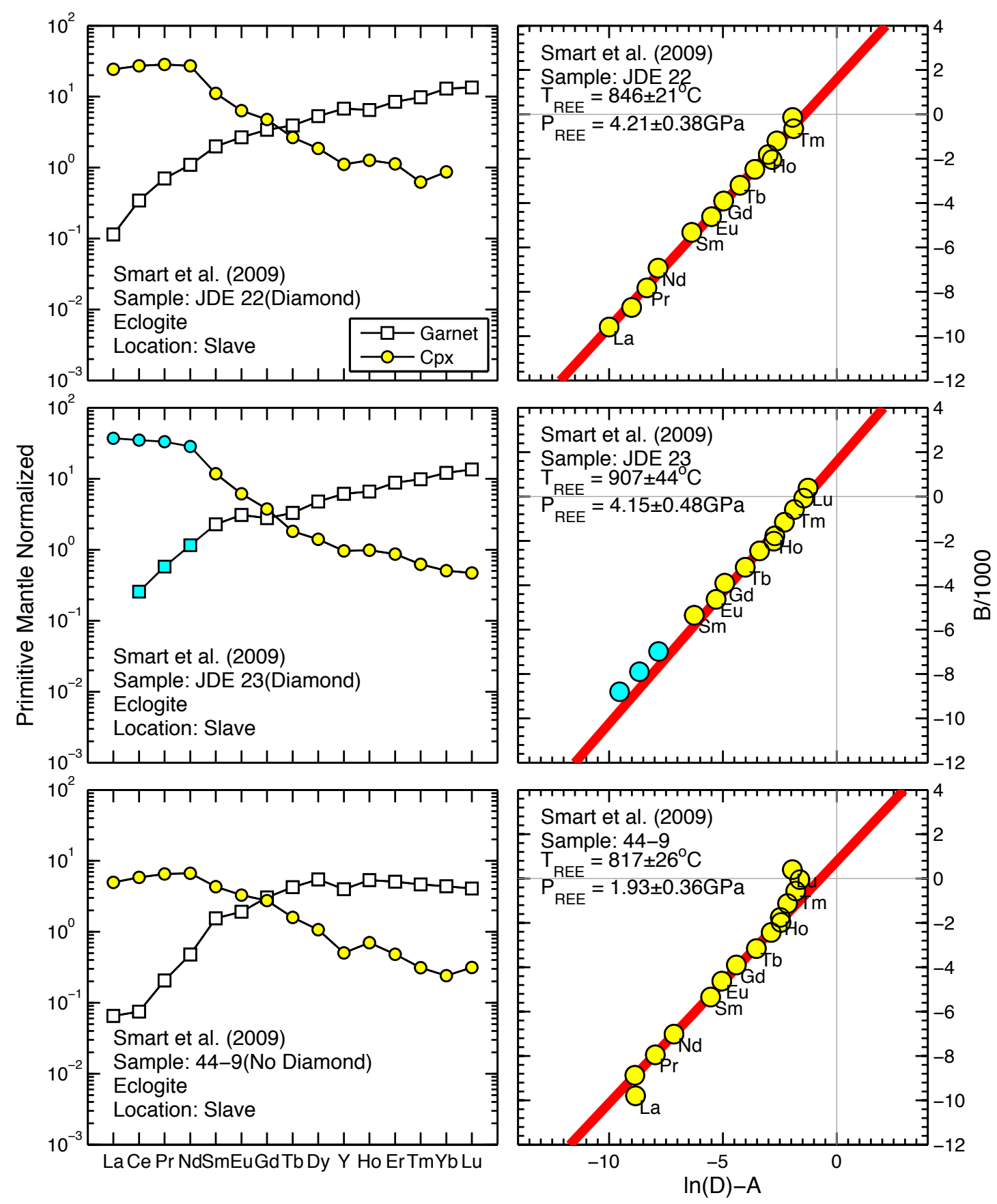
Figure S4(30)

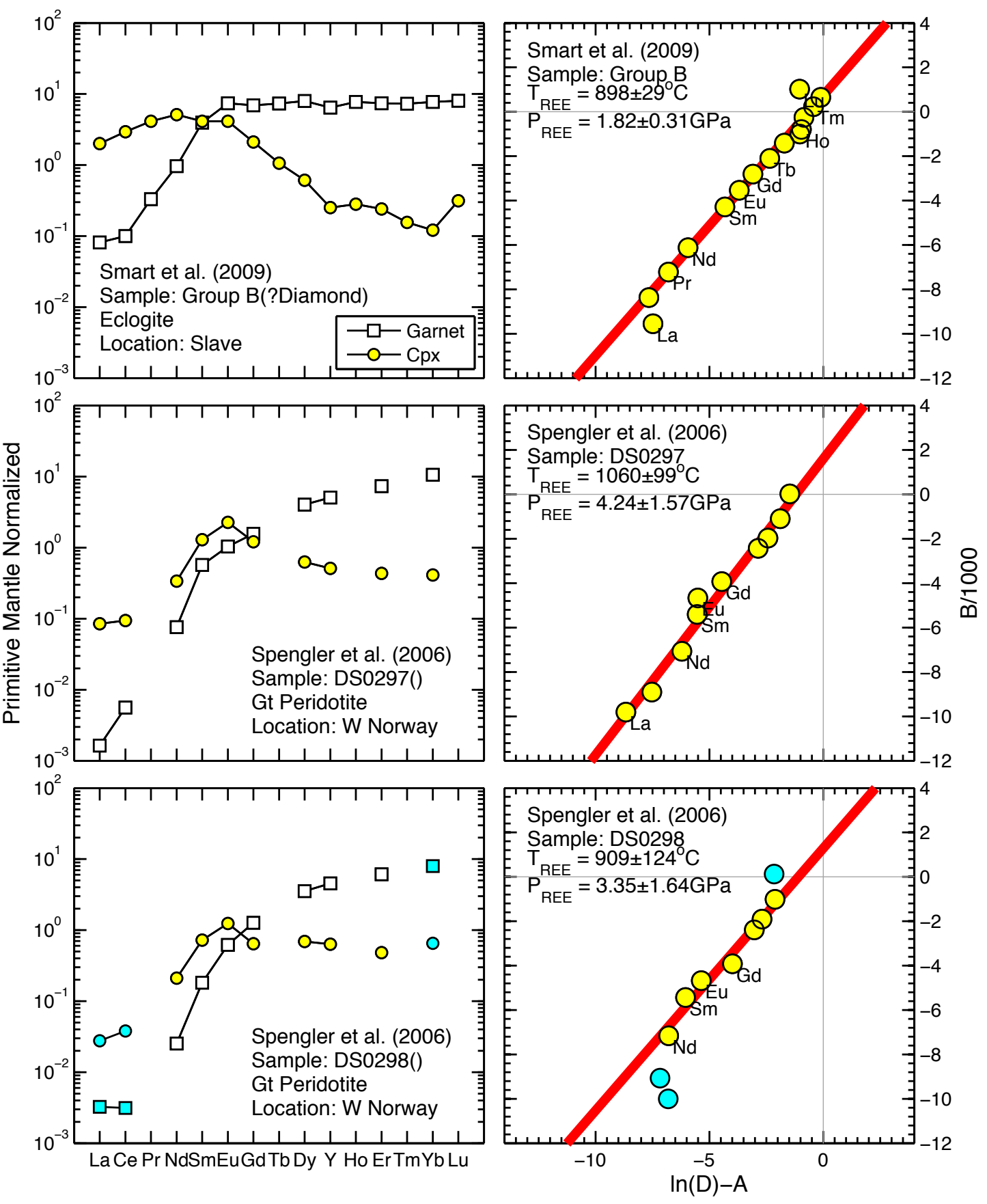


Figure S4(31)

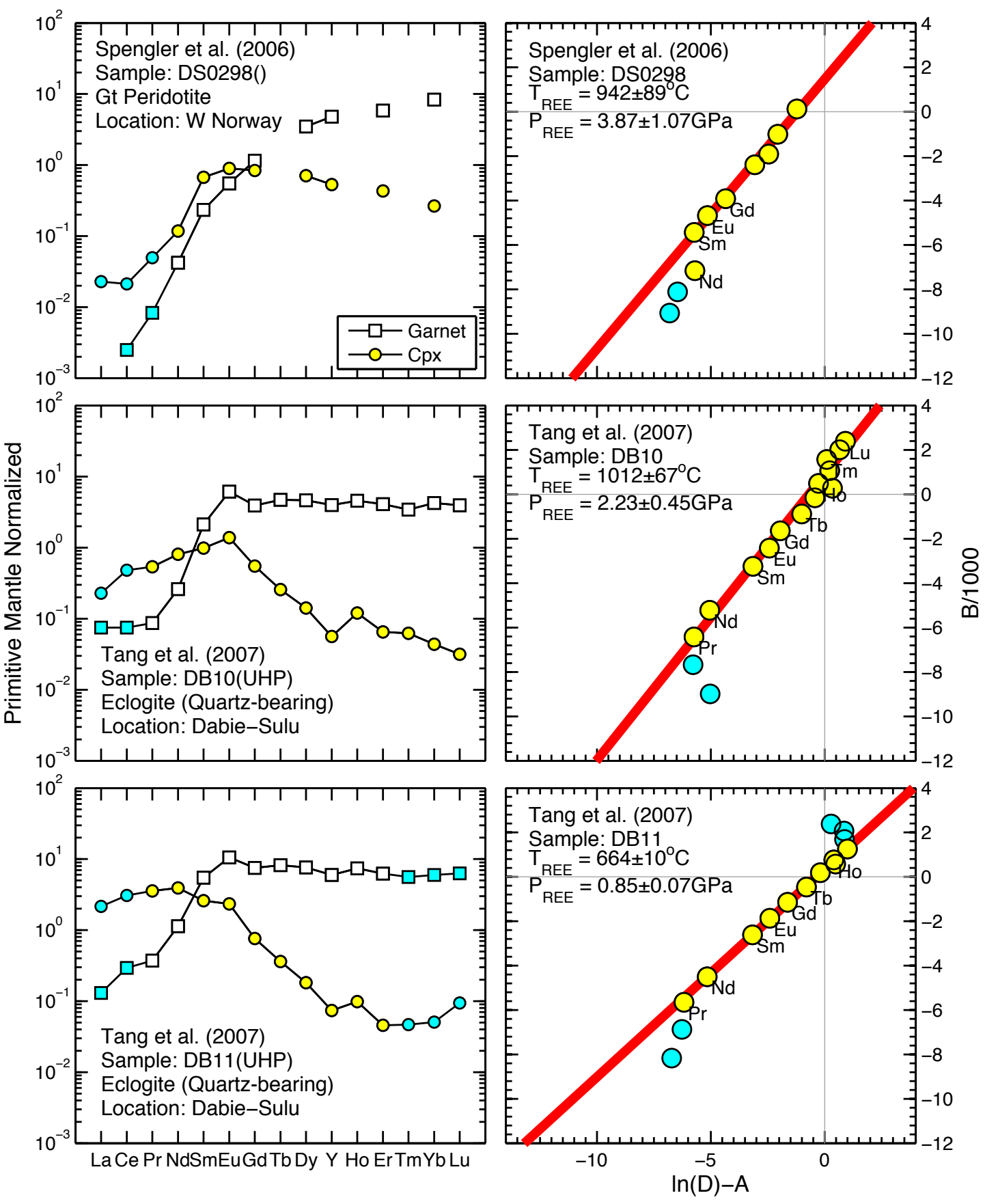


Figure S4(32)
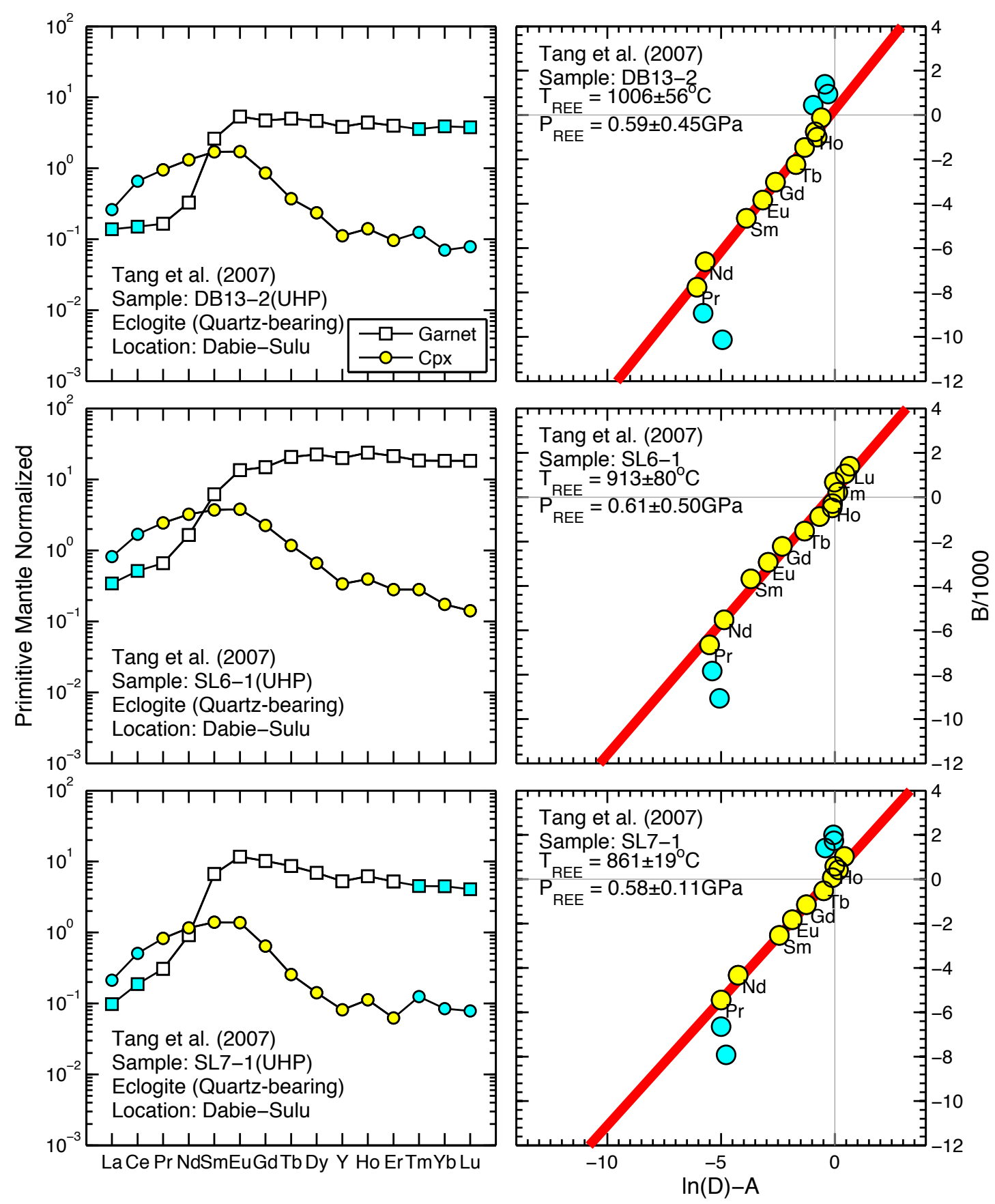
Figure S4(33)

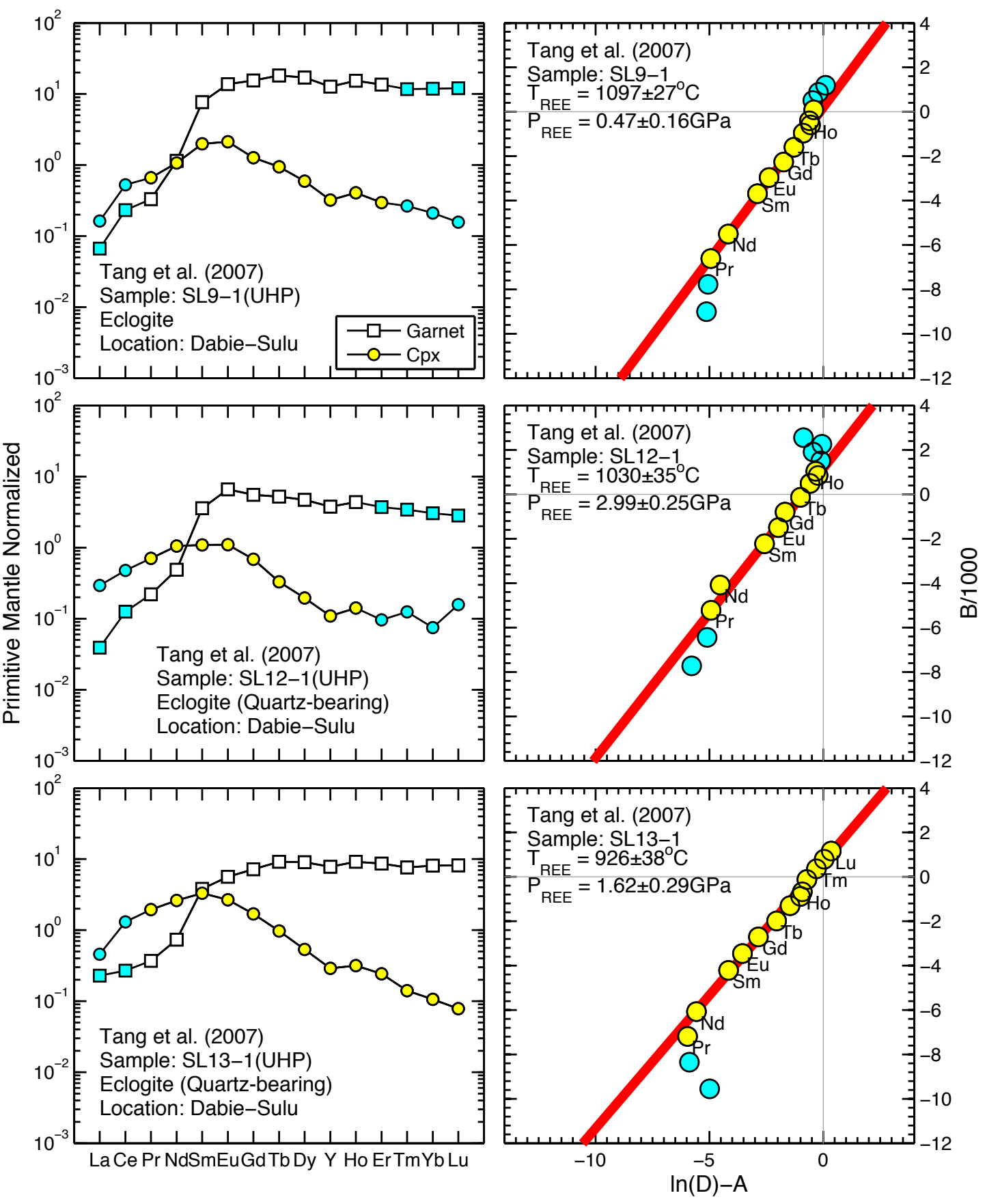

Figure S4 Inversions of the temperatures and pressures from REE abundances in garnet and clinopyroxene for the individual field samples from the literature. 


\section{Figure S5}

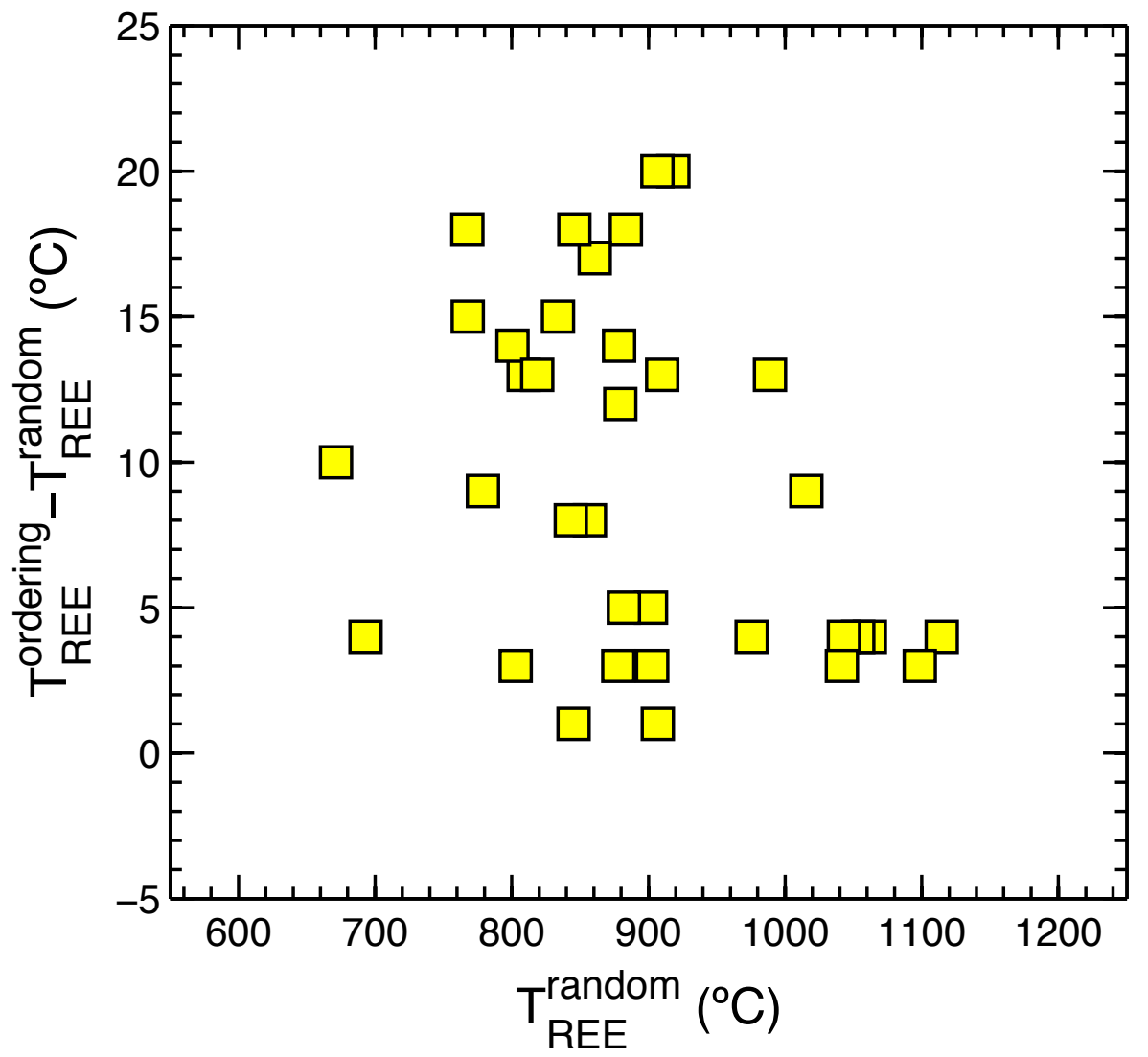

Figure S5 The differences in temperatures calculated using the REE-in-garnet-clinopyroxene thermometers with ordering versus random distribution of $\mathrm{Fe}^{2+}-\mathrm{Mg}^{2+}$ in clinopyroxene as a function of equilibrium temperatures for well-equilibrated mantle eclogite xenoliths. The xenoliths are the same as those used in Fig. 8. 


\section{Figure S6}

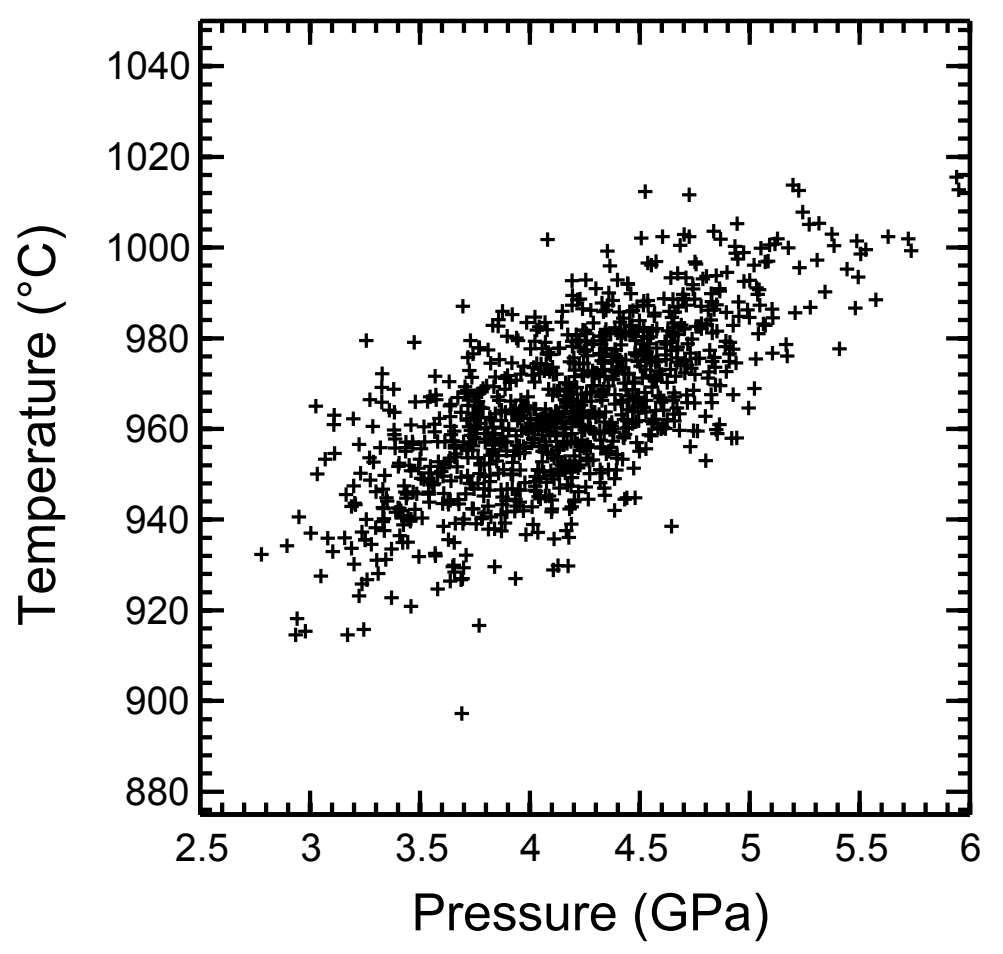

Figure S6 Results of Monte Carlo simulations showing the correlation between temperatures and pressures derived from the REE-in-garnet-clinopyroxene thermobarometer for 1000 sets of synthetic garnet-clinopyroxene REE partition coefficients with $10 \%$ normally distributed random noise. The mineral compositions of the eclogite are the same as those used in Fig. 1. 